\title{
Services unplugged : four empirical studies on consumer evaluations of mobile service innovations
}

Citation for published version (APA):

Kleijnen, M. H. P. (2007). Services unplugged : four empirical studies on consumer evaluations of mobile service innovations. [Doctoral Thesis, Maastricht University]. Maastricht University. https://doi.org/10.26481/dis.20070608mk

Document status and date:

Published: 01/01/2007

DOI:

10.26481/dis.20070608mk

Document Version:

Publisher's PDF, also known as Version of record

\section{Please check the document version of this publication:}

- A submitted manuscript is the version of the article upon submission and before peer-review. There can be important differences between the submitted version and the official published version of record.

People interested in the research are advised to contact the author for the final version of the publication, or visit the DOI to the publisher's website.

- The final author version and the galley proof are versions of the publication after peer review.

- The final published version features the final layout of the paper including the volume, issue and page numbers.

Link to publication

\footnotetext{
General rights rights.

- You may freely distribute the URL identifying the publication in the public portal. please follow below link for the End User Agreement:

www.umlib.nl/taverne-license

Take down policy

If you believe that this document breaches copyright please contact us at:

repository@maastrichtuniversity.nl

providing details and we will investigate your claim.
}

Copyright and moral rights for the publications made accessible in the public portal are retained by the authors and/or other copyright owners and it is a condition of accessing publications that users recognise and abide by the legal requirements associated with these

- Users may download and print one copy of any publication from the public portal for the purpose of private study or research.

- You may not further distribute the material or use it for any profit-making activity or commercial gain

If the publication is distributed under the terms of Article $25 \mathrm{fa}$ of the Dutch Copyright Act, indicated by the "Taverne" license above, 


\title{
Services Unplugged
}

\author{
Four Empirical Studies on Consumer Evaluations of \\ Mobile Service Innovations
}

Mirella Kleijnen 
Services Unplugged:

Four Empirical Studies on Consumer Evaluations of Mobile Service Innovations

(C) M.H.P. Kleijnen, Almere 2007

All rights reserved. No part of this publication may be reprinted or utilized in any form or by any electronic, mechanical or other means, now known, or hereafter invented, including photocopying and recording, or in any information storage or retrieval systems, without written permission from the copyright owner.

ISBN: $\quad 978-90-9021634-8$

Cover design: Conny Nieuwenhuis

Printed by: Datawyse 


\section{SERVICES UNPLUGGED}

Four Empirical Studies on Consumer Evaluations of Mobile Service Innovations

\section{PROEFSCHRIFT}

Ter verkrijging van de graad van doctor aan de Universiteit Maastricht, op gezag van de Rector Magnificus, prof. mr. G.P.M.F. Mols volgens het besluit van het College van Decanen,

in het openbaar te verdedigen op vrijdag 8 juni 2007 om 14.00 uur

door

Mirella Hubertina Petronella Kleijnen 


\section{Promotoren}

Prof. dr. J.C. de Ruyter

Prof. dr. M.G.M. Wetzels

\section{Beoordelingscommissie}

Prof. dr. E.H.J. Vaassen (voorzitter)

Prof. dr. Ir. B.G.C. Dellaert

Prof. dr. P.M.A. Eichholtz 
Voor mijn ouders

"There's still another game to play, and life is beautiful that way"

(Noa - La Vita è bella) 



\section{Acknowledgements}

"Some people come into our lives and quickly go. Some people move our souls to dance. They awaken us to new understanding with the passing whisper of their wisdom. Some people make the sky more beautiful to gaze upon. They stay in our lives for a while, leave footprints on our hearts, and we are never ever the same." $\sim$ Flavia Weedn

Hoewel op de omslag maar één naam staat, zijn er vele mensen die ieder op hun eigen wijze hebben bijgedragen aan dit proefschrift. Het schrijven van dit dankwoord blijkt dan ook moeilijker te zijn dan ik dacht, want wat er ook in mij opkomt, het doet altijd te kort aan de werkelijkheid. Toch wil ik deze gelegenheid niet voorbij laten gaan om persoonlijk dankjewel te zeggen tegen mensen die de afgelopen jaren zo veel voor mij betekend hebben. Als eerste wil ik Ko de Ruyter bedanken. Zonder zijn creativiteit, gedrevenheid, en enthousiasme zou dit proefschrift niet tot stand zijn komen. Ko, jouw pleidooi voor cool research en breed scala aan interesses, voor je vak maar ook daarbuiten, zorgden altijd voor interessante discussies. Je hebt me als geen ander gemotiveerd dit proefschrift af te ronden. Bedankt voor alle tijd en moeite, je persoonlijke begeleiding en alle leuke momenten tijdens borrels, congressen en sociale gelegenheden waar ook plaats was voor andere onderwerpen dan het proefschrift. Ook Martin Wetzels wil ik bedanken voor zijn rol als tweede promotor. Martin, jouw enthousiasme voor statistiek en het begrijpelijk maken daarvan was onmisbaar bij het schrijven van methodologische stukken. Nog steeds ben je de eerste die ik bel als ik statistische adviezen nodig heb! Naast mijn promotoren hebben ook Tor Andreassen en Annouk Lievens een belangrijke rol gespeeld in de totstandkoming van dit proefschrift. Tor, by coincidence our paths crossed each other in Maastricht, which resulted in a very pleasant and fruitful cooperation. I've enjoyed working with you on our image congruence paper and thank you for your always supportive feedback and our good laughs together. Annouk, inmiddels ben je niet alleen een collega, maar ook een echte vriendin geworden. Onze gedeelde interesses in het 'bourgondische leven' zorgden er al snel voor dat onze lunches in Maastricht naar Belgische traditie en zonder karnemelk genuttigd werden. Ik verheug me al op ons volgende avontuur!

Verder een woord van dank aan mijn leescommissie: Eddy Vaassen, Piet Eichholtz en Benedict Dellaert, voor de tijd en de moeite die zij genomen hebben om mijn proefschrift te beoordelen. Ook hebben vele studenten meegewerkt aan de verzameling van de data, waarvoor mijn dank. Tot slot wil ik Ingrid, Jorna, Myriam en Sonja hier bedanken voor het lees- en correctiewerk dat zij voor mij gedaan hebben. 
Naast de mensen die actief aan dit proefschrift meegewerkt hebben, zijn er ook veel mensen die ik dank verschuldigd ben voor hun steun en zeker ook het plezier dat ik de afgelopen jaren met ze heb beleefd. Graag wil ik Jos Lemmink bedanken die mij destijds als voorzitter van de afdeling marketing heeft aangenomen. Ik vind het dan ook erg leuk dat hij de verdediging van mijn proefschrift in zijn nieuwe hoedanigheid als decaan zal voorzitten. Ik heb met veel plezier in Maastricht gewerkt, dankzij leuke collega's binnen en buiten mijn afdeling. Sandra Streukens en Ad de Jong wil ik bedanken voor hun statistische adviezen, geen vraag was hen te veel. Mike, bedankt voor alle koffie verkeerd met croissantjes, zonder jou is ontbijten in de Mensa toch een stuk minder gezellig! Roger, je haarscherpe humor en originele visies op de obstakels van het leven zijn nog steeds ongeëvenaard. Sonja, van het moment dat wij vriendinnen zijn geworden, spreken we elkaar vrijwel dagelijks, en toch hebben we geen tekort aan gespreksstof. Je bent een echte vriendin, die er voor me is geweest in een tijd die moeilijker was dan ik ooit had gedacht. Dankjewel, ik ben blij dat je naast me staat tijdens mijn verdediging! Gaby, jij bent toch wel de rode draad in mijn "academische carrière". Je was mijn eerste docent toen ik begon met studeren, ik deed mijn eerste onderzoekje voor jouw dissertatieonderzoek, schreef mijn afstudeerscriptie onder jouw begeleiding en samen met Kristof de Wulf was jij het die mij enthousiast maakte voor het AIOschap. Bedankt voor al je steun en enthousiasme. Ook de collega's buiten de marketing afdeling, en met name de leden van het befaamde champagnecomité, hebben regelmatig voor ludieke noten gezorgd en leuke uurtjes in de Oude Klok opgeleverd. Dankzij al deze mensen en andere collega's heb ik in Maastricht een fantastische tijd beleefd waar ik met heel veel plezier aan terug denk.

Daarnaast is er geen enkele persoon die een AIO beter begrijpt dan een medeAIO. Zonder het begrip, de steun en de academische humor van mijn 'Nobem Alumni 2000' zou deze periode een stuk minder leuk zijn geweest. Twee mensen die ik hier speciaal wil noemen zijn Amina en Myriam. Amina, onze discussies over de meest gevarieerde onderwerpen en liefde voor 'grand desserts voor twee' zorgde ervoor dat onze vriendschap al snel bezegeld was. Hoewel je de Hollandse tulpen inmiddels voor Australische kangoeroes verruild hebt, hoop ik dat je er toch bij kunt zijn met mijn verdediging, want met wie moet ik anders mijn toetje delen! Myriam, ooit dacht je dat ik een strenge, serieuze docente was waar geen lol mee te beleven was. Na onze eerste cursus samen besloten we al snel dat het toch wel gezellig was met zijn tweetjes. Je bent een fantastische vriendin gebleken, en met dat lol maken samen zit het geloof ik wel goed...

Ondertussen werk ik al weer ruim twee jaar aan de VU in Amsterdam. Ik ben heel blij met de kansen die Ruud Frambach mij geboden heeft, en ik werk met veel plezier bij deze afdeling. Ook hier heb ik het geluk gehad een leuke groep collega's te vinden, die mijn 'integratie als Limburgse meid in de grote stad' zeer bespoedigd 
hebben. De leuke sfeer, op het werk en daarbuiten, hebben ervoor gezorgd dat ik me vanaf het eerste moment thuis heb gevoeld in Amsterdam. Daarbij gaat mijn dank speciaal uit naar Jorna, die inmiddels dan wel geen collega meer is, maar des te meer een vriendin. Jorna, met jouw scherpzinnigheid en fantastische imitaties heb ik geen dag meegemaakt dat ik geen zin had om naar kantoor te gaan, en nu weet je me zelfs mee te slepen naar de sportschool. Gekker moet het toch niet worden.

Tot slot wil ik mijn vrienden en familie bedanken. De vele stapavonden met mijn vrienden hebben er voor gezorgd dat ik als AIO ook aan andere dingen dacht dan onderzoek. Sommige van hen ken ik al jaren, maar vooral Lucas en Yvo wil ik toch bedanken voor alle komische, leuke en interessante gesprekken. Geen enkele zaterdagavond met jullie is ooit saai! Ook muziek speelt een belangrijke rol in mijn leven. Tijdens mijn AIOschap was een zondagochtend fanfare precies wat ik nodig had om letterlijk en figuurlijk even stoom af te blazen, en ik doe dat nog steeds met veel plezier. Met name de gesprekken tijdens de 'barrepetities', waar de zin en onzin des levens grondig onder de loep wordt genomen door mijn medemuzikanten, zou ik niet willen missen.

Tot slot, mijn ouders. Jullie hebben altijd in me geloofd en voor me klaargestaan, zelfs in een tijd dat dat niet zo gemakkelijk was. Mama, jij hebt me laten zien wat het betekent je vast te bijten in iets en nooit op te geven, maar vooral: nooit het plezier in het leven uit het oog te verliezen, ook al lopen de dingen niet zoals je verwacht. Met een luisterend oor en liters thee heb je al mijn verhalen aangehoord, voor me gezorgd en met me gelachen. Papa, al sinds ik een klein kind ben maken we samen muziek. Het heeft ervoor gezorgd dat we samen veel tijd hebben doorgebracht, waarin we veel plezier, maar ook regelmatig serieuze gesprekken hebben. Je bent vaak een voorbeeld voor me geweest. Hoewel ik nu wat verder weg woon ben ik blij dat we af en toe toch nog tijd hebben om samen een 'dröpke' te drinken! Pappa en mamma, bedankt, voor alles. Ik hou van jullie!

Mirella Kleijnen

Almere, 2007 



\section{Table of Contents}

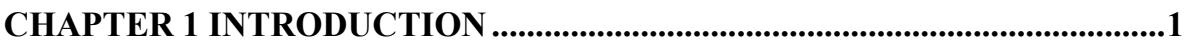

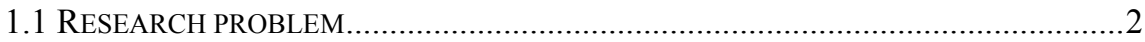

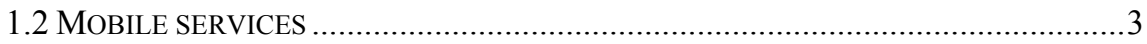

1.3 CONSUMER ADOPTION OF MOBILE SERVICE INNOVATIONS .............................6

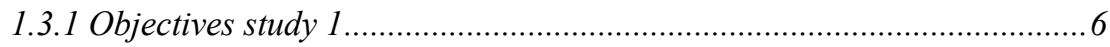

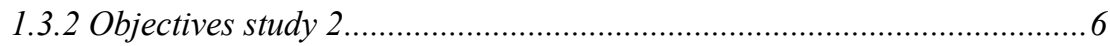

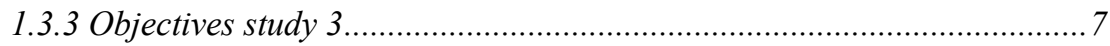

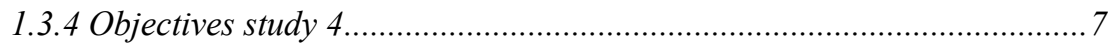

1.4 OUTLINE OF THE DISSERTATION ............................................................. 8

CHAPTER 2 CONSUMER ADOPTION OF WIRELESS SERVICES:

DISCOVERING THE RULES, WHILE PLAYING THE GAME .....................11

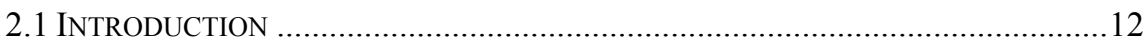

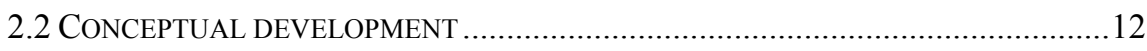

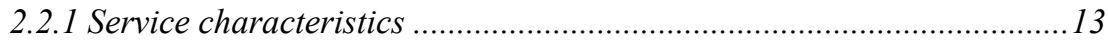

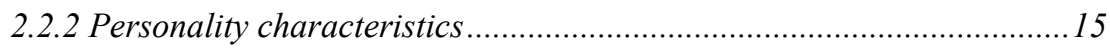

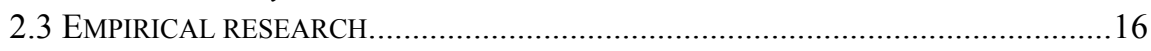

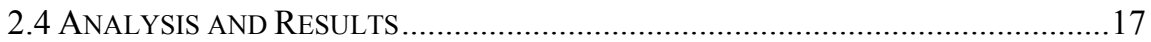

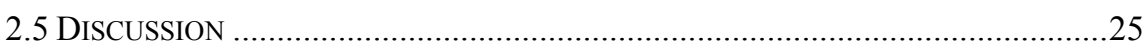

2.6 LIMITATIONS AND SUGGESTIONS FOR FURTHER RESEARCH ............................25

2.7 MANAGERIAL IMPLICATIONS ................................................................26

CHAPTER 3 AN ASSESSMENT OF VALUE CREATION IN MOBILE SERVICE DELIVERY AND THE MODERATING ROLE OF TIME

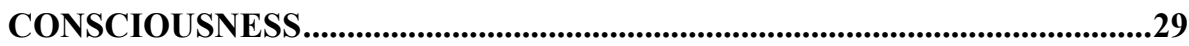

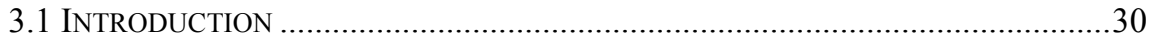

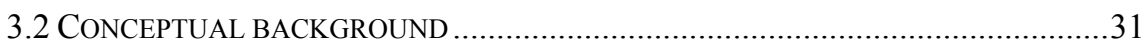

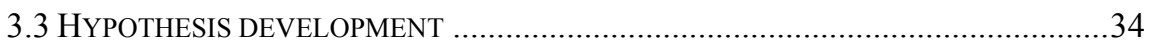

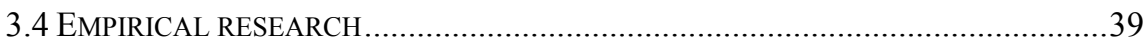

3.5 ANALYSIS AND RESULTS ........................................................................ 41

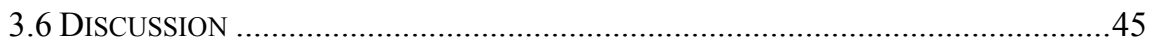

3.7 LIMITATIONS AND SUGGESTIONS FOR FURTHER RESEARCH ..........................47

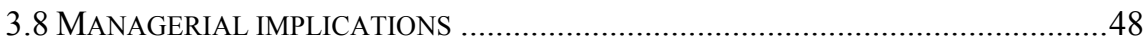

CHAPTER 4 IMAGE CONGRUENCE AND THE ADOPTION OF SERVICE INNOVATIONS ........................................................................................51

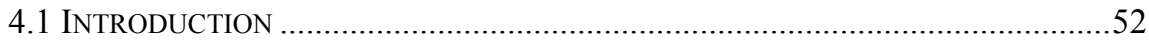

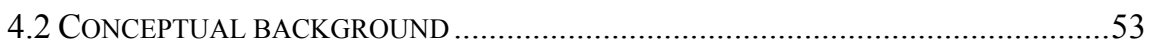

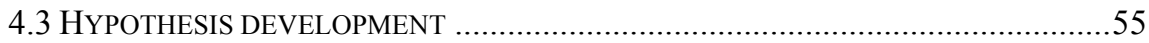

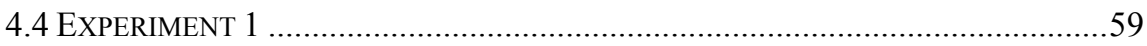




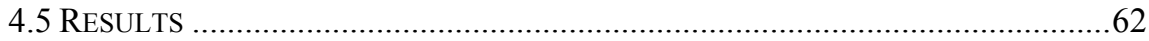

4.6 SIGNIFICANT OTHERS: FRIENDS VERSUS COLLEAGUES ...............................67

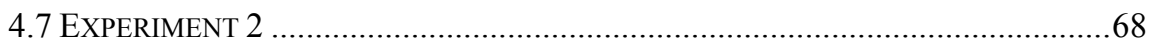

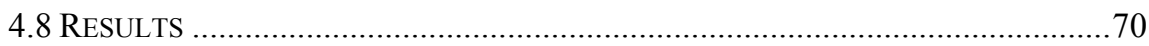

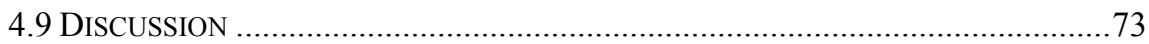

4.10 LIMITATIONS AND SUGGESTIONS FOR FURTHER RESEARCH ...........................74

4.11 MANAGERIAL IMPLICATIONS …............................................................ 75

CHAPTER 5 EXPLAINING CONSUMER INTENTIONS TO USE SERVICE INNOVATIONS: KNOWLEDGE ACQUISITION THROUGH MOBILE SOCIAL NETWORKS..............................................................................77

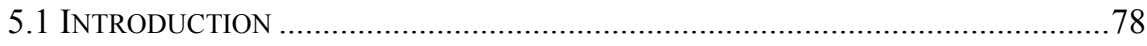

5.2 CONCEPTUAL BACKGROUND: MOBILE SOCIAL NETWORKS .............................80

5.3 HYPOTHESIS DEVELOPMENT …….......................................................... 81

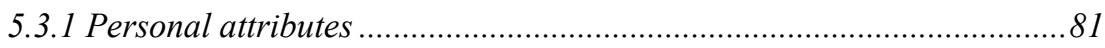

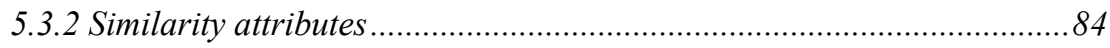

5.3.3 From network position to intention to use .......................................... 85

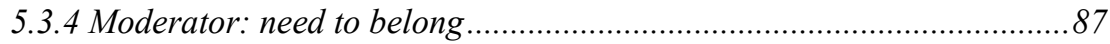

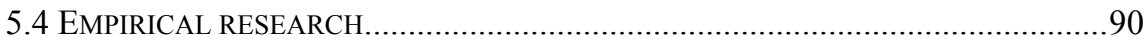

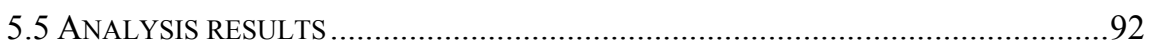

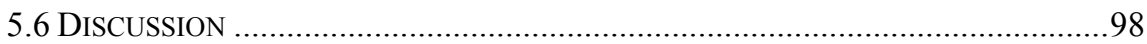

5.7 LIMITATIONS AND SUGGESTIONS FOR FURTHER RESEARCH ….......................101

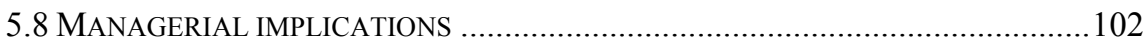

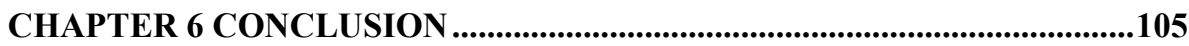

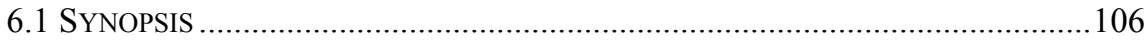

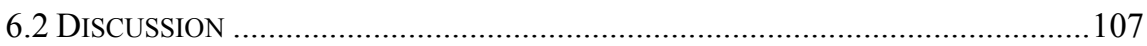

6.2.1 Mobile service characteristics.......................................................... 107

6.2.2 Consumer characteristics ................................................................... 108

6.2.3 The role of the social environment ..................................................... 110

6.3 PERSPECTIVE ON FUTURE RESEARCH........................................................ 111

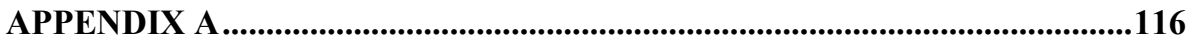

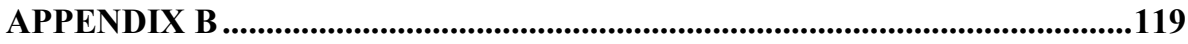

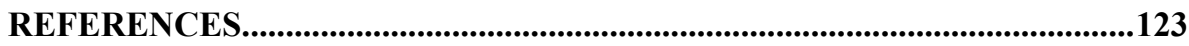

NEDERLANDSE SAMENVATTING ..............................................................143

CURRICULUM VITAE........................................................................147 


\section{Chapter 1}

\section{Introduction}

In this chapter we briefly introduce the topic of this dissertation and its relevance. First, we provide a short description of the innovative services of interest in this dissertation: mobile services. After introducing the central problem statement, we discuss the four studies that are presented in the subsequent chapters. Finally, we conclude with an outline of the dissertation. 


\subsection{Research problem}

Due to a growing understanding of Internet capabilities as well as a boost in highly advanced technologies within the telecommunication industry, joint efforts in this area gave rise to a new business format that is rapidly approaching the market: mobile commerce (Balasubramanian et al. 2002). By 2000, the business forecasts for m-commerce within Europe and United States went sky-high, to the point of incredulity. This was mostly driven by the initial wireless services success in Japan, where NTT DoCoMo's subscription-based i-mode service model has attracted over 46 million users since its launch in 1999 (www.NTTDoCoMo.com). However, more recent numbers illustrate that within Europe and the United States, only about $6 \%$ of mobile phone owners are active users of mobile services (ATKearney 2005).

However, both academics and practitioners believe in the future of these new services. Although forecasts over time have become more modest, analysts believe that m-commerce is not a failure, but is buried in a "shallow grave" (Ward 2003). Service providers are still eager to implement new mobile technologies to further advance their service packages and delivery systems, which seems to create a market that is highly dominated by a technology-push (Basso 2001; Davison et al. 2000; Gerstheimer and Lupp 2004). However, mere existence of wireless technology will not motivate consumers to adopt mobile services. To overcome the initial impediments of consumers' lack of adoption, more insights in factors that drive consumers to use mobile services are desperately needed.

While several researchers called for research on mobile commerce and understanding consumer behavior with regard to mobile service usage (e.g., Balasubramanian et al. 2002; Nysveen et al. 2005a), so far, little attempts have been made. Most studies emerging in the field of mobile commerce cover technological aspects such as design (e.g., Lee and Benbasat 2004), infrastructure (e.g., Ngai et al. 2006; Siau et al. 2001), market structures (e.g., Baldi and Thaung 2002), and mobile value chains (e.g., Barnes 2002; Yuan and Zhang 2003). However, in order to truly advance consumer adoption of mobile services, it is important to understand the driving forces of consumers' intentions to use mobile services and to adapt these services to fulfill consumers' motives for using them (Nysveen et al. 2005a). Therefore, this dissertation aims at contributing to the understanding of mobile service adoption, whereby we take a consumer's perspective. In the next part of this chapter, a more detailed explanation of mobile services is provided, as well as a short overview of the research objectives addressed by the subsequent chapters of this dissertation. 


\subsection{Mobile services}

Repeatedly, m-commerce has been recognized as an extension of e-commerce, as is illustrated by Robinson-Humphreys' definition: "M-commerce is e-commerce over mobile devices" (https://www.mobileinfo.com). Although similarities with ecommerce are recognized, m-commerce should be acknowledged as a business opportunity with its own distinctive characteristics and functions (Müller-Veerse 2000) resulting from the unique advantages wireless technology holds over wired technology (Brokat Technologies 2001). First, wireless devices offer consumers the opportunity of overcoming physical and time limitations through the ubiquity of $\mathrm{m}$ commerce. Ubiquity allows m-commerce users to utilize offered services in complete freedom of time and location choice (Balasubramanian et al. 2002). Consequently, this is perceived as the most obvious advantage of services offered via wireless devices (Nysveen et al. 2005a). Furthermore, the introduction of locationbased services (LBS) will allow consumers to obtain context-specific information to react upon. This unique combination of localization and personalization will generate new opportunities for customer attraction (Brokat Technologies 2001; The Economist 2000). One example is the opportunity to create m-wallets: payment applications that create opportunities for personal information storage, abolishing the necessity to supply credit card information with every transaction performed (May 2001). In sum, mobile commerce can be recognized as location-sensitive, time-critical, and personal, more so than any other channel currently in the market (Okazaki 2004; Turban and King 2003).

A variety of mobile services has already been developed and these types of services are likely to expand through the introduction of alleged "third generation" services that emerge as new wireless technologies such as GRPS and UMTS are implemented. Müller-Veerse et al. (2001) provides a taxonomy of these wireless services, distinguishing four major categories: communication, entertainment, information, and transaction services. Of these four categories, mobile communication and entertainment services are generally recognized as highly interactive services that often depend on person-to-person interactions. Additionally, they are mostly focused on the experience itself, e.g., a mobile conversation with another person or the interaction during a mobile game. Transactions on the other hand are mostly machine-interactive services that are predominantly goal-directed in nature. While this classification is not mutually exclusive (e.g., a text message can be communicative as well as informative in nature), this framework (see Figure 1.1) is commonly agreed upon by researchers as a point of departure (Müller-Veerse et al. 2001; Nysveen et al. 2005a; Okazaki 2005). 
Mobile communication. Communication services are the most elementary and well-known type of mobile services. While voice-to-voice applications traditionally are the primary service in wireless technology, Short Message Services (SMS) are slowly becoming the predominant standard (Igarashi et al. 2005; Reid and Reid 2004). The possibilities of SMS are currently being extended by the introduction of multimedia messages (MMS) that allow for the attachment of audio, video, and pictures in addition to the traditional textual message.

Mobile entertainment. Mobile entertainment entails services varying from mobile casinos to mobile gaming and is recognized as one of the pillars for the imode success (Keryer and Nara 2001). Mobile gaming services are among the mobile applications that have been shown to provide a solid business model and are consequently expected to be in the top three in terms of profitability (Pastore 2000). Already, handset manufacturers have recognized the importance of mobile entertainment, as new wireless service enabling devices are accompanied by community concepts such as 'Club Nokia' and the 'Nokia Gaming Platform' (www.nokia.com). According to the Mobile Entertainment Forum (2001) entertainment will be the 'backbone' of wireless value-adding services for a substantial time period. Especially interactive multi-player games (MPG) against other remote users based on treasure hunt themes (e.g., "inner-city-chasing games") are recognized as particularly promising (Pastore 2000; UMTS Forum 2000). Moreover, m-entertainment applications are recognized as a way of exploring new technology (Stringer and Ward 2001), paving the way to other wireless applications.

Mobile information. Mobile information services are developing into an essential part of m-commerce (Müller-Veerse 2000). According to Du and Crestani (2003), there exists a substantial amount of interest in mobile information regarding daily news, soccer, traveling, and weather reports for instance. Particularly the introduction of context-related information services, e.g., traffic information, local cinema listings, etcetera (for a listing see: Dey et al. 2001), are expected to raise the interest of consumers in these types of services (van der Heijden and Sørensen 2003).

Mobile transaction. Mobile transaction services essentially encompass a variety of mobile services that create transaction opportunities, e.g., m-shopping, mbanking, m-brokerage, and m-payment (Müller-Veerse et al. 2001). Mobile transaction services provide customers with the opportunity to purchase anything at any point in time. 'One-click-purchasing' possibilities will create convenient shopping experiences for mobile customers (Müller-Veerse 2000). Moreover, mobile brokerage is becoming increasingly popular, as the ubiquity of mobile transactions taps into the time-critical needs of consumers using such services. 
Figure 1.1 Framework for mobile services categories

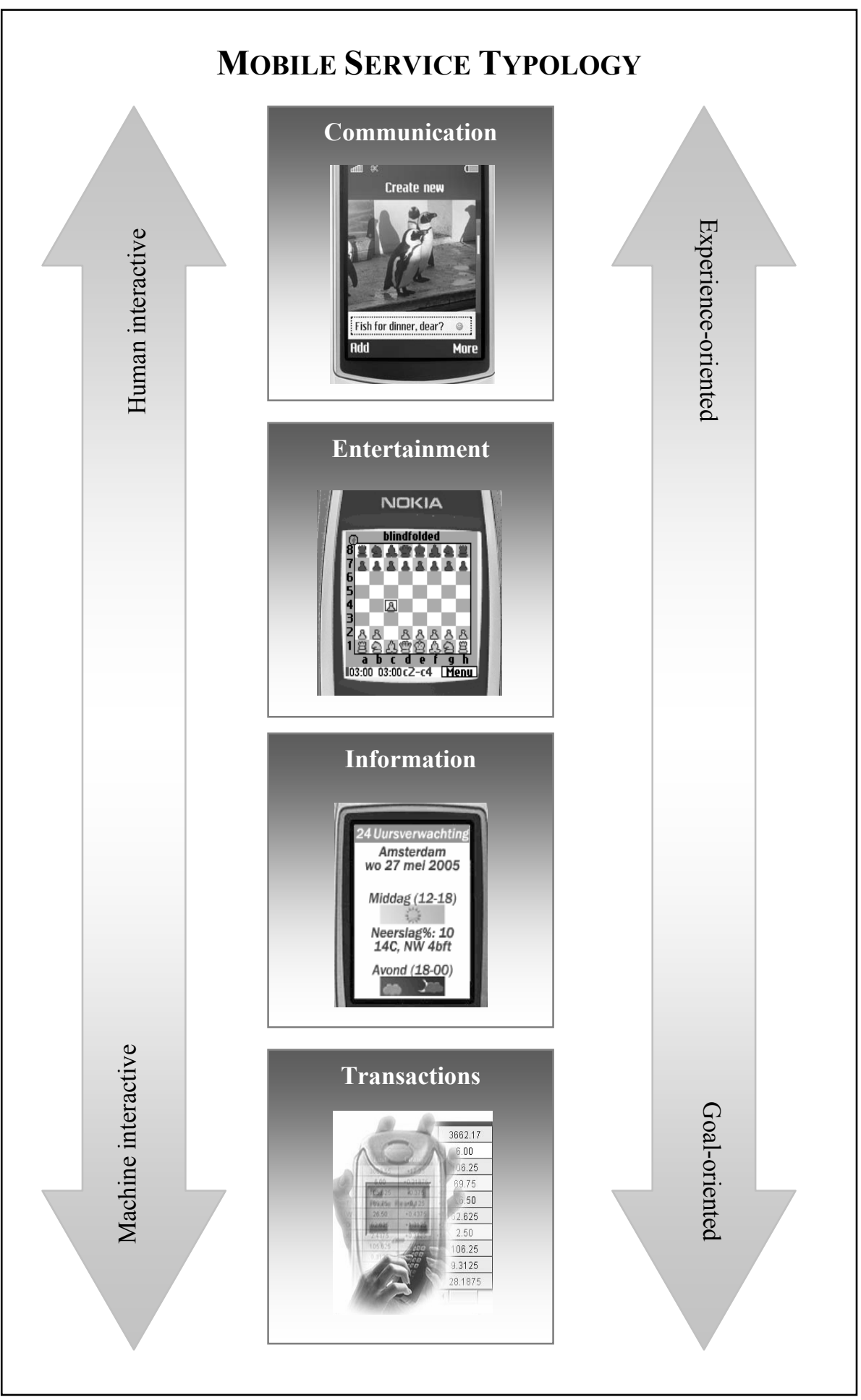




\subsection{Consumer adoption of mobile service innovations}

As pointed out, the number of mobile services in the market is still increasing, despite slow uptake by consumers. These company-driven mobile innovations are even further fueled by the need to compensate the recent failures with regard to UMTS licenses, and the fact that mobile phone penetration is close or even passed $100 \%$ in a large number of countries in Europe, Asia, and the United states. To shed more light on how additional successful mobile service introductions can be accomplished, this dissertation aim is to shed light on the mechanisms consumers use to evaluate these service innovations when deciding whether or not to use them. The central research question in this dissertation therefore is:

What factors contribute to consumers' intentions to use innovative mobile services?

The central research problem will be discussed in four inter-related studies. Each study highlights different aspects.

\subsubsection{Objectives study 1}

In this first study technology characteristics of mobile services are investigated, whereby specific consumer segments are taken into account. Based on existing traditional innovation research, we define a range of mobile service characteristics, including Rogers' (1995) perceived innovation characteristics, as well as mobile specific characteristics. Additionally, we draw attention to the fact that some consumers might evaluate the importance of certain characteristics differently than others, due to differences in personality or experience with other technologies. Consequently, the specific objectives of this chapter are: 1) to identify an importance hierarchy concerning the critical factors influencing mobile services adoption, 2) to examine the trade-offs consumers are willing to make when deciding to actually use mobile services or not, and 3) to define relevant consumer segments that assign different levels of importance to the various mobile service characteristics.

\subsubsection{Objectives study 2}

In study 2, we specifically highlight the role of mobile value and investigate how mobile service characteristics contribute to the creation of mobile value. According to emerging research in the field of mobile services (e.g., Shankar et al. 2003; van der Heijden 2005), one of the primary causes for disappointing m-commerce results may be companies' failure to understand how consumers derive value from mobile services, whereby we focus on utilitarian value in particular. Value has been defined as the customer-perceived trade-off between costs and benefits (Brady et al. 2005) and generally considered a relativistic (i.e., personal and situational) concept 
(Holbrook 1999). By combining traditional value theory and perceived innovation characteristics, we explicitly investigate the relationships between mobile innovation characteristics (i.e., benefits and costs) and value creation, which consequently leads to usage intentions. In this regard, time-related benefits and costs are most-cited in the literature due to the ambiguous nature of mobile services (Nysveen et al. 2005a). However, research has recognized that consumers vary in their awareness of how they spend their time (Francis-Smythe and Robertson 1999). Accordingly, we suggest that time consciousness, defined as a person's predisposition to consider time a scarce resource and plan its use carefully, interacts with the specific benefits and costs that determine mobile value creation. Consequently, this research specifically aims at creating insights into: 1) the specific benefits and costs of mobile value creation, and 2) the moderating influence of the consumer's time consciousness on this process.

\subsubsection{Objectives study 3}

Study 3 takes a more socially-oriented perspective with regard to the evaluation of mobile service innovations, and particularly focuses on image congruence as an evaluation mechanism. Research poses that image should be explicitly investigated as an evaluative criterion (Plouffe et al. 2001; Venkatesh and Davis 2000), whereby image congruence literature (e.g., Sirgy 1982; Sirgy 1985) emphasizes not the image as such to be the most important driver of intentions, but particularly the similarities between the image of the service innovation and the image of the user. In this study, we discuss the concept of image congruence and pose this as an influential factor on consumers' intention to use mobile services. Moreover, we investigate the role of several consumption situations, as mobile services, due to their ubiquitous nature, can be consumed in a variety of contexts. The objectives of this study, therefore, are 1) to test the image congruency theory with regard to mobile service innovations, and 2) to investigate the effects of consumption situations on attitude and intention toward mobile service innovations.

\subsubsection{Objectives study 4}

Study 4 extrapolates further on the role of relevant others in the consumer's social surroundings. More particularly, we investigate the role of mobile social networks and how they contribute to acquisition of knowledge regarding mobile service innovations, which in turn affects consumers' usage intentions. Particularly in relation to service innovations, consumer-to-consumer interaction is valued as a source of information (Hennig-Thurau et al. 2001). Mobile social networks create new ways for consumers to interact and exchange information on such innovations. However, according to social network theory (e.g., Granovetter 1983; Rogers and Kincaid 1981), the amount and heterogeneity of the information that consumers 
obtain is largely dependent on their position in the network. In this study we draw upon organizational and social psychology to uncover the antecedents of a consumer's network position in the mobile network. Hereby, we also consider the moderating effect of a consumer's need to belong as motivation to participate in the network. At the same time, we investigate how this network position contributes to consumers' knowledge acquisition and finally their intention to use mobile services innovations. While the later is an individual action, we do account for the group's ability to adopt as well, since prior research suggests that group characteristics stimulate individual decision making, specifically with regard to innovations (Munshi 2004). Consequently, the objectives of study four are: 1) to identify the antecedents of a consumer's mobile social network position, 2) to investigate the influence of this network position on the consumer's knowledge acquisition and consequently on his or her usage intentions, as well as the effect of the group's ability to adopt on this decision, and 3) to consider the influence of a consumer's need to belong on his on her network socialization process.

\subsection{Outline of the dissertation}

This dissertation is based upon four empirical studies that are discussed in chapters two, three, four, and five respectively (see Table 1.1). While the overall theme of each of these studies is to explain consumer usage intentions with regard to innovative mobile services, these studies maybe read separately. Chapter two focuses on the importance of mobile service characteristics and defines relevant consumer segments based on the importance consumers attach to these characteristics. Chapter three continues with the investigation of mobile service characteristics and investigates their impact on mobile value creation. Special attention is devoted to how these effects are moderated by a consumer's level of time consciousness. The next two studies focus on more social-oriented factors. In chapter four, the role of image congruence in forming consumer intentions is addressed, whereby we account for the different consumption situations that consumers find themselves in while making use of mobile services. Chapter five specifically addresses the position of the individual consumer within his/her social network, and how this position affects the knowledge consumers acquire about a diverse range of mobile services. Finally, chapter six concludes with a contemplation of the main findings about the drivers that explain consumer behavior with regard to mobile services usages, an overview of the implications and guidelines for future research. 


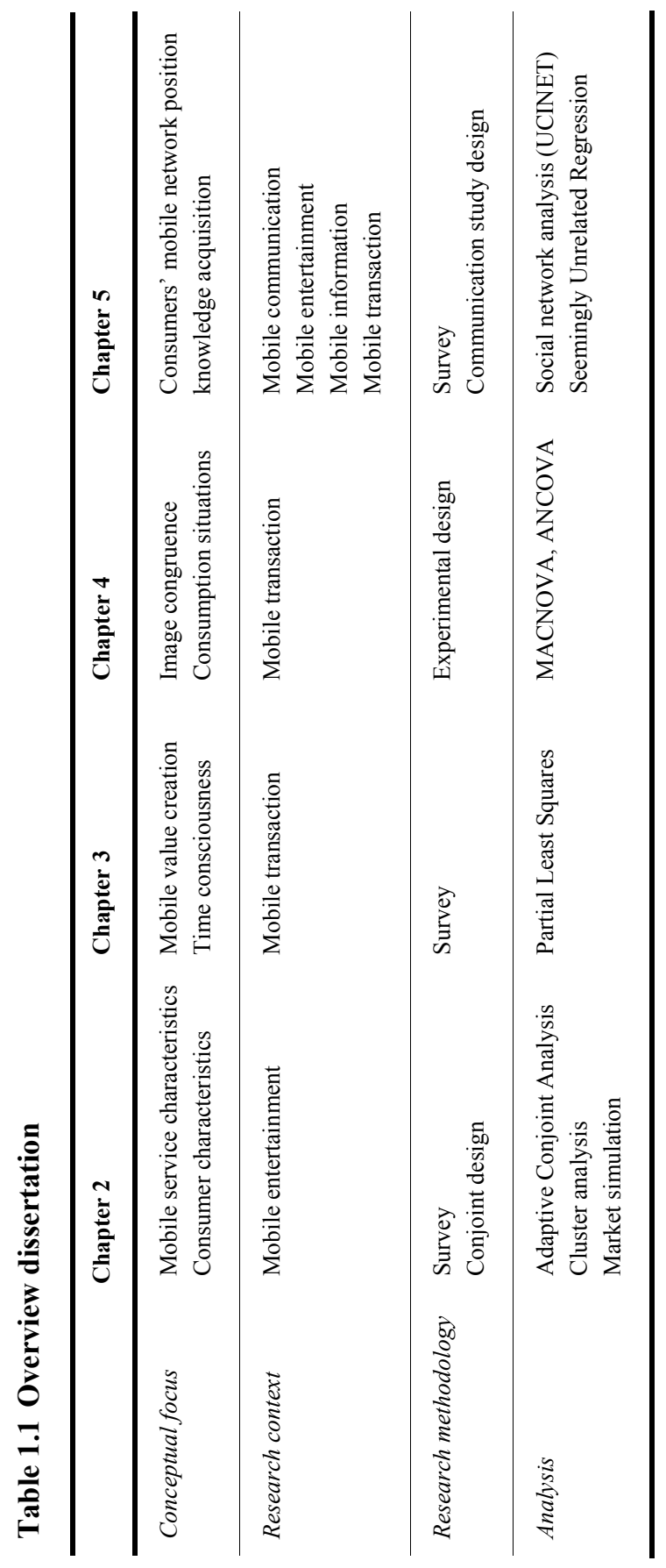





\section{Chapter 2}

\section{Consumer Adoption of Wireless Services: Discovering the Rules, While Playing the Game ${ }^{1}$}

This chapter aim is to explain the adoption of mobile gaming based on a refined model of Rogers' adoption theory, including context-specific factors and consumer traits. Overall, the empirical findings suggest that perceived risk plays a crucial role in the adoption process, followed by complexity and compatibility. Moreover, through cluster analysis we identified three consumer segments, named: Value Seekers, Risk Avoiders, and Game Players. Whereas perceived risk remains the most important factor for the Risk Avoiders, Value Seekers are also concerned about compatibility. Game Players emphasize navigation, communicability, and payment options.

1 This chapter is largely based on Kleijnen, Mirella H.P., Ko de Ruyter, and Martin G.M. Wetzels (2004), "Consumer Adoption of Wireless Services: Discovering the rules, while playing the game," Journal of Interactive Marketing, 18 (2), 51-61. 


\subsection{Introduction}

Wireless or mobile (m-)services have been heralded as the new marketing frontier (Newell and Newell-Lemon 2001, p. 103). This hype was driven by three main factors: the excitement regarding mobile technology; the continuing growth of ecommerce, and the high penetration level of wireless devices worldwide (Shankar et al. 2003). Yet, the present market reality is less overpowering than the hype surrounding wireless services. Only small percentages of AT\&T and Sprint wireless customers in the US are using m-services via their phones and the continuity of a number of European telecommunication companies is seriously threatened as a result of the exorbitant investments that were paid for the licenses of third generation (3G) wireless technology (Brodsky 2001). One of the most important reasons for the disappointing uptake of $\mathrm{m}$-commerce is the failure of firms to understand customer value creation (Shankar et al. 2003). It appears that the added value of wireless services currently being marketed lacks the advantages needed to create a market pull. In fact, it seems that the adoption and diffusion of these services is illustrative of a classic case of technology push (Basso 2001).

While a plethora of new wireless services has been introduced, mobile gaming services are among the few mobile applications that have been shown to provide a solid business model, and thus might generate revenues needed to finance the heavy expenditure on $3 \mathrm{G}$ licenses in Europe (Gold 2001). While m-gaming has been recognized as a profit generator in itself, with an expected growth of $\$ 950$ million in 2001 to $\$ 17.5$ billion in 2006 worldwide (www.datamonitor.com), it furthermore paves the way to create a critical mass needed for the successful integration of more functional-oriented information and transaction services (Sutherland 2001). Mobile gaming services allow consumers to engage in interactive multi-player games (MPG) against other remote users regardless of time or location restrictions. In order to successfully move beyond the technology push and accomplish the adoption of the wireless Web, and wireless gaming in particular, a deeper insight into the factors driving consumers' acceptance of m-services in general and m-gaming more in particular is needed.

\subsection{Conceptual development}

Even though mobile services have received scant attention in academic research so far, past research does provide a solid foundation for theory development in the area of mobile service adoption. To analyze the adoption of mobile services, we adopt Rogers' Adoption of Innovation framework (1995), which has stimulated research and has been validated in various areas (e.g., Kai-Ming Au and Enderwick 2000). 
Hereafter, we present a framework that recognizes two central categories that influence adoption: service characteristics and personal characteristics, which is in line with other studies investigating technology adoption (e.g., Dabholkar and Bagozzi 2002). Next, we discuss the service characteristics followed by personal characteristics.

\subsubsection{Service characteristics}

Rogers (1995) defines five factors influencing consumers' adoption decisions, of which relative advantage, compatibility, complexity, and communicability are considered in the present study. The last factor defined by Rogers, trialability, the extent to which an innovation may be experimented with on a limited basis, but without large commitment (Ortt 1998), is not taken into account here. Reality demands consumers to invest a substantial amount of time and effort in order to try mobile services. Consumers need to acquire a basic understanding of how to utilize WAP portals (Wireless Application Protocol is the most common technology facilitating mobile services at this moment). Furthermore, consumers should personalize configurations according to their preferences, e.g., the sort of games they like and the preferred game level to start with. Additionally, purchasing a hand-held device equipped with technology enabling mobile gaming entails a considerable monetary investment. An additional financial aspect to consider is the cost of the mobile game itself, game participation as well as time spent online to play the game induces costs to the consumer. Finally, the limited offerings of trial opportunities existing concentrate on single player games, and are offered via the Internet, neglecting unique aspects created through mobility. These trials symbolize a poor representation of possibilities within network games, such as the treasure hunt games. As a result, trialability was not taken into consideration in the present study.

The most obvious relative advantage of mobile services is its ubiquity, which allows consumers to engage in time-killing or stress-relieving activities anywhere and at any time (James 2001). For example, consumers use wireless games while traveling to school or friends for instance (www.i-moder.nl). But also the pure enjoyment of the game's challenge, or mobile gaming as a stress-relieving factor is mentioned by consumers as a major reason to engage in m-gaming (James 2001). Mobile gaming is not only about "just playing" but encompasses a hedonic entertainment (Nokia 2001).

Compatibility is often recognized as the construct of perceived usefulness defined by Davis (1989). In this study, it is explained as how well consumers believe mobile services can be integrated in their daily routine. Mobile gaming might fit very well with the behavior of teens, who are used to playing games on other handheld devices such as Nintendo play stations and who have a fairly good basic knowledge of Internet (James 2001). 
Complexity, also frequently identified as ease-of-use, is the extent to which an innovation is perceived as relatively complicated to understand and use (Agarwal and Prasad 1998a; Davis 1989; Karahanna and Straub 1999; Plouffe et al. 2001; Rogers 1995). In our study, complexity is associated with the usage of mobile gaming itself, e.g., the ease of grasping the rules of the game, rather than the mobile device enabling the services delivery.

Finally, communicability is considered. As defined by Rogers (1995) communicability shows strong resemblance to social influence, which has been recognized as a relevant influential factor by several other research streams (e.g., Fang 1998; Fishbein and Ajzen 1975; Karahanna and Limayem 2000; Karahanna and Straub 1999), and which in the current context is linked to the interpersonal influences of friends, colleagues, family or others that are highly respected (Bhattacherjee 2000). Participation in mobile gaming might be recognized by consumers as a manner to play a part in a certain social reference group.

In addition to the Rogers framework, the current study defines four more factors relevant to consumers' adoption of mobile gaming services: perceived risk, navigation, critical mass, and payment options. Particularly in the current context, perceived risk plays an important role, as the use of highly personalized and contextbased technology is particularly prone to consumer risk perception (Newell and Newell-Lemon 2001). Perceived risk is recognized as the degree to which risks are accredited to mobile services. Risk can be acknowledged as total risk, or it can be defined as a specific type of risk (e.g., functional, privacy, or psycho-social risk). In our study we focus particularly on functional risk, which relates to performance. Performance of mobile services is strongly dependent on the technology underlying these services. Possible problem areas that can be recognized are operator network breakdowns or browsers implemented in the mobile device.

Furthermore, readings on m-commerce suggest navigation to have a strong impact on a consumer's decision whether or not to use mobile services (Kaasinen et al. 2000). Dolan (2000) for example mentions design as a significant influence on success of mobile Internet. Currently, newly introduced devices illustrate a strong focus design, especially in relation to navigational features. This is exemplified by the introduction of hand-devices especially designed for mobile entertainment (Nokia 5110 for example). Several options for navigation are implemented in current devices, such as touch screens or 'one-click-access' buttons. Navigation or maneuvering ergonomics associated with the mobile device play a crucial role in network gaming, as it enables the player to react timely to the adversary's actions.

Additionally, critical mass is recognized as an essential factor in the decision to adopt mobile services. This critical mass, once reached, can accelerate the adoption pace (Mahler and Rogers 1999; Schoder 2000). Interactive innovations in particular (like mobile entertainment services) are relying on the amount of users 
who have already adopted the innovation (Mahler and Rogers 1999). Particularly, the experiential value of mobile gaming is increased with critical mass establishment, as social interactivity is a major reason for participating (James 2001). Especially network gaming has generated substantial revenues in the i-mode case. Network games allow competitions against any possible adversary. As more users adopt mobile entertainment services the playground transforms into a greater, potentially global arena.

Payment options is the final factor taken into consideration. Recent studies in the field of $\mathrm{m}$-commerce have indicated that issues related to pricing should not be neglected (e.g., Buellingen and Woerter 2004). The variety in payment options is creating tremendous price differences that might influence consumers' adoption decisions. More particularly, a convenient billing system has been acknowledged as a contributing factor in the success of i-mode in Japan (Dolan 2000). Most commonly, European consumers are charged for their 'wireless time' online. Alternatively, pay-per-use or pay-per-download (Shankar et al. 2003), paying for data bytes downloaded regardless of time spent online (like the i-mode case) are identified as payment options. Especially in the context of mobile gaming prices might fluctuate strongly. The game type for example might have a substantial impact on the time needed to the play the game or the necessity for information download. "Inner-citychasing games" for instance are designed to take a substantial amount of time and require certain skills from players. Aforementioned obstacles would be eliminated by the introduction of a flat fee subscription.

\subsubsection{Personality characteristics}

Hung et al. (in press) stress the need to investigate consumer traits of potential adopters when studying m-commerce. According to Grewal et al. (2000), the success of innovations depends on innovativeness, which introduces the innovation to society, and opinion leadership, which provides social legitimacy to the innovation. Innovativeness is considered to be a personality trait that all individuals possess to a certain extent, since every person adopts some objects or ideas that are new in the context of their individual experience during his or her live (Citrin et al. 2000). Innovativeness is defined as the extent to which an individual or other unit of adoption is early in adopting new ideas relative to other members of a society (Rogers 1995). Opinion leadership is considered as an important variable in wordof-mouth communication, which contributes to the success of an innovation (Grewal et al. 2000). Here, we take innovativeness as well as opinion leadership into account. Finally, Internet usage was considered as a relevant characteristic. Prior experience with similar products or services might influence the adoption of an innovation (Carlson and Zmud 1999; Citrin et al. 2000; Jackson et al. 1997; Rogers 1995). If a consumer is more inured to gaming on other platforms such as Internet, (s)he might 
be inclined to use mobile devices to play similar games. Now that we have introduced our theoretical framework, the next part of the chapter will continue with an elaboration of the research design and the analysis of the results obtained via an empirical study.

\subsection{Empirical research}

This study has two main objectives: 1) to identify an importance hierarchy concerning the critical factors influencing mobile services adoption, and 2) to examine the trade-offs consumers are willing to make when deciding to actually use mobile services or not. Conjoint analysis was recognized as an appropriate tool to accomplish these research objectives. The results of the conjoint analysis are employed at the aggregate level for simulations with "hypothetical" mobile service offerings. Finally, we segment the respondents based on the preference structures resulting from the conjoint analysis.

\section{Measures}

We adopted three constructs as profiling variables for the emergent clusters. Measurement instruments for innovativeness (three items, sample item: compared to my friends I have played a lot of mobile games) and opinion leadership (five items, sample item: overall, in all of your discussions with your friends you are often used as a source of advice) were adopted from Grewal et al. (2000) and adjusted to the specific context of our study. All scales were measured on a 5-point Likert-type scale. Finally, we measured the level of Internet usage by two items: the number of times on line (ranging from never to more than once a day) and the average time spent on line per day (ranging from zero to more than three hours). The service characteristics were operationalized by means of scenarios. Each variable was explained by means of a short text and measured on different levels. The levels have not been quantified, yet remained abstract in nature (e.g., high-medium-low). This is in line with similar research in services by, for instance, DeSarbo et al. (1994), where service quality dimensions are described in scenarios as worse, same, or better than expected. All levels are indicated in Table 2.1.

\section{Sample}

Pseudo-random sampling was applied to select respondents. A total of 99 respondents were intercepted on the streets of Maastricht, a mid-sized city of approximately 120.000 inhabitants in the Netherlands. In order to avoid respondent bias (Bush and Hair Jr. 1985), the research was conducted over a twelve-day period in June 2001 that included weekend days and weekdays, and different hours of the day. 
This sampling approach allowed us to use personal interviewing, which is preferable given the complexity of the task.

By examining the Pearson product-moment correlation coefficient internal validation was obtained (Green and Srinivasan 1978; Sawtooth Software 1997). This coefficient denotes the correlation between the respondent's predicted and actual answers to the calibration concepts. The mean for the Pearson product-moment correlation coefficient equaled .83. An inspection of the frequency distribution revealed that seven respondents showed a coefficient less than or equal to .20, five respondents showed a coefficient between .20 and .40 and three respondents showed a coefficient between .40 and .50 . A cut-off point of .50 was used, which led to a usable sample of 84 respondents $^{2}$. The final sample can be characterized as follows: gender (female: $52.4 \%$, male: $47.6 \%$ ), age (18-25 years: $42.8 \%$, 26-35 years: $28.6 \%$, $>35$ years: $28.6 \%$ ), and level of education (at least secondary education: $52.4 \%$, at least tertiary education $47.6 \%$ ).

\subsection{Analysis and Results ${ }^{3}$}

Since the beginning of the 1970s the use of (metric) conjoint analysis (Green and Rao 1971; Green and Srinivasan 1978) has gained increasingly in popularity both with academics and practitioners (Cattin and Wittink 1982; Wittink and Cattin 1989). The term 'conjoint analysis' envelops techniques, which (Green and Srinivasan 1978, p. 103) "...emphasize the transformation of subjective responses into estimated parameters." Traditionally, two approaches have dominated the data collection method for conjoint analysis: (1) the trade-off approach (2) the full-profile approach (Cattin and Wittink 1982; Green and Srinivasan 1978; Green and Srinivasan 1990; Wittink and Cattin 1989). However, for conjoint analysis with a large number of attributes (typically more than six attributes) these two approaches might not be ideal (Green and Srinivasan 1990; Pullman et al. 1999). Several alternative approaches have been proposed to deal with this problem: self-explicated models (Dorsch and Teas 1992; Srinivasan 1988), hybrid models (Green 1984; Green and Krieger 1996; Moore and Semenik 1988) and Adaptive Conjoint Analysis (Johnson 1987; Sawtooth Software 1993). Overall, the performance of ACA and the fullprofile approach in terms of choice validation appear to be mixed. Some authors report that ACA outperforms the full-profile approach (Huber et al. 1993), some

Although there is no generally accepted cut-off value for this statistic, several authors recommend a medium-sized magnitude in order not to limit the sample size unnecessarily (Chrzan, 1991; Hermann et al., 2001).

3 An earlier version of the preliminary results concerning the conjoint analysis part of the study was presented in: Mobile commerce: Technology, Theory and Applications. Mennecke Brian E. Strader Troy J. (eds.), 2002. 
authors report a worse performance in terms of choice validation of ACA vis-à-vis the full-profile approach (Agarwal and Green 1991; Pullman et al. 1999).

ACA system (version 4.0) guides the respondents through several stages (Green et al. 1991; Sawtooth Software 1997). In the first stage, each respondent ranks his or her preferences (expressed as intention to use the mobile service) for each level of each of the eight adoption factors in the study. An additional feature in this stage allows the respondent to indicate which levels of each critical factor they would consider unacceptable under any circumstance. However, following recommendations by Green et al. (1988) respondents where not allowed eliminating unacceptable levels from the attributes in the study (cf., Metha et al. 1992). In the second stage, the respondent is presented the best and worst levels (obtained form the first stage rankings). Green et al. (1991) recognize the 1 to 4 ranking scale in this stage as a weakness of ACA. However, the version employed in our study (version 4.0) allows a choice of ranking scales. Hence, the respondent in our study was asked to rate the importance of this difference between best and worst level on a 1 to 9 rating scale, where 9 represents highest importance.

Stage three presents the respondent with a set of paired partial profiles, with each set of pairs exposed side by side on the computer screen. For each paired comparison, the respondent indicates his preference for either one or the other combination of adoption factors. For this purpose, a 9-point interval scale is utilized (9 indicating a strong preference for the combination presented on the right side), which later is transferred by ACA in to a range of -4 to 4 with zero denoting the indifference point (Green et al. 1991; Johnson 1991; Sawtooth Software 1997). Green et al. (1991) indicate that for paired concepts simple combinations are preferred for reasons of simplicity for judging and greater utility differences. Therefore, the current study employs a maximum of three adoption factors per concept in this stage. Finally, in stage four the respondent is confronted with five calibration concepts consisting of four different adoption factors. Calibration concepts are chosen by the software so as to progress in preference from highly undesirable to highly desirable (Green et al. 1991; Sawtooth Software 1997). The respondent rates each calibration profile on a 0 to 100 likelihood-of-adoption scale. After being rescaled and normalized using the DIFFS-procedure, the results from the ACA analysis were imported into a SPSS data file for further analysis.

The part-worth utilities obtained from ACA were used to calculate the importance ratings for the eight attributes in the study by subtracting the minimum partworth utility from the maximum part-worth utility for each attribute and consequently dividing this term by the sum of the differences for each attribute. Table 2.1 summarizes the results of the conjoint analysis. It shows that perceived risk is the most important factor in adopting mobile services (20.69\%), followed by complexity (15.19\%) and compatibility (13.71\%). 
Table 2.1 Importance ratings $(n=84)^{\mathrm{a}}$

\begin{tabular}{llcc}
\hline Variable & Level & Importance ratings & Part-worth utilities \\
\hline Perceived risk & No risk & $20.69 \%$ & 157.030 \\
& Medium & & 94.580 \\
& High & & 1.550 \\
\hline Relative advantage & No relative advantage & $10.50 \%$ & 7.740 \\
& Medium & & 52.350 \\
& High & & 67.780 \\
\hline Compatibility & Not compatible & $13.71 \%$ & 9.240 \\
& Medium & & 68.510 \\
& High & $15.19 \%$ & 95.830 \\
\hline Complexity & Low & & 110.154 \\
& Medium & & 78.090 \\
& High & $8.51 \%$ & 1.120 \\
\hline Communicability & Friends & & 50.050 \\
& Colleagues & & 25.640 \\
& Family & $9.86 \%$ & 24.690 \\
\hline Critical mass & Nobody & & 12.090 \\
& Some people & 52.560 \\
& Many people & 57.000 \\
\hline Navigation & Mini-keyboard & $10.73 \%$ & 48.460 \\
& Regular dial buttons & & 26.250 \\
& Dual thumb & 29.700 \\
& Touch screen & 66.740 \\
\hline Payment options & Minutes online & 36.040 \\
& Data download & & 41.470 \\
& Flat fee & 52.290 \\
\hline
\end{tabular}

a An earlier version of the preliminary results concerning the conjoint analysis part of the study was presented in: Mobile Commerce: Technology, Theory and Applications. Mennecke Brian E. Strader Troy J. (eds.), 2002.

\section{Simulations}

We used choice simulations for further validation of our results (Green and Krieger 1988; Green and Srinivasan 1990). This approach allows us to translate utility values for each of the adoption criteria into "market values", allowing for an assessment of the impact of each particular factor on the adoption of mobile services (Green and Srinivasan 1990). The baseline model matches current mobile service standards, while the alternative models were inspired by $3 \mathrm{G}$ mobile services that are currently being introduced in the Japanese market. Table 2.2 exhibits various levels of each adoption variable for the baseline and the alternative models.

In the current study, the First Choice Model and the Share Preference Model in ACA version 4.0 were selected for the simulations, both well-established choice rules (Baier and Gaul 2001). The first choice model uses the max utility rule and as a result preference is allocated entirely to the product with the highest total utility for 
each respondent (Baier and Gaul 2001; Green and Krieger 1988; Wiley and Low 1983). A total utility is calculated for each combination of factors being simulated. The combination with the highest total utility for a respondent is assigned a preference score of " 1 ", the others are given a " 0 ". In contrast, the Share Preference Model uses a logit transformation (or logit rule) to translate utilities into preference shares (Baier and Gaul 2001; Green and Krieger 1988; Wiley and Low 1983). The results for all simulations are reported in Table 2.2.

As shown in Table 2.2, we ran eight simulations against the baseline, changing several of the factors for each. The results of the simulations are in line with our findings. For instance, decreasing perceived risk implies an enormous increase in the intention to adopt ( $\mathrm{FC}+64.28 \%$; $\mathrm{SP}+21.62 \%)$, indicating the profound impact of perceived risk on the adoption decision that is stronger than any of the other factors. This procedure is repeated for several factors and every time it confirms our results as generated by the conjoint analysis.

Additionally, we conducted a simulation combining several factors into one alternative model. This alternative model is based on the new $3 \mathrm{G}$ mobile services that are currently being introduced in Japan. The alternative model assumes the following characteristics: mobile services exhibit low perceived risk, high relative advantage, low complexity, a good fit with the consumers' daily activities and prior experiences, and data input handled via touch screens. Introducing mobile services with these characteristics would increase the likelihood that consumers adopt such services tremendously (FC $+80.96 \%$; SP $+50.10 \%)$. Considering we used $3 \mathrm{G}$ services as a base for our alternative model, this would imply that $3 \mathrm{G}$ services have a greater chance of being adopted successfully than current WAP applications have been so far. 
Table 2.2 Results of simulations

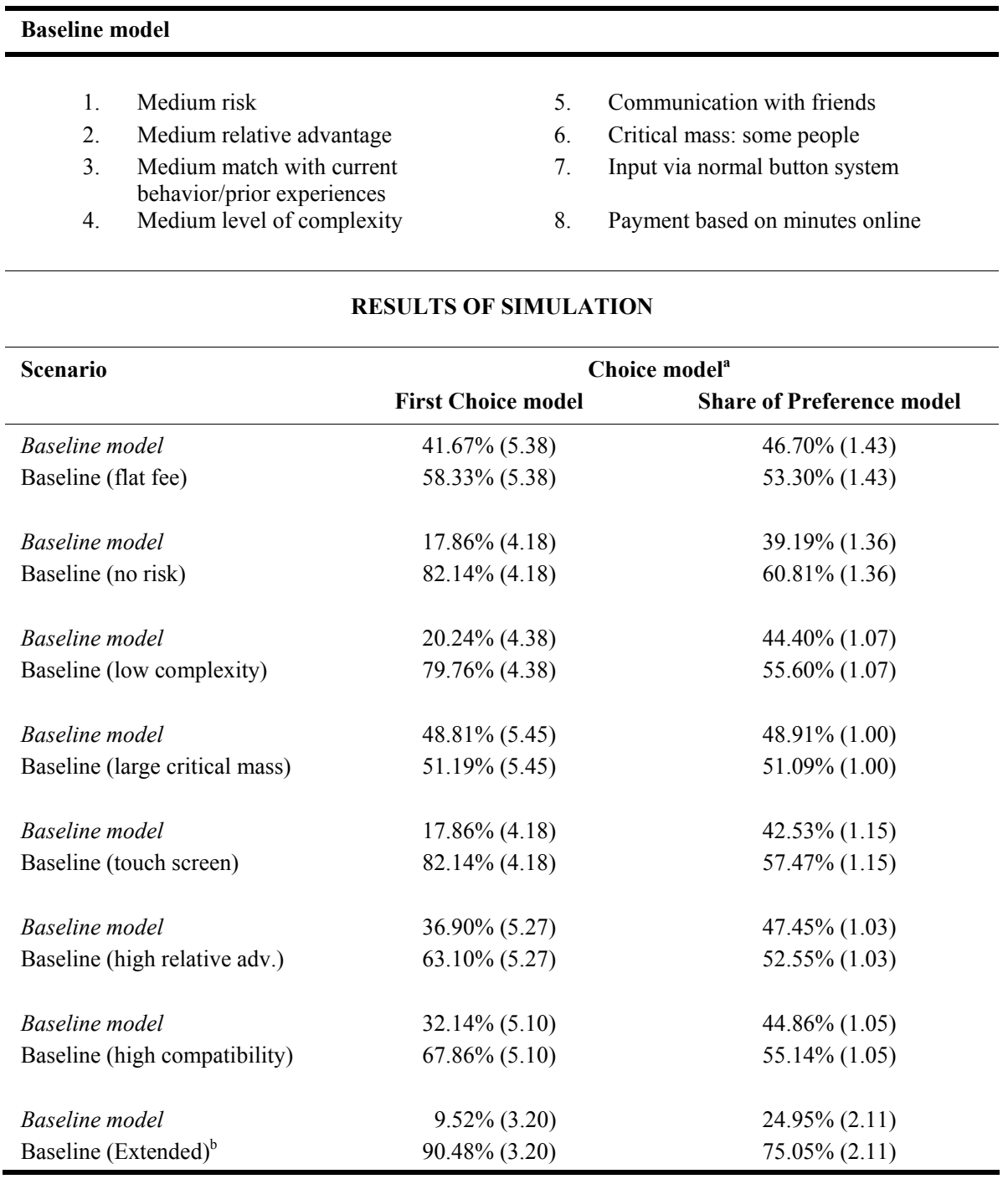

a Standard errors between brackets.

b No risk, high relative advantage, low level of complexity, high degree of compatibility, input via touch screen.

\section{Cluster analysis}

The use of cluster analysis to segment respondents on the basis of conjoint analysis results has been widely acknowledged (Green and Krieger 1991; Hagerty 1985; Kamakura 1988; Vriens et al. 1996). Two basic approaches can be distinguished with regard to segmentation of conjoint analysis results (Vriens et al. 1996): (1) the 
one-stage approach (integrated conjoint segmentation method), in which the estimation of the parameters, or part-worth utilities, in the conjoint model and segmentation are integrated into one stage and (2) the two-stage approach, in which estimation of the parameters in the conjoint model (e.g., DeSarbo et al. 1992; Hagerty 1985; Kamakura 1988; Wedel and Steenkamp 1989) or part-worth utilities, in the conjoint model and segmentation are performed separately (cf. Green and Krieger 1991). Currently however, for ACA-based results only the two-stage approach is available. Furthermore, Vriens et al. (1996) only report negligible and statistically nonsignificant differences between the one-stage and two-stage approaches.

Consequently, we applied a two-stage clustering approach in which a hierarchical algorithm is used to determine the number of clusters and subsequently providing initial cluster seeds for a nonhierarchical algorithm (Punj and Stewart 1983). We used Ward's minimum variance method using squared Euclidian distance for the hierarchical cluster analysis, which appears to be superior to the alternative approaches (Everitt et al. 2001; Milligan and Cooper 1987; Punj and Stewart 1983). Since there are no completely satisfactory methods to determine the number of clusters in hierarchical cluster analysis, we opted for using multiple methods (Milligan and Cooper 1985). We plotted the pseudo F-statistic (Calinski and Harabasz 1974), the pseudo $t^{2}$-statistic (Duda and Hart 1973) and the fusion coefficients against the number of clusters. Inspection of these plots indicated three clusters in the data. Using the fusion coefficients we calculated the critical value $(\mathrm{k})$ for Mojena's (1977) rule 1 stopping rule, which confirmed the existence of three clusters in the data. In the second stage, the centroids of these three clusters were employed as starting seeds for a k-means clustering algorithm. We obtained three clusters with respectively 19,39 , and 26 observations.

\section{Cluster characteristics}

We used the clustering variables, the profiling variables (not used in the clustering procedure), opinion leadership, innovativeness, as well as Internet usage and the demographic variables to characterize the three clusters. Initially, we employed sequential multinomial logistic regression with cluster membership as dependent variable and the three profiling variables and the demographic variables as independent variables (DeMaris 1992; Hosmer and Lemeshow 2000).

A $\chi_{\text {LR }}^{2}$ difference test was calculated on the basis of the difference between the $-2 \log$-likelihood for a restricted model $\left(-2 \mathrm{LL}\left(\mathrm{D}_{0}\right)\right.$ and the -2 maximized $\log$ likelihood for a unrestricted model $\left(-2 \mathrm{LL}\left(\mathrm{D}_{\mathrm{M}}\right)\right.$. The full model contains all the profiling variables: opinion leadership, innovativeness, Internet usage, and the demographic variables (specified as indicator variables: AGE $(18-25=0 ;>25=1)$, 
GENDER (male $=1$; female $=0$ ), EDUCATION (at least secondary level $=0$; $>$ secondary level $=1$ ) as independent variables, whereas the restricted model contains only opinion leadership, innovativeness and Internet usage as independent variables. The $\chi_{\text {LR }}^{2}$ difference test indicated $\left(\Delta \chi^{2}(6)=7.31 ; p=.29\right)$ that the demographic variables do not significantly contribute to the explanatory power of the model (cf. Simonoff 1998). Therefore, we use the reduced model containing only opinion leadership, innovativeness, and Internet usage as independent variables. The model fit of the reduced model is adequate. The hypothesized model differs significantly from the intercept model $\left(\Delta \chi^{2}(6)=22.25, p<.001\right)$ and showed an adequate model fit in terms of the pseudo $\mathrm{R}^{2}$ statistics (Cox and Snell's $R^{2}=.23$; Nagelkerke's $\left.R^{2}=.27\right)$. Inspecting the results of the likelihood ratio test statistic for the independent variables in the hypothesized model revealed that apart from the intercept $\left(\chi_{\text {LR }}^{2}=\right.$ $14.98, p=.001)$, innovativeness $\left(\chi_{\text {LR }}^{2}=9.19, p=.010\right)$ and Internet usage $\left(\chi_{\text {LR }}^{2}=\right.$ $6.51, p<.039)$ exhibited a significant effect $(\alpha=.05)$ on cluster membership. The parameter estimates and the accompanying Wald statistic indicate significant effects $(\alpha=.05)$ for cluster $1(\mathrm{n}=19)$ versus cluster $3(\mathrm{n}=26)$ for innovativeness $(B=.929$; Wald Statistic $=6.33, p=.012$; Odds ratio $=5.220)$ and Internet usage $(B=.939$; Wald Statistic $=5.401, p=.020$; Odds ratio $=5.646)$. For cluster $1(\mathrm{n}=19)$ versus cluster $2(\mathrm{n}=39)$ we find a significant effect $(\alpha=.05)$ for innovativeness $(B=.867$; Wald Statistic $=6.948, p=.008$; Odds ratio $=4.534)$.

Table 2.3 shows the descriptive statistics for the clustering and the profiling variables. We tested for differences among the clusters regarding the personality characteristics, which are included in the cluster analysis. We used the GamesHowell procedure for pairwise comparisons (Games and Howell 1976). This procedure maintains the familywise error rate close to the chosen $\alpha$ for equal and unequal variances and equal and unequal sample sizes (Toothaker 1992). Except for critical mass all the other attributes show statistically significant differences among the clusters as can be observed from the F-statistic and the pairwise comparisons.

Exploratory factor analysis was used for construct validation of the three profiling variables. Adopting principal factoring with oblique rotation with Kaiser normalization (extracting three factors), we found that the items in the pattern matrix loaded high on their respective hypothesized factors (Opinion leadership: .64 - .87; Innovativeness: $.58-.82$; Internet usage: $.78-.80$ ) and exhibited relatively small loadings for the other factors.

Table 2.4 contains the means, standard deviations, intercorrelations, and coefficients alpha for the profiling variables. The reliabilities in terms of coefficient alpha all exceed the recommended cut-off value of .70 (Nunnally and Bernstein 1994). Next, the profiling variables were used to test for differences among the 
clusters. Similarly, we used the Games-Howell procedure for pairwise comparisons (Games and Howell 1976). These results are depicted in Table 2.3.

Table 2.3 Cluster characteristics

\begin{tabular}{|c|c|c|c|c|c|}
\hline \multirow[b]{2}{*}{ Cluster variables } & \multicolumn{3}{|c|}{ Importance ratings $(\%)^{a}$} & \multicolumn{2}{|c|}{ Test } \\
\hline & $\begin{array}{c}\text { Game } \\
\text { players } \\
(n=19)\end{array}$ & $\begin{array}{c}\text { Value } \\
\text { seekers } \\
(n=39)\end{array}$ & $\begin{array}{c}\text { Risk } \\
\text { avoiders } \\
(n=26)\end{array}$ & $F_{(2,81)}$ & $p$ \\
\hline Perceived risk & $14.520^{\mathrm{A}}$ & $18.080^{\mathrm{B}}$ & $29.140^{\mathrm{C}}$ & 45.918 & $<.001$ \\
\hline Relative advantage & $9.590^{\mathrm{A}}$ & $13.160^{\mathrm{B}}$ & $7.200^{\mathrm{A}}$ & 9.040 & $<.001$ \\
\hline Comparability & $9.590^{\mathrm{A}}$ & $17.930^{\mathrm{B}}$ & $10.400^{\mathrm{A}}$ & 23.727 & $<.001$ \\
\hline Complexity & $13.000^{\mathrm{A}}$ & $13.770^{\mathrm{A}}$ & $18.930^{\mathrm{B}}$ & 7.708 & .001 \\
\hline Communicability & $15.510^{\mathrm{A}}$ & $6.710^{\mathrm{B}}$ & $6.130^{\mathrm{B}}$ & 22.743 & $<.001$ \\
\hline Critical mass & 8.490 & 10.890 & 9.340 & 1.234 & .297 \\
\hline Navigation & $15.160^{\mathrm{A}}$ & $9.640^{\mathrm{B}}$ & $9.130^{\mathrm{B}}$ & 7.095 & .001 \\
\hline Payment options & $14.150^{\mathrm{A}}$ & $9.820^{\mathrm{B}}$ & $9.750^{\mathrm{B}}$ & 6.491 & .002 \\
\hline \multirow[t]{2}{*}{ Profiling variables } & \multicolumn{3}{|c|}{ Mean scores } & \multicolumn{2}{|c|}{ Test } \\
\hline & & & & $F_{(2,81)}$ & $p$ \\
\hline Opinion leadership & 3.400 & 3.330 & 2.950 & 1.838 & .166 \\
\hline Innovativeness & $4.420^{\mathrm{A}}$ & $3.550^{\mathrm{B}}$ & $3.120^{\mathrm{B}}$ & 7.215 & .001 \\
\hline Internet usage & $3.970^{\mathrm{A}}$ & $3.570^{\mathrm{A}}$ & $3.020^{\mathrm{B}}$ & 5.976 & .004 \\
\hline
\end{tabular}

a Identical subscripts indicate no statistically significant differences at $\alpha=.05$ using the Games-Howell procedure for pairwise comparisons.

Table 2.4 Means, standard deviations \& intercorrelations of profiling variables ${ }^{\mathrm{a}}$

\begin{tabular}{lcclll}
\hline Constructs & M & SD & $\mathbf{1 .}$ & $\mathbf{2 .}$ & $\mathbf{3 .}$ \\
\hline 1. Opinion leadership & 3.23 & .92 & $.85^{\mathrm{b}}$ & & \\
2. Innovativeness & 3.61 & 1.23 & .53 & .87 & \\
3. Internet Use & 3.49 & .98 & .27 & .37 & .91 \\
\hline
\end{tabular}

a All intercorrelations are significant at $\alpha=.05$.

b Coefficient alpha on the diagonal.

For the first cluster, communicability, payment options, and navigation appear to be the most important. These technology characteristics are all strongly related to game playing. Therefore, this cluster is specified as 'Game Players'. Furthermore, the respondents in this cluster distinguish themselves by expressing a significantly higher level of innovativeness. In the second cluster, labeled 'Value Seekers', consumers focus on the additional value in using mobile services and the fit to their current living style and value system. In the final cluster, perceived risk as well as complexity are prominently present. The consumers in this cluster will only 
use mobile services if they are sure that these will be delivered as promised. Accordingly, the importance of complexity might be explained by the fact that increased complexity will make it difficult for the consumer to deliver the proper input, which can also result in mobile services not living up to the expectations of the customer. Additionally, it can be noted that consumers in this particular cluster can be characterized by a low level of Internet usage. This cluster is referred to as 'Risk Avoiders'.

\subsection{Discussion}

Several conclusions result from the current study. Conjoint analysis as well as the conducted simulations allowed us to identify perceived risk, complexity, and compatibility as the three main adoption factors. In this realm the most imperative motivation for not engaging in a wireless transaction is risk (Newell and NewellLemon 2001). For wireless, the level of customer intimacy is even greater than for wired transactions, whereby the role of security and privacy issues become of crucial importance. Complexity of current mobile services forms another impediment. Despite the fact that one of the primary objectives of m-commerce is to simplify life for consumers (Koranteng 2000), many first-time users find the ease-of-use of current mobile service far below desired levels of comprehension. Finally, compatibility of mobile gaming to consumers' life style needs more attention. Although mobile phone penetration is high, consumers do not recognize how the use of mobile services can fit to their lives. Critical mass and communicability appear to have the least influence. These factors relate to social aspects associated with mobile services and mobile gaming particularly. Yet, our results indicate that for the time being $\mathrm{m}$ commerce is mainly considered as a personal technology. Finally, cluster analysis resulted in a three-cluster solution, identifying Internet usage and innovativeness as discriminating characteristics between clusters, which offers possibilities to segment customers consistent with their needs and fine-tune company strategies accordingly.

\subsection{Limitations and suggestions for further research}

Part of the strength of a study lies in the acknowledgment of its limitations. These limitations lead to suggestions for future research and elucidate theoretical implications. Firstly, despite a thorough literature review we might have overlooked relevant variables. One additional variable that deserves particular attention in further research is price, especially considering the attention that has been devoted to this factor in recent studies on wireless commerce (e.g. Hung et al. in press). While 
the current research has made an attempt to include a related variable (payment options), further research should explicitly account for the effect of price.

Additionally, further validation of the use of abstract attributes such as relative advantage and compatibility is necessary. Conjoint studies typically include concrete product or service features that are fairly easy to be manipulated and understood by consumers. Although other research in this area has validated these manipulations in an experimental setting (de Ruyter et al. 2001), the operationalization of these constructs by defining more concrete aspects that constitute for example relative advantage would enhance the validity of the study. Furthermore, the study was conducted in the Netherlands, which might imply limited external validity of the results to countries where uptake of mobile commerce has been anticipated to be faster and more widespread. Moreover, the sample size was rather small. Although Green and Srinivasan (1990) state that conjoint analysis applied on an individual level is not extremely dependent on the sample size, the external validity of the results might be limited. A further limitation in this realm is the contextual setting of our study. Given the fact that our research was embedded in a mobile gaming context, the external validity of the obtained results is not guaranteed for differing types of mobile services. For future research, we recommend that our results should be cross-validated using multiple methods, additional samples, and contexts.

\subsection{Managerial implications}

Several managerial implications can be derived. The findings explicate a substantial influence of perceived risk on the mobile service adoption process. Consequently, a predominant focus on risk reduction and $\mathrm{m}$-trust creation is imperative for successful establishment of mobile services. Companies need to invest in systems that assure reliable and secure data transmission, prohibiting bad system performance as well as misuse/abuse of personal information (Nyshadham 2000). Additional implications arise from the customer profiles that have been identified providing marketers the opportunity to segment the market and to target each segment in a unique way. Several recommendations can be formulated with respect to the identified segments. For 'Game players' it is important to improve navigation systems, especially in $\mathrm{m}$ entertainment but also in other service categories. Recently navigation and design aspects are receiving increased attention and several device producers are offering additional features to improve mobile navigation, such as mobile joysticks. A next important factor is payment options (e.g., subscription-based service usage). This factor is expected to become more ubiquitous with the introduction of new wireless technologies as it leads to less insecurity regarding service prices. 'Game Players' 
also distinguish communicability as a relevant technology characteristic. Increasing visibility of mobile services can be accomplished by providing communities or buddy list options enabling customers a convenient channel to inform their peers or invite them to join for a game. Finally, 'Game Players' discriminate themselves from other segments through a higher level of innovativeness. Stressing the novelty of mobile services in advertising and providing exclusive access to new games before market introduction might be useful tools for marketers in reaching these customers.

'Value Seekers' concentrate on the relative advantage of mobile services and the compatibility to daily life style as essential adoption criteria. Consequently, companies need to focus on the unique advantages of mobile services, thereby not only stressing ubiquity of $\mathrm{m}$-commerce but also pointing out the opportunities of localization and personalization. The latter are expected to pop up with the introduction of $3 \mathrm{G}$ technologies.

Finally, 'Risk Avoiders' mainly focus on perceived risk, but also complexity is of significant importance. This illustrates a need for information on m-services usage. This need is confirmed by the fact that risk avoiders show a significantly lower level of Internet usage, indicating less experience with technology. Marketers can provide this usage information through various channels. Furthermore, the usage of relatively uncomplicated services should be stimulated. Customer acquaintance to this category of m-services will also lower the barrier to exploit other m-services. 



\section{Chapter 3}

\section{An Assessment of Value Creation in Mobile Service Delivery and the Moderating Role of Time Consciousness ${ }^{4}$}

This chapter focuses on the perceived utilitarian value of a new service delivery mode, the mobile channel. The authors develop a framework that incorporates three mode-specific benefits - time convenience, user control, and service compatibilityas well as two costs-perceived risk and cognitive effort-as antecedents of perceived value. Because of the pervasiveness of time criticality as a value-added characteristic of the mobile channel, they also investigate the moderating influence of consumers' time consciousness. They empirically investigate the model using mobile brokerage services as an illustrative application. The results reveal that the identified antecedents, with the exception of service compatibility, have a strong impact on mobile channel value perceptions, which in turn influence behavioral intentions. The authors also find that time consciousness moderates the aforementioned relationships.

4 This chapter is largely based on Kleijnen, Mirella H.P., Ko de Ruyter, and Martin G.M. Wetzels (2007), "An assessment of value creation in mobile service delivery and the moderating role of time consciousness," Journal of Retailing, 83 (1), 33-46 (Special Issue on Competing Through Service Excellence, best paper award). 


\subsection{Introduction}

Mobile (m-)commerce has frequently been proclaimed the new service frontier (Kleijnen et al. 2004; Newell and Newell-Lemon 2001). In addition to communication and entertainment services, wireless devices, such as mobile phones, personal data assistants, and pagers, can be used effectively to deliver value-added service transactions (Nysveen et al. 2005a). Both traditional retail (e.g., banks like Wells Fargo, ING, and Fidelity) and online (e.g., Amazon, Yahoo) service providers have added such m-commerce enhancements to their multichannel operations. However, despite the widespread introduction of new mobile services, recent market reports reveal poor bottom-line results. According to a recent ATKearney (2005) market analysis, only a small minority of consumers in the United States and Europe (5\% and $6 \%$, respectively) expressed an interest in using their mobile phone for service transactions. The primary cause for these disappointing $\mathrm{m}$-commerce results may be companies' failure to understand how consumers derive utilitarian value from mobile services (Shankar et al. 2003; van der Heijden 2005). Therefore, an understanding of the specific drivers of and barriers to value creation is crucial to help companies effectively allocate their resources to enhance consumer value perceptions.

Current research on customer value creation, however, offers little guidance. Across a variety of retail services, support for the antecedents of service value perceptions remains equivocal (e.g., Cronin et al. 2000). Furthermore, there is a relative paucity of knowledge about the specific costs and benefits associated with innovative mobile services and how they determine consumer value perceptions. Finally, empirical assessments of value creation appear subject to cross-sectional heterogeneity across users due to their personal characteristics (Bolton and Drew 1991). Thus, both a theoretical and a managerial need exist for a more in-depth understanding of value creation in the context of mobile transaction services. This study contributes to the emerging but limited body of research on consumer usage of mobile services by addressing two critical issues.

First, consistent with theorizing on customer value perceptions, we propose a direct effects model of utilitarian value creation that reflects the main costs and benefits associated with mobile service delivery. Value has been defined as the customer-perceived trade-off between costs and benefits (Brady et al. 2005) and generally considered a relativistic (i.e., personal and situational) concept (Holbrook 1999). This conceptualization emphasizes the importance of incorporating contextspecific costs and benefits as predictors of overall value judgments. Many costs and benefits have been associated with the use of mobile services, such as timeliness, easy access, place and time interdependence, security issues, costs, and so forth 
(Kleijnen et al. 2004; Newell and Newell-Lemon 2001; Nysveen et al. 2005a). To delineate a theoretically derived set of value predictors, we adopt the perceived characteristics of innovations (PCI) framework, as defined by Rogers (1995). In addition, we examine whether customer value perceptions drive intentions to use mobile services.

Second, an exclusive focus on direct relationships to explain the use of mobile services may mask divergent consumer reactions to the specific nature of mobile technologies and thus inhibit a more comprehensive understanding of consumer evaluations of such services (Kleijnen et al. 2004). Moreover, value theorists acknowledge that personal traits interact with costs and benefits in the value formation process (Holbrook 1999). The most prominently cited feature of mobile services is the time efficiency that results from the ubiquitous nature of mobile devices, which enables consumers to use services anytime and anywhere (Nysveen et al. 2005a). However, research has demonstrated that consumers differ in their awareness of how they spend their time (Francis-Smythe and Robertson 1999). Accordingly, we propose that time consciousness, defined as a person's predisposition to consider time a scarce resource and plan its use carefully, interacts with the specific benefits and costs that determine mobile value creation. In this paper, therefore, we explore whether time consciousness has a moderating effect on the value creation process for the context of mobile services.

\subsection{Conceptual background}

M-commerce refers to the mobile character of wireless devices that support electronic service transactions. Although m-commerce is frequently characterized as an extension of e-commerce, it also might be regarded as a separate channel, because it can deliver a unique value proposition to consumers (Balasubramanian et al. 2002) through the technological differences it encompasses, including its communication mode, protocols, and access devices. From a consumer perspective, however, a uniquely defining characteristic of $\mathrm{m}$-commerce is its ubiquity, that is, the ability it offers to engage in commerce anytime and anywhere. In this sense, the value of $\mathrm{m}$ commerce represents greater sophistication in eliminating temporal and spatial constraints to the delivery of services (Nysveen et al. 2005a).

To gain an understanding of technology-mediated services, prior research has often embraced the technology acceptance model (TAM) as frame of reference to explain consumer technology adoption (Davis 1989). However, whereas some researchers favor TAM because it is a parsimonious model (Plouffe et al. 2001; Venkatesh and Davis 2000), others argue this parsimony represents a major drawback. Furthermore, TAM has been criticized for its limited application beyond the 
workplace, as the model does not fully reflect the variety of different contexts. In addition, empirical tests of the model have rendered mixed and inconclusive results, leading to questions about its validity (Meuter et al. 2005). For example, several studies report that a positive attitude toward a new technology is not an invariably significant predictor of consumers' intentions to use that technology (e.g., Jackson et al. 1997; Taylor and Todd 1995). Consistent with contemporary theorizing on consumer attitudes, which proposes a shift in focus from parsimony to specificity (Bagozzi 1992), value, rather than a broad attitudinal construct, may be a driver of consumer behavioral intentions (Chang and Wildt 1994). Across a variety of service contexts, Cronin et al. (2000) and Brady et al. (2005) confirm that service value consistently mediates the impact of service quality (i.e., benefits) on behavioral intentions.

Whereas value generically has been conceptualized as a cost/benefit tradeoff, service value consistently is modeled as the difference between service quality attributes and sacrifice (Brady et al. 2005; Sweeney et al. 1999). In this sense, sacrifice represents a broad construct that comprises monetary and nonmonetary costs, such as effort and risk perceptions. However, research in retail service settings provides mixed results with regard to service value as a compensatory trade-off. Several studies report insignificant findings on the sacrifice-value relationship (e.g., Cronin et al. 2000), whereas Brady et al. (2005) find that sacrifice is a strong predictor of value across multinational and multiservice settings. One explanation for these divergent findings may be that the concept of value is relativistic or context dependent (e.g., Bolton and Drew 1991), which would indicate that in value-centric models, it is conceptually necessary to identify domain-specific predictor-criterion relationships. However, before we specify value antecedents, we must conceptually delineate the nature of transactional value.

Value literature often distinguishes between hedonic and utilitarian value (Mathwick et al. 2001) in relation to both offline and online retail services. Similarly, m-commerce research notes that, in contrast to mobile communication and entertainment services, mobile transactions are driven particularly by utilitarian value (Nysveen et al. 2005a). Fiore et al. (2005) also suggest that though experiential value can create positive feelings toward the service provider, instrumental or utilitarian value drives usage intentions, because it relates directly to the consumer's goal of completing the mobile transaction. Transaction-focused mobile services thus can be regarded as goal-directed services, such that consumers want to accomplish a specific goal or task and hence are motivated by utilitarian benefits because of goal fulfillment and/or rewards (Nysveen et al. 2005a). In turn, value creation depends on a successful outcome rather than the experience of the process for its own sake (Mathwick et al. 2001). 
To identify the antecedents of mobile value creation, we build on the PCI framework (Rogers 1995), which offers the opportunity to specify a finite number of characteristics (Suoranta et al. 2005), namely, relative advantage, compatibility, complexity, trialability, and observability. However, systematic research suggests that only relative advantage, compatibility, and complexity relate consistently to innovation adoption (Agarwal and Prasad 1998b; Tornatzky and Klein 1982). Moreover, the PCI framework can be used to explain consumers' value perceptions (Plouffe et al. 2001). To specify the nature of our mobile value predictors further, as well as the nature of their relationships with the criterion variable, we incorporate findings from recent research in the m-commerce domain (e.g., Kleijnen et al. 2004). First, we define two benefits that represent the relative advantage of mobile transaction services: time convenience and user control. Second, with regard to compatibility, instead of a general fit with the consumer's values, we focus on the fit between the mobile channel and the consumer's service needs. Our choice of these benefits is corroborated by Hourahine and Howard (2004), who reveal that convenience, increased control, and need fulfillment are the main advantages reported by mobile consumers.

In forming value perceptions, consumers balance costs against benefits. Complexity refers to the extent to which a service is perceived as relatively difficult to understand and use (Rogers 1995). In relation to mobile services, the cognitive effort associated with overcoming the complexity of the service may be perceived as a cost factor (Hourahine and Howard 2004). Following recent work on technologymediated service delivery (Meuter et al. 2005), we also include perceived risk as an antecedent of mobile service value because of the intangible nature of services. Using this set of predictor variables, we develop hypotheses that reflect the core model of mobile value creation (see Figure 3.1). 


\section{Figure 3.1 Conceptual model mobile value creation}

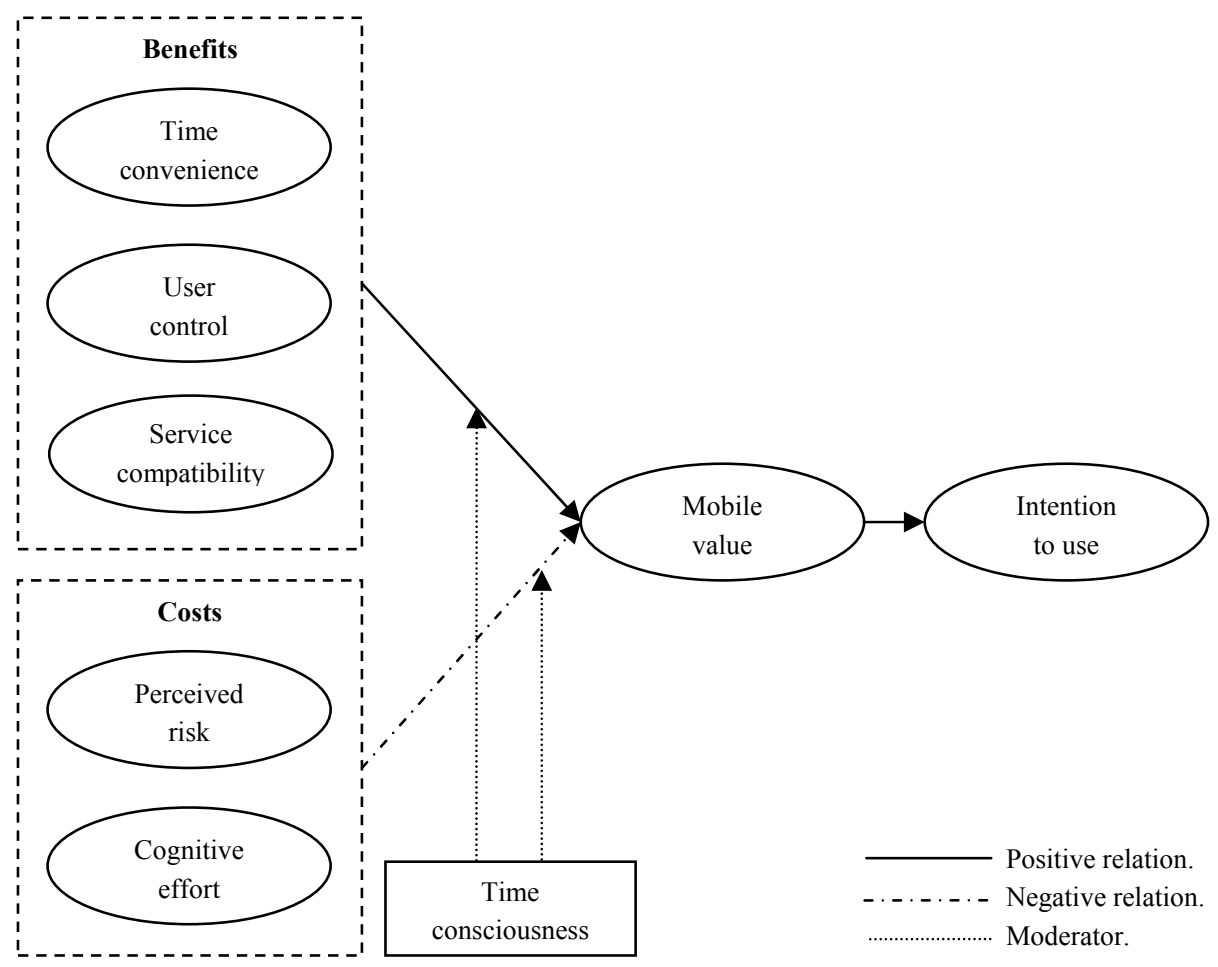

\subsection{Hypothesis development}

Time convenience

Consumers derive utilitarian value from efficient and timely service delivery in general (Childers et al. 2001). This argument holds specifically for mobile devices, which enable consumers to collect information and conduct transactions at any time and place (Balasubramanian et al. 2002). Newell and Newell-Lemon (2001) argue that in a time-sensitive marketplace, companies compete for time, which represents the consumer's most precious and least replaceable asset, and that mobile service value is derived from time savings. Shankar et al. (2003) observe that a central premise of mobile value creation is that mobility enables end-users to fulfill their consumption goals more economically than do other channels. Particularly in retailing, perceptions of the benefit of time convenience facilitate the attainment of services, which is especially relevant for time-critical services, such as last-minute reservations, limited-time travel offers, order status tracking, and stock quote requests (Hourahine and Howard 2004). Leveraging the ubiquity of the mobile 
channel by exploiting its time and efficiency utilities therefore will contribute to consumer value perceptions. As we hypothesize:

H1 Greater perceived time convenience is associated with greater perceived value of mobile channel usage.

\section{User control}

Hoffman and Novak (1996) identify user control as a key feature of interactive technologies. It also frequently is mentioned as a benefit of mobile transaction services (Hourahine and Howard 2004). We define user control as the extent to which consumers can determine the timing, content, and sequence of a transaction. Early research in environmental psychology (Proshansky et al. 1974) shows that people's perceptions of control over situations increase the likelihood of their positive feeling toward the experience. Furthermore, user control leads consumers to believe they can influence their goal attainment process and thereby increase their confidence about the outcome (Bateson and Hui 1987). Extrapolating to the domain of mobile services, which provide consumers with real-time, on-demand access to services, we propose that this benefit will enhance their perceived value, which leads to the following hypothesis:

H2 Greater perceived user control is associated with greater perceived value of mobile channel usage.

Service compatibility

Within the PCI framework, compatibility is defined as the degree to which consumers perceive innovations as consistent with their needs, values, past experiences, and routines (Rogers 1995). This conceptualization of compatibility also has been used in relation to mobile technology adoption (e.g., Kleijnen et al. 2004), but we propose that explaining mobile value creation requires a more focused definition. According to Laforet and Li (2005), consumers use mobile channels primarily because of the opportunity they offer to fulfill specific service needs. Therefore, we examine the compatibility of mobile channels with particular transactional services needs, that is, service compatibility. Research on mobile transaction services reveals that as many as two-thirds of the financial service transaction needs of respondents-such as the ability to access the services "when sitting in a public place" or "walking along"remain unfulfilled (Hourahine and Howard 2004) because traditional channels do not offer the ubiquity provided by a mobile channel. Because mobile channels enable consumers to fulfill these service needs, we predict that service compatibility will enhance perceived value. Consequently, we hypothesize: 
H3 Greater perceived service compatibility is associated with greater perceived value of mobile channel usage.

\section{Perceived risk}

Previous research suggests that perceived risk may be considered a cost weighed against benefits in value perceptions (Sweeney et al. 1999). In addition, consumers feel particularly vulnerable to risks in the mobile environment, because the allocation of responsibility for a failure or loss (i.e., who is to blame) may not always be clear in this technology-mediated environment (Bahli and Benslimane 2004). Newell and Newell-Lemon (2001) note that the diffusion of mobile transaction services depends primarily on consumers' risk perceptions. Consumers are very sensitive with regard to services that involve monetary transactions, in which case they worry about both money and information loss (Hourahine and Howard 2004). Hence, perceived risk should have a negative effect on value perceptions.

H4 Greater perceived risk is associated with lower perceived value of mobile channel usage.

\section{Cognitive effort}

As a second cost factor, cognitive effort is derived from the complexity innovation characteristic. Whereas complexity often has been conceptualized as an innate aspect of technology or mobile devices (Lee et al. 2003), it is the cognitive effort involved in understanding the mobile service process that may be perceived as a barrier (Kleijnen et al. 2004). For example, consumers using mobile financial services have a hard time understanding what specific actions they must perform to complete their transactions (Suoranta et al. 2005). Drawing on information search literature, Lynch and Ariely (2000) find that when information processing is less effortful, consumers develop a more positive attitude and are willing to buy more. Therefore, cognitive effort represents an information search cost. In the context of mobile services, information search costs also act as a value barrier (Suoranta et al. 2005).

H5 Greater perceived cognitive effort is associated with lower perceived value of mobile channel usage.

\section{Intention to use}

From a marketer's perspective, the importance of perceived value is underscored by its impact on company-relevant performance parameters. In traditional service literature (e.g., Bolton and Drew 1991; Chang and Wildt 1994) and for technologymediated service delivery (Parasuraman and Grewal 2000), perceived value consti- 
tutes one of the most important determinants of behavioral intentions. However, in the domain of m-commerce, little empirical evidence of this relationship exists. Therefore, we extend the present literature on value creation by investigating the following hypothesis:

H6 Greater perceived value of the mobile channel is associated with higher intentions to use the mobile channel.

\section{Time consciousness}

Speed and time efficiency often are positioned as the main benefits that consumers can achieve through the use of technology in retailing, which has led Roulac (2001, p. 128) to conclude that "profound to the future of retailing are issues that surround time consciousness." Across many scientific disciplines, researchers have examined how people perceive, experience, and value their time by assessing their time perceptions according to valued outcomes and behavior. Awareness of time thus has been associated with economic actors' consumption tendencies as they pertain to scarce resources or impulsivity and instant gratification (Becker and Mulligan 1997). However, the experience of time may be related to an inherent personality characteristic; George and Jones (2000, p. 659) conceptualize it as "an intrinsic property of consciousness," and Kaufman et al. (1991) propose that people differ in terms of their temporal profiles, which depend on the extent to which they are generally aware of passing time, their need to set and meet deadlines, their tendency to plan time, and the extent to which they engage in several activities simultaneously. Individual temporal tendencies reflect how people innately track and account for time and vary in their sensitivity toward time-sensitive issues (Francis-Smythe and Robertson 1999), such that higher time consciousness has been associated with adherence to deadlines and schedules and an awareness of the rate at which tasks must be performed. Considering the inherent time-criticality of mobile transaction services, time consciousness therefore is an important psychographic characteristic that should be considered when studying mobile value creation from a consumer perspective. For the context of our study, we define time consciousness as the extent to which consumers are aware of the passing of time and how they spend it. We suggest that this consumer characteristic moderates the impact of the benefits and costs of mobile service on the perceptions of mobile service value.

First, we argue that time-conscious consumers are more prone to recognize the scarcity of time as a resource. As they engage in goal-directed behavior, these consumers will seek shopping options that offer the opportunity to leverage their time. Time convenience therefore appeals particularly to the temporal concerns of time-conscious consumers (e.g., Conte et al. 1998). In turn, we posit that the 
influence of time convenience on mobile service value will be stronger for consumers with heightened time consciousness.

Second, as a result of the escalating demands on consumers' time and decreasing discretionary time available, consumers are more concerned with time planning (Matthews 1982). Because time planning implies control, consumers who are conscious of the way they spend their time seek to self-regulate and exert an influence over the amount of time they spend acquiring goods and services in relation to leisure activities (Roulac 2001). Therefore, the creation of mobile service value depends more strongly on perceptions of user control for time-conscious consumers.

Third, time-conscious consumers are more receptive to "smarter" channels of service delivery and develop service needs that focus on immediate gratification (Kaufman et al. 1991). In other words, immediacy is more critical to maximize the value perceptions of time-conscious consumers than it is for consumers who are less aware of temporal constraints. Service compatibility can increase productivity during what otherwise would have been "down time" (Mort and Drennan 2005) and offer immediacy; the resultant time synergies it provides are highly appreciated by time-conscious consumers. Consequently, we expect the relationship between service compatibility and mobile value to be strengthened by time consciousness.

Fourth, according to literature on the relationship between risk perceptions and information search behavior, perceptions of risk and resulting feelings of anxiety prompt consumers to engage in problem-solving strategies aimed at reducing perceived risk (Dowling and Staelin 1994). Because time consciousness is indicative of a cognitive style in which people explicitly reflect on ways to manage their time actively (Matthews 1982), we argue that such consumers are better able to contemplate what they can actively do to relieve their risk. Moreover, due to their explicit exploration of the time-related benefits of mobile transactional services, time-conscious consumers will be more prone to take into consideration how these benefits might outweigh risk perceptions. Such persons are more likely to overcome their risk perceptions as they recognize the opportunities (i.e., benefits) offered to them. In contrast, consumers with a weaker sense of time consciousness are likely less aware of either time-related benefits or the actions they can undertake to reduce their risk perceptions. Therefore, the relationship between perceived risk and mobile value is attenuated by time consciousness.

Fifth, in processing information about time-related issues, time-conscious consumers are more likely to economize their cognitive effort associated with the use of mobile services. An increased awareness of time-related benefits, which are regarded as sufficiently relevant and valuable, may explain why time-conscious consumers are less bothered by the required cognitive effort and more motivated to acquire information to overcome this barrier. Therefore, time-conscious consumers 
will select explicit ways to master the scripts associated with the delivery of this new type of services. Such an investment is considered advantageous because it increases the chances of accurate service delivery and thus successful goal fulfillment (van der Heijden 2005). In contrast, consumers with lower levels of time consciousness are more likely to employ patterns of behavior that have been repeatedly and routinely associated with traditional service delivery formats than they are to consider new ways of service delivery. These consumers maintain a smaller inventory of timemanagement strategies to deal with the cognition requirements of changing circumstances. Consequently, we suggest that for consumers with a high degree of time consciousness, the relationship between cognitive effort and mobile value is attenuated. Overall, we hypothesize the following moderating relationships:

H7 The relationship between the five predictor variables and perceived value is moderated by time consciousness, such that (a) time convenience has a stronger positive relationship, (b) user control has a stronger positive relationship, (c) service compatibility has a stronger positive relationship, (d) risk has a weaker negative relationship, and (e) cognitive effort has a weaker negative relationship with perceived value for consumers with a higher time consciousness versus consumers with a lower time consciousness.

\subsection{Empirical research}

\section{Setting}

We tested our value creation model in a mobile transaction services setting, specifically, mobile brokerage. Mobile brokerage services enable consumers to retrieve time-critical financial information and act on this information immediately. Due to the success of "wired" banking and brokerage, financial service providers are eagerly advancing into the wireless dimension (Mort and Drennan 2005). Moreover, transaction-based services, particularly in the form of mobile banking and brokerage applications, may create an essential stepping stone to a broader m-commerce environment. Contrary to previous predictions however, recent estimations of market growth are less positive because consumer adoption of these services has been rather slow (ATKearney 2005).

\section{Measurement development}

We obtained the data for this study through a survey. The items for each construct are based on an extensive literature study and measured using multiple-item, Likerttype scales. We devoted special attention to the construct of time consciousness, and because its measures are quite diverse and not well validated in the literature, we 
developed a (multiple-item) measurement instrument using the scale development procedures for latent constructs (Churchill 1979; Netemeyer et al. 2003).

Initially, we created a pool of 15 items on the basis of existing literature (e.g., Francis-Smythe and Robertson 1999; Morello 2000) and qualitative interviews with 20 respondents, equally divided in terms of gender and age. Our quantitative pretest, which we discuss next, resulted in a final measure with 9 items for the construct of time consciousness, developed on the basis of exploratory factor analysis (principal axis factoring), item-to-total correlations, and coefficient $\alpha$. For the other constructs, we reformulated items to fit the current context and subjected them to a qualitative pretest of 20 respondents, equally divided in terms of gender and age, that we conducted through personal, in-home interviews. We made minor wording revisions to the questionnaire on the basis of this pretest.

After this revision, we conducted a quantitative pretest, for which we employed the following respondent selection criteria to ensure the quality of the data: possession of a mobile phone, acquaintance with mobile technologies such as Wireless Application Protocol (WAP), and affinity with brokerage. These criteria provided a usable sample of 232 respondents, 55\% of whom were men and $45 \%$ women and who had an average age of 22 years. We performed exploratory factor analyses (using principal axis factoring) with oblique rotations to investigate the unidimensionality of the measures and maintained only those items that minimally loaded .60 on the proper factor and maximally cross-loaded .30 on the other factors to enhance the distinctiveness of the intended constructs. For all measures, the coefficient $\alpha$ s exceeded .70. We report the final items for each construct in Appendix A. Because overall risk perceptions often are based on various risk dimensions, we conceptualize perceived risk as a second-order construct, including three risk dimensions in relation to mobile service transactions (Hourahine and Howard 2004; Newell and Newell-Lemon 2001): financial, security, and performance risk. Moreover, we include two relevant covariates in addition to the variables defined in our conceptual model: perceived value of the electronic channel and perceived value of the retail channel. Finally, we assessed the distributional properties of the measures. We find that the indicators in our study show predominantly negative skewness $\left(\sqrt{ } b_{l}\right)$ and negative kurtosis $\left(\left[b_{2}-3\right]\right)$. However, the deviations in terms of univariate normality are only minor; only 8 indicators exhibit a $\sqrt{ } b_{1}$ larger than $|1|$ but none exceed $|2|$, and only 14 indicators exhibit $\left[b_{2}-3\right]$ greater than $|1|$, of which 3 are greater than $|2|$ but none exceed $|3|$. In testing for multivariate normality, we find a significant deviation from normality on the basis of Small's omnibus test for multivariate normality (DeCarlo 1997). 


\section{Sample}

We collected the final sample in Maastricht, a mid-sized city of approximately 120.000 inhabitants the Netherlands, through street-intercept personal interviews conducted at various times and days over a two-week period in January 2004. For this sample, we employed the same criteria, that is, possession of mobile phone, acquaintance with mobile technologies, and affinity with brokerage. Moreover, to ensure that all respondents had the same understanding of mobile transaction services, we provided a short introduction to the questionnaire that explained what mobile transaction services were. Specifically, it introduced mobile banking and brokerage and gave several examples of the possibilities involved with these services. Of all the potential subjects approached, 70\% participated in the research. Of the $30 \%$ of respondents who refused, $7 \%$ did so because they did not own a mobile phone; most of these were older consumers. After screening the questionnaires for incompleteness and inconsistencies, we obtained a usable sample of 375 respondents comprising $43 \%$ women and $57 \%$ men. The ages of the respondents were as follows: $30 \%$ younger than $25,24 \% 25-40,26 \% 41-55$, and $20 \%$ older than 55 years of age.

\subsection{Analysis and results}

\section{Partial Least Squares (PLS) path modeling}

We use the partial least squares (PLS-Graph 3.0, Chin 2001) approach to path modeling to estimate the measurement and structural parameters in our structural equation model (Chin 1998). Unlike the covariance-based approach to structural equation modeling implemented by, for example, LISREL, PLS path modeling is component based and therefore does not require multivariate normal data, places minimum requirements on measurement levels, and is more suitable for small samples (Chin 1998; Falk and Miller 1992; Hulland 1999; Tenenhaus et al. 2005). In addition, PLS path modeling is more appropriate for models that contain complex relationships and/or a large number of manifest variables $(>25)$, as our conceptual model does (Chin 1998; see Figure 3.1).

\section{Measurement validation}

In our study, we specify reflective indicators (Mode A; Chin 1998) for all our constructs (see Appendix A). To assess the psychometric properties of the measurement instruments, we specify a null model with no structural relationships. We evaluate reliability by means of composite scale reliability (CR; Chin 1998; Fornell and Larcker 1981) and average variance extracted (AVE; Chin 1998; Fornell and Larcker 1981). For all measures, the CR is well above the cut-off value of .70, and 
the AVE exceeds the .50 cut-off value (Fornell and Larcker 1981). In addition, we evaluate convergent validity by inspecting the standardized loadings of the measures on their respective constructs (Chin 1998; Howell and Aviolo 1993) and find that all measures exhibit standardized loadings that exceed .70 (Hulland 1999). Furthermore, we measure risk as a second-order construct that contains three dimensions (security, financial, and performance), and PLS path modeling allows for the conceptualization of higher-order factors through its repeated use of manifest variables (Tenenhaus et al., 2005). We also report the loadings of the first-order constructs on the second-order risk construct in Table 3.1. The CR and AVE calculated on the basis of these loadings still fulfill the necessary requirements with regard to the cut-off values.

We next assess the discriminant validity of the measures. A construct should share more variance with its measures than it shares with other constructs in the model (Chin 1998; Howell and Aviolo 1993), so the square root of the AVE should exceed the intercorrelations of the construct with the other constructs in the model (Fornell and Larcker 1981). In our study, none of the intercorrelations of the constructs exceed the square root of the AVE of the constructs (Table 3.1). Moreover, we inspect the Theta matrix $(\Theta)$ and confirm that no item cross-loads higher on another construct than it does on its associated construct (Chin 1998) and that the correlations of the residual terms across blocks do not exceed |.2| (Falk and Miller 1992). Consequently, we conclude that all constructs exhibit satisfactory discriminant validity.

Table 3.1 Assessing discriminant validity

\begin{tabular}{lcccccccccc}
\hline & $\mathbf{1 .}$ & $\mathbf{2 .}$ & $\mathbf{3 .}$ & $\mathbf{4 .}$ & $\mathbf{5 .}$ & $\mathbf{6 .}$ & $\mathbf{7 .}$ & $\mathbf{8 .}$ & $\mathbf{9 .}$ & $\mathbf{1 0 .}$ \\
\hline 1. Time convenience (TC) & $\mathbf{. 9 1}$ & & & & & & & & & \\
2. User control (UC) & .64 & $\mathbf{. 8 8}$ & & & & & & & & \\
3. Service compatibility (SC) & .01 & -.05 & $\mathbf{. 8 5}$ & & & & & & & \\
4. Risk (RISK) & -.43 & -.37 & .02 & $\mathbf{. 9 3}$ & & & & & & \\
5. Cognitive effort (CE) & -.24 & -.19 & .02 & .32 & $\mathbf{. 8 9}$ & & & & & \\
6. M-value (MVAL) & .57 & .44 & -.03 & -.44 & -.41 & $\mathbf{. 8 3}$ & & & & \\
7. E-value (EVAL) & .22 & .26 & -.12 & -.26 & -.32 & .38 & $\mathbf{. 9 0}$ & & & \\
8. R-value (RVAL) & -.14 & -.12 & .10 & .28 & .25 & -.11 & -.12 & $\mathbf{. 8 5}$ & & \\
9. Intention to use (INT) & .54 & .41 & -.10 & -.46 & -.31 & .60 & .17 & -.22 & $\mathbf{. 8 8}$ & \\
10. Time consciousness (TiC) & .07 & .06 & -.02 & -.06 & -.10 & .01 & -.01 & -.10 & .03 & $\mathbf{. 8 3}$ \\
\hline
\end{tabular}

Notes: The square root of AVE is on the diagonal. E-value = electronic value and R-value = retail value.

\section{Hypotheses testing}

As suggested by Chin et al. (2003), we use PLS path modeling to estimate both the main and the interaction effects in our model. To test the five moderating hypothe- 
ses, we resort to the two-step score construction procedure (Chin et al. 2003; supplement $\mathrm{A})^{5}$. The PLS approach allows for explicit estimation of latent variable (LV) scores; after saving the standardized LV scores (cf. Tenenhaus et al. 2005), we calculate the interaction terms and include them in the model. This method enables us to test for a relatively large number of interaction effects while simultaneously correcting for measurement error (Chin et al. 2003).

To test the effects and statistical significance of the parameters in the structural model, we use a (nonparametric) bootstrapping procedure with 500 resamples (Chin 1998; Chin 2001). As suggested by Chin et al. (2003), we employ a hierarchical approach to test our hypotheses, in which we first estimate a model with the main effects (and covariates) only and then add the interaction effects. We obtain the estimates that we report next from the final model that includes the interaction effects. The results illustrate that our hypotheses are largely confirmed. At a significance level $(\alpha)$ of .05, our results reveal a positive and significant effect for time convenience $(\beta=.35)$ and user control $(\beta=.10)$ on the value of the mobile channel, whereas risk $(\beta=-.15)$ and cognitive effort $(\beta=-.23)$ have significant negative effects. Service compatibility has no significant impact on the value of the mobile channel. On the basis of these results, we conclude that the hypotheses pertaining to the benefits and sacrifices that create value for the mobile channel are supported, with the exception of H3. Furthermore, the value of the mobile channel significantly and positively affects intention $(\beta=.61)$, in support of H6. Finally, the covariates, the value of the electronic $(\beta=-.08)$ and retail $(\beta=-.16)$ channels, exhibit a negative and significant effect on intention.

With regard to the moderating hypotheses, we find that except for $\mathrm{H} 7 \mathrm{c}$, all interaction effects are significant at $\alpha=.05 . \mathrm{H} 7 \mathrm{a}(\beta=.11$, strengthened), $\mathrm{H} 7 \mathrm{~d}(\beta=.10$, attenuated), and $\mathrm{H} 7 \mathrm{e}(\beta=.08$, attenuated) are supported by the data; for $\mathrm{H} 7 \mathrm{~b}(\beta=$ -.06 , attenuated), we find a significant effect in the opposite direction of the hypothesized effect. The direct effect of the time consciousness moderating variable is not significant at $\alpha=.05$. The $R^{2}$ for the value of the mobile channel in the final model (including both main and interaction effects) is .46; that in the main effects only model yields .43. Using an incremental $F$ test (Chin et al. 2003; Pedhazur 1997), we find that the $\Delta R^{2}$ of .03 is statistically significant at $\alpha=.05\left(F_{(5,364)}=4.13\right.$ $[p<.001])$. We calculate $f^{2}$ to assess the effect size of the interaction terms in the final model (Chin et al. 2003; Cohen 1988), and the results suggest a small to

The product indicator approach suggested by Chin et al. (2003) would have resulted in the addition of 279 product indicators for the latent variables that represent the moderators, because each interaction effect consists of the product of the indicators that originate from the predictor and moderating variables. Although Chin et al. (2003) show that PLS path modeling is hardly affected by the inclusion of a large number of product indicators, their results are restricted to one moderator and the addition of 144 product indicators for the moderating latent variable. 
moderate effect size of $f^{2}=.05$. The $R^{2}$ for intention in the final model (including main effects and interaction effects) is .39. Although PLS path modeling includes no proper single goodness-of-fit measure, such as the $\chi^{2}$ statistic and its derived measures for covariance-based structural equation modeling, the $R^{2}$ values of the endogenous constructs can be used to assess model fit (Chin 1998; Tenenhaus et al. 2005). In accordance with the categorization of $R^{2}$ effect sizes by Cohen (1988; small: .02; medium: .13; large: .26), we conclude that these effect sizes are large (value of the mobile channel: $R^{2}=.46$; intention: $R^{2}=.39$ ). Finally, Tenenhaus et al. (2005) recently developed a global fit measure (GoF) for PLS; in our model, the GoF is .54 (.52 for the main effects model), which indicates a good fit (see Table 3.2).

Table 3.2 Hypothesis testing in the structural model

\begin{tabular}{|c|c|c|c|c|}
\hline Hypothesis & Relationship & $\begin{array}{l}\text { Hypothesized } \\
\text { direction }\end{array}$ & $\begin{array}{l}\text { Standardized } \\
\text { Coefficient }(\beta)\end{array}$ & Results \\
\hline$H 1$ & $\mathrm{TC} \rightarrow \mathrm{MVAL}$ & positive & $.35 * *$ & Supported \\
\hline$H 2$ & $\mathrm{UC} \rightarrow \mathrm{MVAL}$ & positive & $.10 * *$ & Supported \\
\hline$H 3$ & $\mathrm{SC} \rightarrow \mathrm{MVAL}$ & positive & n.s. & Not significant \\
\hline$H 4$ & RISK $\rightarrow$ MVAL & negative & $-.15^{* *}$ & Supported \\
\hline H5 & $\mathrm{CE} \rightarrow \mathrm{MVAL}$ & negative & $-.23 * *$ & Supported \\
\hline H6 & MVAL $\rightarrow$ INT & positive & $.61 * *$ & Supported \\
\hline Covariate & $\mathrm{RVAL} \rightarrow \mathrm{INT}$ & negative & $--.16^{* *}$ & Supported \\
\hline Covariate & EVAL $\rightarrow$ INT & negative & $-.08 *$ & Supported \\
\hline$H 7 a$ & $\mathrm{TC}^{*} \mathrm{TiC} \rightarrow \mathrm{MVAL}$ & positive (strengthened) & $.11 * *$ & Supported \\
\hline$H 7 b$ & $\mathrm{UC} * \mathrm{TiC} \rightarrow \mathrm{MVAL}$ & positive (strengthened) & $-.06^{*}$ & Rejected \\
\hline$H 7 c$ & $\mathrm{SC}^{*} \mathrm{TiC} \rightarrow \mathrm{MVAL}$ & positive (strengthened) & n.s. & Not significant \\
\hline$H 7 d$ & RISK $* \mathrm{TiC} \rightarrow \mathrm{MVAL}$ & positive (attenuated) & $.10 * *$ & Supported \\
\hline$H 7 e$ & $\mathrm{CE}^{*} \mathrm{TiC} \rightarrow \mathrm{MVAL}$ & positive (attenuated) & $.08 *$ & Supported \\
\hline $\begin{array}{l}\text { Fit } \\
\text { Measures }\end{array}$ & $\begin{array}{l}\text { Endogenous } \\
\text { Construct }\end{array}$ & Main Effect Model & Final Model & \\
\hline \multirow[t]{2}{*}{$R^{2}$} & MVAL & .43 & .46 & \\
\hline & INT & .39 & .39 & \\
\hline$G o F^{a}$ & & .52 & .54 & \\
\hline
\end{tabular}

a By taking the square root of the product of the variance extracted of all constructs with multiple indicators and the average $R^{2}$ value of the endogenous constructs, we can calculate a fit measure ranging between 0 and 1 . According to the categorization by Cohen (1988) and using .50 as a cut-off value for communality (Fornell and Larcker 1981), the GoF criteria for small, medium, and large effect sizes are $.10, .25$, and .36 .

$* \quad p<.05$.

$* * p<.01$. 


\subsection{Discussion}

This study contributes to contemporary research on services retailing in two ways. First, we develop a model to explain utilitarian value creation in mobile services delivery and examine how this value accounts for consumer usage intentions. The analyses show strong support for our conceptual model, which identifies specific benefits and costs. With regard to the core model, our results also illustrate that time convenience is the most important benefit, in line with previous research on innovation theory that recognizes relative advantage as a dominant factor (e.g., Tornatzky and Klein 1982). Our study extends and adds nuance to these findings by demonstrating that for mobile service delivery, consumers are most concerned with the time-related gains they can obtain. This finding also confirms prior assertions about the importance of time convenience in relation to mobile transaction services (Mort and Drennan 2005). Another relative advantage, user control over the service delivery process, affects utilitarian value perceptions. Given the time criticality of mobile service delivery, the positive effect of user control may be due to what Ariely (2000, p. 234) calls "dynamic heterogeneity," or the tendency for people's information needs to change during the information exchange process. Arguably, the context of mobile brokerage services could be characterized as a dynamic information exchange process in which the information requirements of users must be updated dynamically. In contrast, service compatibility does not constitute a significant antecedent of value. Berman and Thelen (2004) argue that channel/service fit decisions are primarily the responsibility of service providers and that consumers frequently regard it as a hygiene factor, which may explain these findings. Although risk has received considerable attention as a barrier to mobile services adoption (e.g., Bahli and Benslimane 2004), the respondents in this study seem relatively more concerned with the cognitive effort the service process requires. In relation to previous research in the domain of innovation theory, this result is surprising, because risk often is considered the strongest impediment to new product/service adoption. However, a recent domain-specific market study confirms that consumer risk perceptions are indeed decreasing (ATKearney 2005), possibly because of the rapid diffusion of mobile technology in today's society, which has made more and more consumers familiar with the transactional possibilities of their handheld devices (Hourahine and Howard 2004). Our core model also illustrates that mobile value has a strong impact on consumers' usage intentions, in support of prior assertions that had been left empirically unverified (e.g., Shankar et al. 2003).

Furthermore, the covariates, which reflect the value of the alternative channels, have a significant negative impact on mobile channel usage intentions. Therefore, consumers who assign higher value perceptions to alternative service delivery 
channels are less likely to use the mobile channel. In addition, traditional, face-toface service delivery frequently is associated with an opportunity for social interaction (e.g., Dabholkar and Bagozzi 2002), so consumers with a high need for personal interaction may not be inclined to use mobile services. Likewise, we find a negative effect of the perceived e-channel value on intentions to use the mobile channel. However, this effect is not as strong as that for the retail format, which means that the value of Web-based service delivery is less a threat to consumer usage of the mobile channel. This suggestion falls in line with previous research that finds consumers who have already been using technology-mediated formats to shop are more likely to use technology innovations (Balabanis and Vassileiou 1999). In that sense, the use of a mobile service might be the result of an additive experience, and employing a new technology might be less cumbersome for Internet-savvy consumers.

Second, we include time consciousness as a moderating variable. Thus far, contemporary research on mobile service delivery has not moved beyond an examination of traditional demographics as explanatory consumer-related variables (e.g., Mort and Drennan 2005), but our results reveal that time consciousness significantly helps explain value perceptions. Except for service compatibility (which did not exhibit a main effect), all interactions with the antecedents are significant. Whereas consumers with a higher time consciousness illustrate a stronger positive relationship between time convenience and value than those with a lower level, the effect of user control runs counter to our expectations. For consumers with higher time consciousness, the positive relationship between user control and value is weaker than it is for consumers with a lower level. This surprising finding might relate to the implication that user control means control is taken (partly) away from the company and given to the consumer, which may cause inefficiencies for that consumer. For example, user control might cause time inefficiencies because the consumer experiences a lack of role clarity with regard to his or her responsibilities as a coproducer of the service. Alternatively, consumers may feel they do not possess sufficient knowledge to undertake the role expected of them. Especially with such novel services, they may feel too inexperienced or lack the self-confidence to play such important roles in the service delivery process. These factors would contribute to a less efficient delivery of the service, which likely concerns more time-conscious consumers.

Finally, as we predicted, the relationships between costs (perceived risk and cognitive effort) and mobile value are attenuated. Apparently, a stronger awareness of how time can be used most efficiently weakens the negative impact of cost perceptions. 


\subsection{Limitations and suggestions for further research}

Any study's contribution must be evaluated in light of its limitations, and this research is no exception. First, the cross-sectional nature of our research might create some confounds. Mobile transaction is still in its infancy, and as consumer awareness and experience with the mobile service field increases, our results should be reassessed to ensure the robustness of our model.

Second, we may have encountered common method bias. An inherent problem for this particular design, which can be solved by measuring outcome and predictor variables independently. Specifically, in place of self-perceived measures of intention, actual behavior data would improve the quality of our data.

Third, in our conceptual development, we employ value rather than attitude as an explanatory variable of intention. Although our results suggest a strong impact of value on consumer intentions, we do not make empirical comparisons with attitudinal models. Further attention therefore should be devoted to the comparison of rival models in explaining consumer intentions.

Fourth, our study is embedded in the context of mobile transaction services, which can be classified as time critical, less focused on interactions, and more functional than other categories such as mobile entertainment (Kleijnen et al. 2004). Mort and Drennan (2005) conclude that consumers perceive mobile services as heterogeneous and evaluate their value on the basis of different usage benefits. Therefore, a natural extension of our research would explore the role of hedonic value (e.g., killing time, relieving stress), which may be important for services that are oriented more toward leisure activities (Nysveen et al. 2005a). Further studies should investigate which antecedents are relevant for different service categories to assess the value creation for those services more fully.

Fifth, utilitarian value perceptions should be explored further. Recently, Noble et al. (2005) suggested that utilitarian value consists of multiple facets that reflect not only the delivery of the core service but also the attainment of information and price comparison functions. In relation to the latter, research could explore the impact of in-store usage of mobile services for price comparison purposes on value perceptions. In other words, a more in-depth understanding of the different aspects of utilitarian value may be contingent on the usage situation, which makes it a fruitful research path to pursue. Also, though our model helps explain the usage intentions of consumers, a fuller understanding requires the investigation of use diffusion (Shih and Venkatesh 2004). Because of the diversity of mobile channel applications, investigating both the variety and the rate of use, as suggested by Shih and Venkatesh (2004), may create a richer understanding of consumer adoptions of mobile channels. 
Sixth and finally, additional research should be devoted to exploring the role of time consciousness. In this regard, it seems particularly relevant to include the role of culture, which typically influences time perceptions. People experience, feel, and evaluate time differently depending on their cultural background (Morello 2000), so future studies should examine behavioral styles, values, and beliefs related to time while taking cultural differences into consideration.

\subsection{Managerial implications}

Our results also offer several implications for managers. Particularly in transactional services, mobile channels can provide added value, because such transactions often are time critical, such that consumers demand the ability to react to real-time developments. We find that both time convenience and user control have strong impacts on consumer value perceptions, and our findings suggest several ways managers could emphasize these value propositions, such as offering account statements that contain balances and recent transactions, real-time credit and debit information, specific event messages that require client decisions, and so forth.

In addition to these specific service enhancements, companies should consider more general promotional initiatives, such as those that producers of mobile devices have launched to familiarize consumers with mobile service delivery. For example, Nokia has created the "Culture of Mobility" (www.culture.nokia.com), which presents a diverse range of mobility issues to create more consumer awareness of the impact of mobility. Discussions on "capturing the moment" and "mobile shopping opportunities" highlight the possibilities for consumers to exploit the mobile channel for transaction services.

In relation to costs, though risk is still important to consumers, managers should devote their attention to alleviating the effort required for consumers to use mobile services by providing simpler service designs (e.g., easier menu structures) and more information/instructions to consumers via selling points or Web sites that clarifies the consumer's role in the service delivery process. For example, NTTDoCoMo, the world's largest mobile service provider, provides effective illustrations of user options, as well as instructions, on its Web site (ww.nttdocomo.com). However, risk concerns should not be overlooked entirely. As Newell and Newell-Lemon (2001) point out, risk is a delicate matter in the highly personal mobile channel, and this higher level of intimacy calls for effective risk management. Companies are investing in mobile risk management by securing better mobile infrastructures and sophisticated data protection schemes. Retailers and other service providers should pay particular attention to risk and cognitive 
effort, because consumers seem more fixated on the costs of the mobile channel than its benefits.

Finally, research has suggested that retailers might become more competitive by improving their response and delivery time to consumers, which is particularly relevant for time-conscious consumers. These consumers are particularly focused on time convenience, so they must be kept informed about how the mobile channel can deliver time-related benefits. For example, companies could target consumers through mobile community memberships that introduce them to the latest developments and allow them to learn from similar consumers about how to optimize the use of their mobile channel (e.g., Windows Mobile; mopilot.com). Consumers with a low sense of time consciousness, in contrast, are concerned about the costs of the mobile services, which means they are likely to require a more persuasive type of promotion strategy to induce their positive evaluation of the mobile value. Seals of approval provided by trusted third parties (e.g., www.verisign.com) could help companies convince such consumers and decrease their risk perceptions. 



\section{Chapter 4}

\section{Image Congruence and the Adoption of Service Innovations 6}

In this chapter we investigate whether or not the fit between consumers' image and the image of an innovation, commonly referred to as "image congruence", has an impact on customers' attitudes towards innovative services as well as the intention to use these new services. Moreover, situational influences (i.e., private versus public, and friends versus colleagues) are examined. The results of the two experiments show that image congruence has a significant impact on consumer attitudes and the usage decision. Moreover, there is also an interaction between image congruence and the consumption situation. Contrary to our expectations, consumers with low image congruence are influenced more by their surroundings than consumers with high image congruence. It seems that as long as the fit between the consumer's self-image and the service image is high, signals from the consumer's environment are overruled.

6 This chapter is largely based on Kleijnen, Mirella H.P., Ko de Ruyter, and Tor W. Andreassen (2005), "Image Congruence and the Adoption of Service Innovations," Journal of Service Research, 7 (4), 343-59. 


\subsection{Introduction}

As a rule of thumb, innovative services typically do not make it beyond the early market of technology enthusiasts (e.g., Moore 2002). Ample research in the field of marketing has focused on what makes visionaries and pragmatists adopt an innovative service, i.e. cross the proverbial 'innovation chasm' (Moore 2002). While the importance of investigating technology characteristics is widely acknowledged in the literature (e.g., Davis et al. 1989), several authors point to the relevance of studying consumer-related factors as well (e.g., Meuter et al. 2000). Recent studies in both the technology acceptance literature (Venkatesh and Davis 2000) and innovation research (Plouffe et al. 2001) have emphasized the need to expand traditional adoption theory by including image as a relevant factor in the adoption process. While these previous studies focus solely on the image of the product or service innovation, Schlosser (2002) suggests that the use of mobile technology is dependent on the consumer's self-identity, as the use of such technology allows the consumer to express who (s)he is. This seems especially relevant for the study at hand, which examines a new service category called mobile commerce. Mobile commerce refers to services that are delivered via wireless technology, by means of mobile devices, such as a mobile phone, and can be consumed anywhere and at any time (Balasubramanian et al. 2002). The importance of self-image in the adoption of mobile services is also illustrated in practice. For example, when Nokia replaced the old 9110 Communicator with the Communicator 9210i, the advertising focused on the benefits to image and status that users would enjoy from association with the new model. Rather than communicating technology features, Nokia focused on communicating perceived benefits, such as the match between the services the Nokia communicator delivers and the consumer's lifestyle or image. Why this change in communication strategy? Research has found that consumers often prefer brands and stores with images that are consistent with their own self-image (e.g., Sirgy 1982; Sirgy 1985). In the literature this phenomenon is referred to as the image congruence hypothesis (e.g., Grubb and Grathwohl 1967). Since consumers may buy brands that can create and enhance self-image (i.e., how a consumer actually sees him/herself), we suggest that image congruence plays a crucial role in the consumer adoption process. The serious need for new knowledge in this area is reflected in the Marketing Science Institute's research priorities ${ }^{7}$, which define the interplay between users and image as a subtopic of significant interest.

In this paper, we examine image and innovation adoption in the context of consumer usage situations. Several studies in the field of consumer behavior

“2002-2004 Research Priorities. A guide to MSI research programs and procedures”, Marketing Science Institute. 
illustrate the impact of the consumer's surroundings on decision-making. For example, Graeff (1997) suggests that certain products or brands are consumed in a particular situation because the consumption of these items bestows upon the user a certain image. Therefore, we suggest that the consumer's usage situation has an effect on the decision of whether or not to adopt mobile services. Previous research regarding image has investigated private versus public brands/products (e.g., Schmitt and Shultz II 1995), where private relates to situations in which consumers are isolated and public to situations in which consumers are in proximity to others. This seems particularly relevant when studying the adoption of mobile services. Due to the ubiquity of mobile services (Balasubramanian et al. 2002), they can be consumed in a number of different consumption situations. The customer is in complete control of the decision as to when, what and particularly where services are consumed, implying that these services can be used in private as well as public situations.

The objectives of this paper, therefore, are 1) to test the image congruency theory in the adoption of an innovative service, and 2) to investigate the effects of consumption situations on attitude and intention to adopt an innovative service. The paper is organized as follows. First, we present an overview of the literature regarding image. Second, we discuss our first experiment which focuses on the effects of image congruence and the effects of private versus public situations. A second experiment is then conducted to confirm and extend the findings of the first experiment. Finally, the implications of the findings are discussed.

\subsection{Conceptual background}

As image is central to this study, and because it has been discussed and studied in the services marketing and in the adoption literature, the following section provides a brief summary of relevant literature.

\section{Image, decision-making, and adoption}

According to Olson (1972), an object's image can be an extrinsic information cue and may influence customer choice and adoption. In this respect, image becomes an issue of attitudes and beliefs impacting awareness and recognition (Aaker 1991), customer satisfaction and consumer behavior (Fornell 1992). As customers receive new information or have new experiences pertaining to an object, this information will act as an input to either maintain or update (be it positively or negatively) their perceptions and attitudes towards the object.

In adoption research, image has been implicitly included in the factor of relative advantage. For example, Rogers (1995) indicates that one aspect of relative 
advantage is most certainly image. However, Tornatzky and Klein (1982), contrary to previous studies, found support for separating the constructs of image and relative advantage. Similarly, Chau (1996) has recognized that the desire to gain social status might be one of the most important motivations for a consumer to adopt an innovation. Following this line of reasoning, we argue that image should be recognized as a construct in itself, distinctly different from traditional adoption drivers such as relative advantage.

We take this thought one step further by incorporating image congruence as a relevant adoption criterion. Martineau (1958) was one of the first to propose that a consumer exhibits a preference for a store which has a personality consistent with the consumer's image of him/herself. More specifically, the attitudes or purchase intentions towards a product or service seem to be highly dependent on the extent to which these products or services display similarities to the consumer's image of him/herself, also referred to as the self-image (Graeff 1996). Onkvisit and Shaw (1987) suggested that this self-image is significant and relevant to the study of consumer behavior, as many purchases made by consumers are directly influenced by the image individuals have of themselves. The fit between the self-image and the service image has been defined as the image congruence hypothesis (Grubb and Grathwohl 1967). Despite its intuitive logic numerous studies report inconclusive findings concerning this relationship (c.f. Hogg et al. 2000). Additionally, research on image congruence within a service context is virtually non-existent. In the context of innovative services associated with life-style products (i.e., mobile phones), the investigation of image congruence seems to be particularly relevant. Services by definition are intangible, which makes them difficult to evaluate. Signals relating to, for example, added value or trustworthiness become crucial, especially in the case of innovative mobile services, where information is limited in comparison to other services. Consequently, the current study aims at clarifying the impact of image congruence on consumer adoption by focusing on the creation of consumer attitudes towards mobile services as well as the intention to use these services.

Both attitudes and intentions have been recognized as central constructs in the adoption process. Ajzen and Fishbein (1980) indicate that attitude is one of the focal constructs to be included when studying intentional behavior. According to Graeff (1996), a consumer's self-concept can be used to influence attitudes and purchase decisions. Creating an image of a product or service that compares favorably with the image of the consumer will positively influence his/her attitude towards the product or service (e.g., Ericksen and Sirgy 1992). Other researchers have suggested direct effects of image perceptions on consumer choices (e.g., Plouffe et al. 2001). Therefore, we consider both attitudes and intentions as relevant dependent variables in our research. 
Finally, usage situations are taken into account. Previous studies have indicated that usage situations have a considerable effect on consumer decision-making (e.g., Belk et al. 1982). As the role of image congruence might be different for consumers depending upon their usage situation (e.g., Graeff 1997; Hogg et al. 2000) we believe that there is a distinction between private and public situations. This assertion is consistent with literature pertaining to categorization (i.e. members fall within fuzzy boundaries) and stereotyping (i.e., the dynamic process through which social groups make sense of and pursue their identity-related goals within intergroup contexts). Therefore, we investigate the role of the usage situation and its direct impact on consumer attitudes and intentions, as well as the joint effect of image congruence and usage situation. In the following section, we explain the first study we conducted, investigating the role of image congruence and the impact of private versus public usage situations.

\subsection{Hypothesis development}

A substantial amount of literature has been devoted to the role of image congruence in consumer decision-making (e.g., Hogg et al. 2000). The main message that can be derived from this research is that image congruence is a relevant factor to consider. Another stream of relevant literature we draw upon is self-brand connections. According to studies in this field, consumers tend to make decisions that are consistent with their existing self-conceptions. Self-brand connections can be explained as the extent to which individuals have incorporated a brand into their self-concept (Escalas and Bettman 2003). When brand associations are used to form the consumer's self-image, or to communicate this self-image to others, a strong connection is developed between the brand and the consumer's self-identity. Subsequently, this has a positive effect on consumers' evaluations of the brand (Moore and Homer 2003). Consumers are more likely to adopt innovations that display a good fit with their own values, beliefs (Rogers 1995) and lifestyle (Kleijnen et al. 2004). This idea is similar to that of Grubb and Grathwohl (1967) who link the individual's self-concept with the symbolic value of consumer purchases. Therefore, consumers may rely on image congruence as a signal, and decide whether or not to adopt an innovation contingent upon the level of congruence. This is particularly relevant for mobile services. Due to the unique advantages of mobile commerce (Kleijnen et al. 2004), mobile services are considered more personal than any other form of remote service delivery. This also suggests a need for a fit with the self-image, as m-commerce is indissolubly connected to its users. This notion is confirmed by Schlosser (2002), who states that the use of wireless technology is highly related to the consumer's self-identity and the extent to which wireless 
innovations fit to this self-identity. Therefore, a match between the image of mobile services and the consumer's self-image seems crucial for attitude formation and the adoption decision. Consequently, we suggest the following hypothesis:

H1 Consumers who perceive high image congruence will experience innovative, wireless services more positively than consumers who experience low image congruence in terms of:

Hla: attitude

H1b: intention to adopt

Past studies of image have identified image as a multidimensional construct (for an overview see Sirgy 1982). Several researchers have recognized self-image as a two-fold concept: the actual self-image - how an individual sees her/himself - and the ideal self-image - how s/he would ideally wish to be seen. Onkvisit and Shaw (1987) argue that researchers should make an explicit specification and justifiable reasoning for selecting a particular self-component. The merit of differentiating between types of self-concepts has been validated by several studies (e.g., Dolich 1969; Landon Jr. 1974). On the basis of these studies, it has been concluded that some preferences are associated with the actual self-image, while others display stronger correlation with the ideal self-image (Onkvisit and Shaw 1987). The underlying reason for this difference originates from the consumption situation, where some services are typically consumed in a private situation and other products most often in a public situation. In other words, "the self is a collection of masks each tied to a particular set of social circumstances" (Sirgy et al. 2000). Previous research has investigated these effects by focusing on, for instance, private and public brands. However, in these studies, it was possible to differentiate brands to represent either the private or the public brand. With mobile services, this type of distinction cannot be made. The elimination of geographical and time-related boundaries is regarded as the key advantage of mobile services (Balasubramanian et al. 2002) by companies and consumers. This implies that mobile services can and will be consumed in different types of situations, i.e., private and public. Moreover, earlier research (Graeff 1997) has also indicated that consumers reveal strong similarities between actual and ideal self-image, and different effects of the actual versus ideal self-image congruence are hardly distinguishable. Therefore, we hypothesize that: 
H2 In the adoption of innovative, wireless services, actual self-image congruence and ideal self-image congruence will have an equally strong (positive) effect on:

H2a: consumer attitude

H2b: intention to adopt

Besides image congruence, we also investigated the effects of usage situations on consumer adoption of innovative services. Research has demonstrated how consumers exhibit different preferences in different consumption situations (e.g., Hogg et al. 2000). Research in both psychology and marketing has confirmed the need for understanding situational contexts, which allows us to considerably enhance the ability to explain, predict, and control behavior (Schmitt and Shultz II 1995). Social identity theory (Tajfel and Turner 1986) suggests that consumers are inclined to let their choice be determined by the social groups surrounding them in order to gain social acceptance of peer groups considered relevant (Chau 1996; Graeff 1997). Additionally, the self-monitoring literature suggests that selfenhancement is dependent on the product or brand being a publicly recognized symbol (Belk et al. 1982). Snyder and Gangestad (1986) suggest that some people are more sensitive to adapting to social contexts (self-monitoring). Whereas people described as low self-monitors are said to rely on dispositional information and direct their behavior internally, high monitors rely on situational information to direct their behavior externally (Snyder 1979). The theory of self-monitoring therefore suggests that consumers make different decisions in different situations and that these decisions are particularly dependent upon who's surrounding them.

In earlier research, the distinction between private and public situations has been made repeatedly (Dolich 1969; Graeff 1997; Graeff 1996). In a private situation, consumers are not surrounded by others and, therefore, do not experience any social pressure. Conversely, consumers will be influenced by their surroundings in a public setting to a large extent. Previous research has recognized social pressure as a usage motivation (e.g., Karahanna and Limayem 2000). Generally, mobile phones and user extensions, such as mobile services, are described as innovative (Kleijnen et al. 2004), trendy (BBC 2000), and social (Jarvenpaa et al. 2003), implying a positive public opinion towards mobile services. Consequently, consumers might evaluate mobile services more positively in a public setting due to group influences. Finally, in Fishbein and Ajzen's (1975) Theory of Reasoned Action, and Warshaw and Bagozzi's (1990) Theory of Trying the importance of subjective norms (or social beliefs) in consumers' decision-making processes is discussed. Numerous studies have confirmed the idea that consumers are heavily influenced by their surroundings when evaluating products or services (e.g., Karahanna and 
Limayem 2000; Venkatesh and Davis 2000). Based on the previous discussion, we posit that:

H3 Consumers in a public situation will evaluate innovative, wireless services more positively than consumers in a private situation in terms of:

H3a: attitude

H3b: intention to adopt

Although studies on the image congruence hypothesis have been generally supportive, there is no extensive body of research that has examined variables interacting with image congruence (Graeff 1996). According to Schmitt and Shultz II (1995) the impact of situational variables on consumer preferences seems particularly relevant for products or services which are typically recognized as image enhancers. In fact, consumers might find it more important to bestow a particular image upon themselves in certain situations than in others. However, the various situations in which this phenomenon might occur are only developed to a limited extent.

Consumers in a private situation (e.g., at home) have a lesser need to portray a strong image. Consequently, image congruence will not have such an influential role when compared to public situations. In contrast to the private situation, we argue that in a public situation consumers often seek to profile themselves in a certain environment to create an identity of social presence (Grewal et al. 2000). Consequently, cases of high congruence, consumers' attitudes and intentions to use innovative services in public situations will increase, due to the opportunity to express their image to others. Consequently, the following hypothesis is developed:

H4 Consumers in a public situation experiencing high image congruence will evaluate innovative, wireless services more positively than consumers in a private situation experiencing high image congruence in terms of:

H4a: attitude

H4b: intention to adopt

In order to test our hypotheses, an experiment was conducted. The following section discusses the details of the research design and presents our findings. 


\subsection{Experiment 1}

\section{Research context}

According to Barwise and Strong (2002), the mobile channel is an extremely personal medium that consumers carry with them at all times and optimistic forecasts claim that mobile internet will develop into a pervasive element of everyday business and personal life. Rapid advances are being made, especially with regards to wireless financial services (Barnard et al. 2001; Viquez 2001). Several banks have launched initiatives to create wireless opportunities for their customers. For example, a large European bank (www.postbank.nl) gave out 500.000 WAP-enabled mobile phones to their customers, enabling them to use mobile banking services. However, at this time, the market seems to be more supply- than demand-driven. Although some consumers have expressed interest in interacting with service providers via remote channels (Adriaenssens 2001), the wireless delivery of banking services is not yet accepted by the majority of consumers (Adrian 2001). The reason for this might be that companies have stressed the functional aspects of mobile services as the key advantage, thereby neglecting the social value that can be derived from mobile services. Consequently, the image of mobile services could affect a consumer's decision as to whether or not to adopt such services. This has also been acknowledged by Becker et al. (2002), who emphasize the need for financial service providers to create favorable images for new banking channels in order to be successful.

\section{Experimental design}

We conducted a between-subjects experiment to examine whether or not there is a relationship between image congruence and attitudes towards the use of mobile services as well as the intention to adopt these services, manipulating only the situation that subjects were assigned to. Before the situation was presented, subjects were asked to fill out a questionnaire containing questions related to the image of mobile banking, their actual self-image, and their ideal self-image. Following this, a particular consumption situation was presented to them (private or public). Subjects were randomly assigned to a scenario (see Figure 4.1). The respondents were then asked to imagine themselves in that situation and answer questions concerning their attitudes and intentions to adopt. In order to assess whether or not these scenarios reflected the intended state of mind, manipulation checks were added (Perdue and Summers 1986).

The scenarios were subjected to a qualitative pretest in which 20 respondents were asked to critically evaluate the scenarios in terms of clarity and realism. The 
interviews resulted in only minor adaptations of the scenarios, related to fine-tuning sentence formulations rather than radical changes in content.

\title{
Figure 4.1 Scenario description: private versus public situation
}

\begin{abstract}
Base scenario
You have put aside some money every month for a number of years and saved a considerable amount. Because the return on your savings account is very low, your financial advisor has suggested that you invest the money in stocks. You have followed his advice.
\end{abstract}

\section{Situation manipulation}

Private: You are sitting at home in front of the television with nothing special on TV. In this situation, you receive an SMS from your financial advisor. He is advising you to buy certain stocks now, because of the real time developments that are occurring on the stock exchange market. You can execute the transaction he has proposed via your mobile phone by using the mobile transaction services. If you decide to execute the transaction, you will later receive an SMS with the details of the transaction.

Public: You are sitting in a lounge, surrounded by strangers. You do not know any of the people around you. In this situation, you receive an SMS from your financial advisor. He is advising you to buy certain stocks now, because of the real time developments that are occurring on the stock exchange market. You can execute the transaction he has proposed via your mobile phone by using the mobile transaction services. If you decide to execute the transaction, you will later receive an SMS with the details of the transaction. If you decided to use your mobile phone to execute the transaction, the people around you would notice that you use these mobile services.

\section{Questionnaire development}

We employed a series of semantic differential scales to measure the various types of image, as this has been recognized as the most popular technique for this type of study (Graeff 1997). The dimensions were adapted partly from Graeff (1997) and expanded with relevant dimensions based on a review of domain-specific (i.e., mobile services) literature. These dimensions were evaluated and discussed extensively by means of individual interviews with 20 respondents, evaluating both the clarity and the relevance of the image dimensions. The resulting dimensions are reported in table 4.1. These dimensions were utilized to measure three types of image: image of wireless finance, the actual self-image of the respondent, and the ideal self-image of the respondent. Attitudes towards using mobile services as well as the intention to adopt mobile services were included as the relevant dependent variables in our study (see Table 4.1). 
Table 4.1 Questionnaire items

\begin{tabular}{|c|c|c|c|c|c|}
\hline \multirow[t]{2}{*}{ Variable } & \multirow[t]{2}{*}{ Items } & & \multicolumn{2}{|c|}{ Alpha } & \multirow[t]{2}{*}{ Based on: } \\
\hline & & & Study 1 & Study 2 & \\
\hline Image & $\begin{array}{l}\text { not very career focused - career focused } \\
\text { old fashioned - modern } \\
\text { unsuccessful - successful } \\
\text { local - global } \\
\text { easy-going - economical } \\
\text { inefficient - efficient } \\
\text { slow - fast } \\
\text { conventional/solid - YUP/trendy } \\
\text { unimportant - influential } \\
\text { technological follower - technological } \\
\text { pioneer }\end{array}$ & $\begin{array}{l}\text { Bank: } \\
\text { Actual: } \\
\text { Ideal: }\end{array}$ & $\begin{array}{l}.87 \\
.86 \\
.85\end{array}$ & $\begin{array}{l}.75 \\
.72 \\
.75\end{array}$ & Graeff (1997) \\
\hline Attitude* & $\begin{array}{l}\text { good - bad } \\
\text { pleasant - unpleasant } \\
\text { harmful - beneficial } \\
\text { favorable - unfavorable }\end{array}$ & & .96 & .95 & $\begin{array}{l}\text { Dabholkar and } \\
\text { Bagozzi (2002) }\end{array}$ \\
\hline Intention* & $\begin{array}{l}\text { unlikely - likely } \\
\text { improbable - probable } \\
\text { impossible - possible } \\
\text { uncertain - certain } \\
\text { definitely would not use - definitely would use }\end{array}$ & & .97 & .97 & $\begin{array}{l}\text { Bruner II and } \\
\text { Hensel (1998)/ } \\
\text { Dabholkar and } \\
\text { Bagozzi (2002) }\end{array}$ \\
\hline
\end{tabular}

* note that the questionnaire explicitly focused on the attitude and intention towards using the mobile channel for wireless transactions

\section{Sample}

Respondents were approached on the streets of mid-sized cities in the Netherlands of approximately 120.000 (Maastricht) to 200.000 (Eindhoven) inhabitants. Data was collected in May 2004 during a fourteen-day period that included weekdays, weekends, and different hours of the day. In our sample selection we employed the following selection criteria: possession of mobile phone, acquaintance with mobile technologies such as WAP, and familiarity with brokerage (meaning that they are knowledgeable about stock trading and have personal experience with trading stocks). These qualifications were necessary in order for the respondents to understand the scenarios presented to them. Questionnaire completion was obtained by means of personal interviews. In total 298 people were approached, of which $29 \%$ were not willing to participate or did not fit the selection criteria ${ }^{8}$. After screening

8 Of those $29 \%, 85 \%$ simply refused to participate. In addition, $13 \%$ did not have an affinity with brokerage, and the final $2 \%$ did not posses a mobile phone. 
the questionnaires for incompleteness and abnormalities (Tabachnik and Fidell 1996), a usable sample of 209 respondents was obtained, which were randomly assigned to a scenario (104 private respondents versus 105 public respondents). The sample contained $49 \%$ women and $51 \%$ men and a broad range of age categories: < 25 years: $26 \%, 25-40$ years: $26 \%, 41-55: 26 \%,>55$ years: $22 \%{ }^{9}$.

\subsection{Results}

\section{Manipulation check}

Manipulation checks were performed in order to assess whether the intended manipulations were understood by the respondents. Bipolar scales ranging from 1 to 7, where 4 represents the neutral point ("this situation can be described as a public situation" vs. "this situation can be described as a private situation") were used to measure the respondents' evaluation of the situation. The results of the manipulation checks strongly suggested that there were differences between the private and public situations $\left(F_{1,207}=1269.126, p<.001\right)$.

\section{Measuring congruence}

In line with previous research (Graeff 1997; Graeff 1996), the overall difference score reflecting degree of congruence between mobile services and self-image was calculated with a general Euclidean distance model:

$$
D=\sqrt{\sum_{i=1}^{n}\left(P_{i}-S_{i}\right)^{2}}
$$

Where:

$\mathrm{D}=$ overall difference score reflecting degree of congruence between service and self-image

$\mathrm{I}=$ a particular personality image dimension

$\mathrm{P}_{\mathrm{i}}=$ perception of the mobile service on image dimension $\mathrm{i}$

$\mathrm{S}_{\mathrm{i}}=$ perception of self on image dimension $\mathrm{i}$

A small (large) difference indicates a high (low) degree of similarity between the mobile service and selfimage.

First, we investigated the effect of different types of image congruence (actual and ideal) on the dependent variables in different situations. These relationships

Similar patterns were found within each sub sample, leading to no significant differences between sub samples. 
were examined using correlation analysis. Table 4.2 presents the correlations between image congruence (self and ideal) and attitudes and intentions.

Table 4.2 Correlations: private versus public

\begin{tabular}{lccccc}
\hline & \multicolumn{2}{c}{$\begin{array}{c}\text { Private consumption situation } \\
(\mathbf{n}=\mathbf{1 0 4})\end{array}$} & & \multicolumn{2}{c}{$\begin{array}{c}\text { Public consumption situation } \\
(\mathbf{n}=\mathbf{1 0 5})\end{array}$} \\
\cline { 2 - 3 } \cline { 5 - 6 } & $\begin{array}{c}\text { Actual } \\
\text { congruence }\end{array}$ & $\begin{array}{c}\text { Ideal } \\
\text { congruence }\end{array}$ & & $\begin{array}{c}\text { Actual } \\
\text { congruence }\end{array}$ & $\begin{array}{c}\text { Ideal } \\
\text { congruence }\end{array}$ \\
\hline Attitude & $-.83^{* *}$ & $-.80^{* *}$ & & $-.36^{* *}$ & $-.39^{* *}$ \\
Intention & $-.75^{* *}$ & $-.74^{* *}$ & & $-.36^{* *}$ & $-.40^{* *}$ \\
\hline
\end{tabular}

** Significant at $\mathrm{p}<.01$ (2-tailed)

The significant correlations indicate that image congruence had a significant positive relationship with the variables defined (remember that the congruence score is similar to a reversed scale, therefore the negative correlation actually implies that when the congruence increases, the intention to adopt increases). Based on these results, actual as well as ideal self-image has a significant influence on attitude (H1a) and intentions to use (H1b).

Although there seem to be some (marginal) differences between the image congruence correlations in the various situations, these differences are rather small, as was expected (H2). In order to test the differences between correlations, several authors have suggested Hotelling's $T_{l}$ as an appropriate tool (e.g., Ferguson 1976). However, according to Steiger (1980) this test is not to be used, as the underlying assumptions regarding distributions are often not met. Therefore, Steiger suggests other methods, of which the $T_{2}$ statistic developed by Williams (1959) is considered the most optimal solution. Comparing the correlations based on the $T_{2}$ statistic reveals that there are actually no statistically significant differences between the correlations for actual and ideal congruence (all $p$-values $>.05$ ). Therefore, we can conclude that both types of image congruence have a significant effect on the dependent variables, regardless of the situation presented (H2).

Considering these results and the high correlation between actual and ideal congruence $(r=.92, p<.01)$, we will examine the joint effects of (actual and ideal) image congruence and consumption situation on attitudes and intentions to adopt in the following analysis. This is in line with the suggestions of Graeff (1997). We calculated the average of actual and ideal image congruence and used this variable of "overall" image congruence as a covariate in our further analysis. 


\section{Testing assumptions}

Considering the large sample size and the robustness of MANOVA to departures from multivariate normality (Tabachnik and Fidell 1996), violations of multivariate normality are not expected to be severe. Inspection of the histograms, normalprobability plots, skewness and kurtosis for each dependent measure for each cell showed some departures from normality. However, skewness and kurtosis are well within the expected values (Hair Jr. et al. 1995). Moreover, in larger samples of 100 or more cases, the impact of departures from normality disappear (e.g., Tabachnik and Fidell 1996). Consequently, MANCOVA has generally been shown to be robust against violations of the multivariate normal distribution and therefore we continued the analysis maintaining the variables in their original form. Moreover, MANCOVA assumes linear relationships among all pairs of dependent variables in each cell, as a deviation of this assumption would lead to a reduction in power of the statistical tests. Plotting the dependent variables indicates a clear presence of linear relationships. The same procedure was conducted to inspect whether or not the same holds true for correlations of the covariates with the dependent measure(s). As this is the case, the inclusion of image congruence as a covariate is appropriate. Finally, applying MANCOVA would be superfluous in case the dependent variables are uncorrelated, therefore the correlation between attitude and intention to adopt was evaluated as significant $(r=.72, p<.01)$.

\section{MANCOVA: private versus public}

To test our hypotheses, we conducted a MANCOVA. The results are reported in Table 4.3.

Table 4.3 Results of MANCOVA tests: private versus public

\begin{tabular}{lcrrc}
\hline Effect & Pillai-Bartlett trace $(\boldsymbol{V})$ & $\boldsymbol{F}_{2,204}$ & $\boldsymbol{p}$-value & Partial $\boldsymbol{\eta}^{\mathbf{2}}$ \\
\hline Main effects & & & & \\
Situation & .059 & 6.366 & .002 & .059 \\
Image congruence & .515 & 108.229 & $<.001$ & .515 \\
Two-way interaction & & & & \\
Situation * Congruence & .237 & 31.725 & $<.001$ & .237 \\
\hline
\end{tabular}

$R^{2}$ adjusted Attitude $=.568$

$R^{2}$ adjusted Intention $=.432$

Research concerning the robustness of the statistics available for MANCOVA has proposed the Pillai-Bartlett trace criterion (V) as the most robust statistic for general protection against departures from multivariate normality and homogeneity of variance-covariance matrices (Tabachnik and Fidell, 1996). The results of this test indicate significant results for the interaction effect $\left(V=.237 ; F_{2,204}=31.725, p\right.$ 
$<.001)$ as well as significant effects for situation $\left(V=.059 ; F_{2,204}=6.366, p=.002\right)$ and image congruence $\left(V=.515 ; F_{2,204}=108.229, p<.001\right)$.

Table 4.4 Results of Omnibus ANCOVA tests: private versus public

\begin{tabular}{llrrr}
\hline Dependent variables & Effect & $\boldsymbol{F}_{1,208}$ & $\boldsymbol{p}$-value & Partial $\boldsymbol{\eta}^{2}$ \\
\hline Attitude & & & & \\
$\left(R^{2}\right.$ adj. $\left.=.568\right)$ & & & & \\
Main effects & Situation & 12.284 & .001 & .057 \\
& Image congruence & 186.849 & $<.001$ & .477 \\
Two-way interaction & Situation * Congruence & 64.054 & $<.001$ & .230 \\
\hline Intention & & & & \\
$\left(R^{2}\right.$ adj. =.432) & & & & \\
Main effects & Situation & 5.044 & .026 & .024 \\
& Image congruence & 125.536 & $<.001$ & .380 \\
Two-way interaction & Situation * Congruence & 24.727 & $<.001$ & .108 \\
\hline
\end{tabular}

In addition to our hypothesized model, we investigated an alternative model. In this model we used the image of the wireless services as an independent variable instead of image congruence, as past literature has indicated that this image in itself might explain attitude formation as well as consumer intentions (see our discussion: "Image, decision-making, and adoption"). This alternative model however yielded a very low $R^{2}$ adjusted for both attitude $\left(R^{2}\right.$ adj. $\left.=.065\right)$ and intention $\left(R^{2}\right.$ adj. $\left.=.021\right)$. This leads to the conclusion that our original model provides a better explanation for the role of image with regard to attitudes and intentions. To further investigate our hypotheses we used univariate analyses. The results of the omnibus ANCOVA tests are presented in Table 4.4. Moreover, the cell means for the interaction between image congruence and situation are depicted in Figure 2.

It should be pointed out that in case of significant interaction effects the main effects in themselves do not fully explain the results of our experiment and should be interpreted in light of the interaction effect (Keppel 1991). Therefore, we start by interpreting the interaction effects first. With regard to attitude towards wireless finance (Table 4.4), the test indicates significant results for the interaction effect $\left(F_{1,208}=64.054, p<.001 ; \eta^{2}=.230\right)$. However, looking at the means presented in Figure 2, the results indicate that the type of consumption situation had a significant effect on attitudes only for the subjects exhibiting low overall congruence, whereas the attitudes for subjects with high overall image congruence did not differ between situations. Therefore, although the interaction effect is present, hypothesis $4 \mathrm{a}$ is not supported. 
Figure 4.2 Effects of situation and congruence (private versus public)

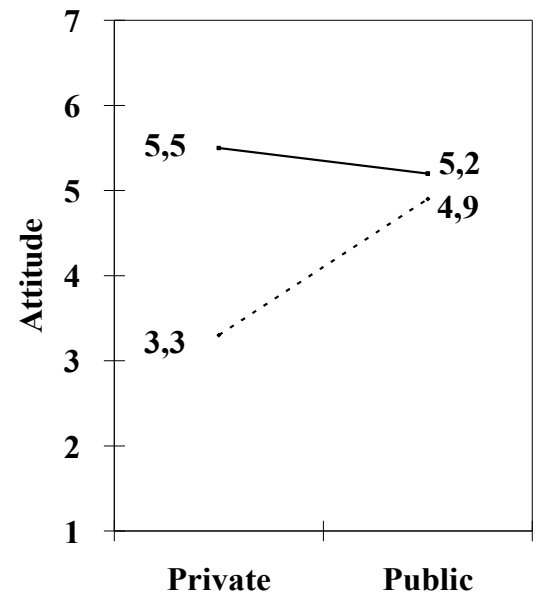

Consumption Situation

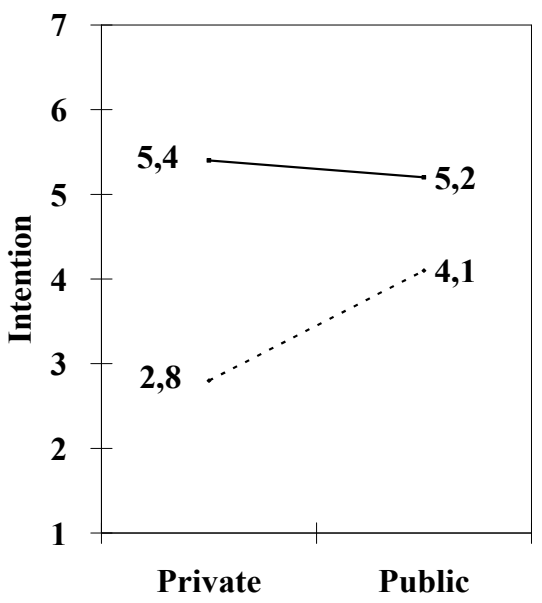

Consumption Situation

Note:

- High congruence

- - - Low congruence

Averages are based on a median split of total image congruence, resulting in a high group and a low group

The main effect of the situation, although significant (H3a), is relatively weak $\left(F_{1,208}=12.284, p=.001 ; \eta^{2}=.057\right)$ which is not surprising considering the interaction effect we found. The results for image congruence $\left(F_{1,208}=186.849, p<.001\right)$ seem to suggest that the main effect of image congruence should not be overlooked (H1a) as the partial effect size is highest for this effect $\left(\eta^{2}=.477\right)$. In light of the significant interaction effect, however, the evidence of the ANCOVA alone is not conclusive. Therefore, we conducted additional tests to inspect the main effects without the inclusion of the interaction effect (Jaccard et al. 1990). One-way ANOVAs were conducted with attitude as a dependent variable. These analyses also provided support for the main effect of image congruence $\left(F_{37,171}=2.08, p=.005\right)$, suggesting in line with hypothesis H1a that subjects with a high overall congruence exhibited a more favorable intention to adopt than subjects with a low overall congruence. Additionally, we found a main effect of the situation $\left(F_{1,207}=12.284, p\right.$ $<.001$ ) as attitudes were significantly higher in the public situation compared to the private situation, supporting $\mathrm{H} 3 \mathrm{a}$.

The general pattern of the means for intention to adopt displays great similarity to that of the means for the attitudes. Again, the interaction effect $\left(F_{1,208}=\right.$ $24.727, p<.001$ ) was significant (Table 4.4). Also in this case the results reveal that the type of consumption situation only influenced the intention to adopt wireless 
finance for the subjects exhibiting low overall congruence, whereas the intention for high overall congruence subjects did not differ between situations. This result does not support the expected interaction effect $(\mathrm{H} 4 \mathrm{~b})$. Again, the ANCOVA suggests significant main effects for image congruence $\left(F_{1,208}=125.536, p<.001\right)$ and situation $\left(F_{1,208}=5.044, p=.026\right)$. Subjects with a high overall congruence exhibited a more favorable intention to adopt than subjects with a low overall congruence. Moreover, intention to adopt was significantly higher in the public situation compared to the private situation. To further investigate these effects, the one-way ANOVAs are inspected for image congruence $\left(F_{37,171}=5.928, p<.016\right)$ and situation $\left(F_{1,207}=3.077, p<.001\right)$. Based on these results both H1b and H4b are supported. To ensure correct interpretation of our results we also posed an open question to our respondents as to what motivated their choices in the current scenario. After careful screening, we were able to determine five broad answer categories: novelty, fit with personality/style, social surroundings, control and convenience. In the private situation, "fit with personality/style" was mentioned most frequently ( $73 \%$ mentioned this as one of the reasons), while in the public situation social surrounding was the most dominating motivator (85\%). This suggests that our interpretations of the results are correct.

The results we found are only partially supported by the literature discussed. Moreover, this study does not define any particular group in the public setting. To further investigate the effects of image congruence and usage situation, we conducted a second experiment where a more refined insight into the effects of the public setting is given.

\subsection{Significant others: friends versus colleagues}

While the first study merely investigates the effect of the presence of others, this study investigates the type of others that are of influence. Members of a social group are defined on the basis of their similarities or differences with a particular group (Graeff 1997; Tajfel and Turner 1986). In order to validate our findings and to further refine the effects of the public surroundings, we investigated the effects of particular groups of significant others (Shah 2003), namely friends and colleagues. Previous adoption research has focused on either investigating friends (e.g., Grewal et al. 2000) or colleagues (e.g., Karahanna and Limayem 2000). It seems particularly relevant to include both groups when studying mobile service adoption. Due to the ubiquity of mobile services (Balasubramanian et al. 2002), they can be consumed in different consumption situations, dissolving traditionally pre-defined borders between leisure time and work (Kleijnen et al. 2004). 
Friends are recognized as people who are known intimately, while coworkers are people who are known on a more superficial level. We therefore expect the social influence of friends to be stronger than the influence of colleagues. Moreover, many of the mobile services offered are based on interactions and social networks with friends rather than with colleagues. This leads to the following hypothesis:

H5 Consumers in a "friends" situation will evaluate innovative, wireless services more positively than consumers in a "colleagues" situation in terms of:

H5a: attitude

H5b: intention to adopt.

Also, in this study we expect an interaction effect between image congruence and the usage situation. However, the results of our previous experiment indicate a different interaction than we hypothesized. It seems that consumers experiencing low congruence are influenced by their surroundings instead of consumers with high congruence. The reason for this might be that consumers feel a need to express an image that is not their own (by means of mobile service use) in order to gain social approval of their environment. This is in line with Herr et al. (1991), who state that signals from the consumer's surroundings overrule other negative information. Since friends are known intimately, there is no reason to portray a certain image. Colleagues however might pass judgment and therefore clear profiling might be necessary in order to gain a certain position in this particular group setting. Therefore, the following hypothesis is formulated:

H6 Consumers in a "colleagues" situation experiencing low image congruence will evaluate wireless services more positively than consumers in a "friends" situation experiencing low image congruence in terms of:

H6a: attitude

H6b: intention to adopt.

Again, we test our hypotheses by means of an experiment.

\subsection{Experiment 2}

The design and procedure for experiment 2 are identical to that of experiment 1 . The objective of this experiment is to 1) replicate our findings concerning the relationship between image congruence and attitude toward mobile services and the intention to adopt; and 2) investigate if a particular group of people (friends versus 
colleagues) surrounding the consumer have an influence on these relationships. The situations are presented in Figure 4.3.

The colleagues' scenario mainly differs regarding the description of the people surrounding the respondent: "imagine you are in your office and colleagues are present." Furthermore, these colleagues were described as "casual acquaintances". Again, these scenarios were presented to 20 respondents, who critically assessed clarity and realism of both scenarios. Also in this case, the scenarios were adjusted in terms of clarity rather than actual content.

The questionnaire contained the same items as the previous experiment. The coefficient alphas are again reported in Table 4.1. The sample, which was retrieved in a similar way to the first experiment (number of people contacted was 305 , actual participation rate $67 \%)^{10}$, consisted of 102 respondents for the friends scenario, and 102 respondents for the colleagues scenario. The sample consisted of $49 \%$ women and $51 \%$ men, and can be characterized as follows in terms of age: $<25$ years: $25 \%$, 25-40 years: $27 \%, 41-55$ : $25 \%,>55$ years: $23 \%{ }^{11}$.

\section{Figure 4.3 Scenario description: friends versus colleagues}

\section{Base scenario}

You have put aside some money every month for a number of years and saved a considerable amount. Because the return on your savings account is very low, your financial advisor has suggested that you invest the money in stocks. You have followed his advice.

\section{Situation manipulation}

Friends: You are in a lounge with your friends. You have known each other for years and do not have any big secrets from one another. In this situation, you receive an SMS from your financial advisor. $\mathrm{He}$ is advising you to buy certain stocks now, because of the real time developments that are occurring on the stock exchange market. You can execute the transaction he has proposed via your mobile phone by using the mobile transaction services. If you decide to execute the transaction, you will later receive an SMS with the details of the transaction. If you decided to use your mobile phone to execute the transaction, your friends would notice that you use these mobile services.

Colleagues: You are in a lounge with your colleagues. You recently got a new job, so your colleagues do not know you very well. In this situation, you receive an SMS from your financial advisor. He is advising you to buy certain stocks now, because of the real time developments that are occurring on the stock exchange market. You can execute the transaction he has proposed via your mobile phone by using the mobile transaction services. If you decide to execute the transaction, you will later receive an SMS with the details of the transaction. If you decided to use your mobile phone to execute the transaction, your colleagues would notice that you use these mobile services.

10 Of the 305 individuals approached, 33\% did not participate. Again, the majority refused to participate $(79 \%)$, while others did not have affinity with brokerage $(17 \%)$ or did not own a mobile phone $(4 \%)$.

11 Similar patterns were found within each sub sample, leading to no significant differences between sub samples. 


\subsection{Results}

\section{Manipulation check}

Bipolar scales ("situation where I am surrounded by friends that know me well" vs. "situation where I am surrounded by colleagues that do not know me very well") were used to measure the respondent's evaluation of the situation. The results of the manipulation checks strongly suggested that there were differences between the friends versus colleagues situation $\left(F_{1,202}=489.394, p<.001\right)$.

\section{Measuring congruence}

Again, the overall difference score reflecting degree of congruence between service and self-image was calculated with a general Euclidean distance model. To validate our findings from the previous study, we again investigated the effect of different types of image congruence (actual and ideal) on the dependent variables in the two situations. Table 4.5 presents the correlations between image congruence (actual and ideal) and the dependent variables.

Table 4.5 Correlations: friends versus colleagues

\begin{tabular}{|c|c|c|c|c|}
\hline & \multicolumn{2}{|c|}{$\begin{array}{l}\text { Friends consumption situation } \\
\qquad(n=104)\end{array}$} & \multicolumn{2}{|c|}{$\begin{array}{l}\text { Colleagues consumption situation } \\
\qquad(n=105)\end{array}$} \\
\hline & $\begin{array}{c}\text { Actual } \\
\text { congruence }\end{array}$ & $\begin{array}{c}\text { Ideal } \\
\text { congruence }\end{array}$ & $\begin{array}{c}\text { Actual } \\
\text { congruence }\end{array}$ & $\begin{array}{c}\text { Ideal } \\
\text { congruence }\end{array}$ \\
\hline Attitude & $-.77 * *$ & $-.77 * *$ & $-.78 * *$ & $-.79 * *$ \\
\hline Intention & $-.76^{* *}$ & $-.74 * *$ & $-.74 * *$ & $-.75 * *$ \\
\hline
\end{tabular}

** Significant at $\mathrm{p}<.01$ (2-tailed)

Based on these results, actual as well as ideal self-image has a significant influence on attitudes and intention to use (H1). We also find significant correlations in this study indicating a significant positive relationship between image and the variables defined (H2). Again, based on the $T^{2}$ statistic, we could not find any significant differences between the correlations for actual and ideal congruence with regard to attitudes and intentions. The correlation between actual and ideal congruence for this sample was $.90(p<.01)$. Similar to the previous study, we used the means of actual and ideal image congruence to further investigate the joint effects of congruence.

\section{MANCOVA friends versus colleagues}

After testing the assumptions using the same procedures as in study 1 (correlation between attitude and intention was $r=.72, p<.01$ ), a MANCOVA was conducted 
to further explore the effect of public surroundings, i.e., we investigated the effect of different peer groups: friends versus colleagues. The results of the MANCOVA are summarized in table 4.6. Also for these scenarios we found a significant interaction effect $\left(V=.143 ; F_{2,199}=16.607, p<.001\right)$ as well as significant main effects for both situation $\left(V=.049 ; F_{2,199}=5.151, p=.007\right)$ and image congruence $(V=.667$; $\left.F_{2,199}=198.864, p<.001\right)$. Again, the alternative model with image of mobile banking instead of image congruence yielded poor results $\left(R^{2}\right.$ adj. attitude $=.054 ; R^{2}$ adj. intention $=.073$ ). ANCOVAs were conducted to further explore our hypotheses. The results are presented in Table 4.7. The cell means for the interaction between image congruence and situation are depicted in Figure 4.4.

Table 4.6 Results of MANCOVA tests: friends versus colleagues

\begin{tabular}{lcrrc}
\hline Effect & Pillai-Bartlett trace $(\boldsymbol{V})$ & $\boldsymbol{F}_{2,199}$ & $\boldsymbol{p}$-value & Partial $\boldsymbol{\eta}^{2}$ \\
\hline Main effects & & & & \\
Situation & .049 & 5.151 & .007 & .049 \\
Image congruence & .667 & 198.864 & $<.001$ & .667 \\
Two-way interaction & & & & \\
Situation * Congruence & .143 & 16.607 & $<.001$ & .143 \\
\hline
\end{tabular}

$R^{2}$ adjusted Attitude $=.420$

$R^{2}$ adjusted Intention $=.482$

Table 4.7 Results of omnibus ANCOVA tests: friends versus colleagues

\begin{tabular}{llrrr}
\hline Dependent variables & Effect & $\boldsymbol{F}_{\mathbf{1 , 2 0 0}}$ & $\boldsymbol{p}$-value & Partial $\boldsymbol{\eta}^{2}$ \\
\hline Attitude & & & & \\
$\left(R^{2}\right.$ adj. $\left.=.660\right)$ & & & & \\
Main effects & Situation & 10.245 & .002 & .049 \\
& Image congruence & 373.004 & $<.001$ & .651 \\
Two-way interaction & Situation * Congruence & 33.214 & $<.001$ & .162 \\
\hline Intention & & & & \\
$\left(R^{2}\right.$ adj. $\left.=.610\right)$ & & & & .026 \\
Main effects & Situation & 5.243 & .023 & .593 \\
& Image congruence & 290.981 & $<.001$ & .104 \\
\hline Two-way interaction & Situation * Congruence & 23.296 & $<.001$ & \\
\hline
\end{tabular}

In line with study 1 , the significant interaction effect $\left(F_{1,200}=33.214, p<\right.$ .001 ) indicates that the type of consumption situation had a significant effect on attitude only for the subjects exhibiting low overall congruence, whereas the attitudes for high overall congruence subjects did not differ between situations. Although we expected this interaction effect based on our first experiment, attitudes are evaluated more positively when the consumer is surrounded by friends instead of colleagues. Therefore, hypothesis $6 \mathrm{a}$ is not supported. Additionally, the results imply 
that high overall congruence leads to a more favorable attitude than a low overall congruence $\left(F_{1,200}=373.004, p<.001\right)$. Furthermore, subjects had a significantly more favorable attitude in the friends situation compared to the colleagues situation $\left(F_{1,200}=10.245, p=.002\right)$. The main effects are again separately investigated by means of one-way ANOVAs. These again illustrate significant results for image congruence $\left(F_{27,176}=3.183, p=.001\right)$ providing additional support for hypothesis 1a. Moreover, significant results are found for the situation $\left(F_{1,202}=10.570, p<\right.$ .001 ), confirming hypothesis $5 \mathrm{a}$.

\section{Figure 4.4 Effects of situation and congruence (friends versus colleagues)}

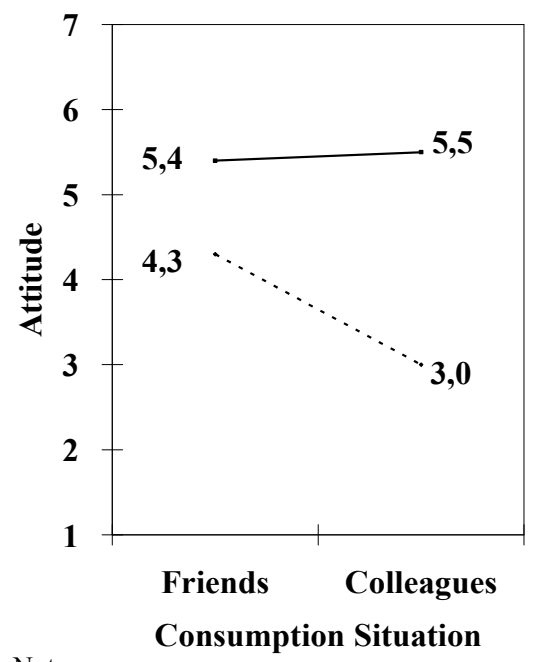

Note:

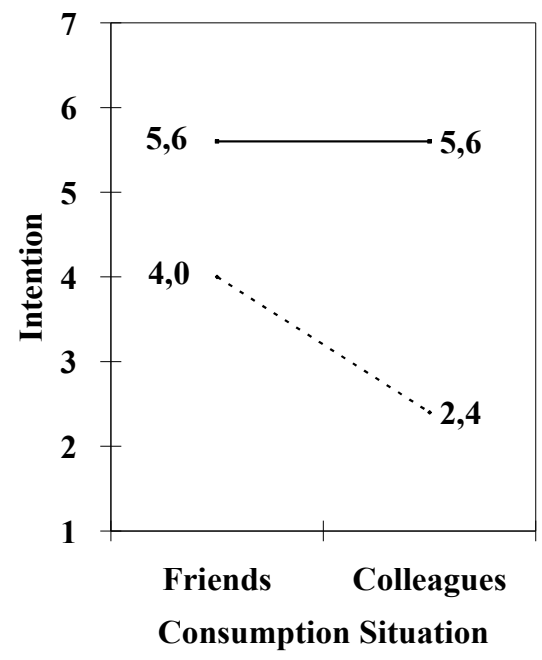

- High congruence

- - - Low congruence

Averages are based on a median split of total image congruence, resulting in a high group and a low group

The same results were found regarding intention to adopt wireless services. A significant interaction effect was found $\left(F_{1,200}=23.296, p<.001\right)$, which again illustrated that the type of consumption situation had an effect on subjects displaying a low overall congruence. However, also in this case the effect was found to be stronger in the friends situation, implying that our results do not support hypothesis 6b. Moreover, the main effects seem to suggest that subjects with an overall high congruence display a significantly higher intention to use wireless services than those with low overall congruence $\left(F_{1,200}=290.981, p<.001\right)$, whereas consumers in the friends situation demonstrate a higher intention to use wireless services than subjects in the colleagues situation $\left(F_{1,200}=5.243, p=.023\right)$. Further inspection of the main effects leads to further support for our hypotheses. For both image congruence $\left(F_{27,176}=3.978, p<.001\right)$ and situation $\left(F_{1,202}=12.730, p<.001\right)$ significant 
results were found, validating our initial results regarding hypothesis $1 \mathrm{~b}$ and providing support for hypothesis 5b. Again, we used an open-ended question as a check for our results. In the friends situation, the social surrounding was mentioned most often by the respondents as the reason for their behavior (94\%). In the colleagues scenario, however, fit with personality/style was cited most frequently (75\%). The implications of these findings are now discussed.

\subsection{Discussion}

The general purpose of this study was to identify the effect of image congruence on attitudes and intentions to adopt wireless services. Moreover, we aimed at investigating how these effects were moderated by the consumption situation. Consistent with previous findings (e.g., Graeff 1997; Hogg et al. 2000), image congruence seems to have a substantial effect on consumers' evaluations. However, concerning the effects of different types of self-image, a number of interesting results were found. Based on our findings, we can conclude that both actual and ideal self-image have an influence on the adoption of mobile services, regardless of the situation. Both effects are present and have a significant impact on attitudes and intentions to adopt. Our results also enable us to nuance this general finding with regard to the different types of consumption situations that have an effect on the consumer's attitude and intention to adopt. More specifically, consumers seem to be influenced by social situations. This is consistent with our expectations based on research concerning social identity (Grewal et al. 2000; Tajfel and Turner 1986). When investigating the type of social situation, results indicate that consumers are influenced more strongly by their friends than by their colleagues. An explanation for this might be that the respondents experience a stronger social tie, or even social pressure, when surrounded by their friends as opposed to their colleagues. Additionally, the working environment might be recognized as a less personal environment where social influences are experienced less strongly by consumers. However, these types of strategies will only be effective for consumers whose self-image is inconsistent with the service image, whereas the results demonstrate that consumers exhibiting a high overall congruence seem to be fairly stable in their evaluations. Although surprising, this effect may be interpreted as follows. When the image congruence is low, consumers may look for other signals. Herr et al. (1991) in their research have found that influences from the consumer's environment lead to favorable attitudes, even when extensive, diagnostic attribute information is available that would lead to less positive evaluations. Similarly, in the current setting, the situational influence overrules the effect of low congruence, leading to a more positive attitude and 
intention to adopt when consumers are surrounded by others, and more specifically by friends.

Overall, we can conclude that image congruence has a strong impact on consumer evaluations. While previous research has already demonstrated the relevance of image in the adoption process as such (Plouffe et al. 2001), these results indicate the importance of the fit between a consumer's image and the image of innovative, wireless services.

\subsection{Limitations and suggestions for further research}

During the process of our research, several limitations were encountered. These limitations suggest directions for future research and point to a number of theoretical implications. First of all, the experimental design pertained to a "laboratory experiment". As a consequence, the generalizability of the findings would be limited with regards to real-life settings. Furthermore, an experimental design might suffer from limitations pertaining to a possible lack of realism. For instance, our study involved a single sample of each subject group judging one hypothetical scenario on the basis of limited information. Even though the results of the manipulation check demonstrate successful manipulation of various consumer situations, there might be a difference between simulation and real experience, affecting the way in which respondents react to the situation. Several researchers (e.g., de Ruyter and Wetzels 1998) have suggested the use of audio-visual scenarios which are more realistic than verbal stimuli. However, simulating consumption situations might be complicated in the current research setting. While our study adds to the understanding of the role image congruence plays in determining consumer intentions, it is merely a first step in fully understanding the impact of the various dimensions of the self-concept. Sirgy (1982) provides an overview of these dimensions. While the two dimensions actual and ideal self are most predominantly present in the literature, further insights could be gained by incorporating additional dimensions of the self-image, such as the relational-self or social-self.

Additionally, other situational influences could be incorporated. While the focus in the current research has been on significant others surrounding the consumer, further research may investigate consumer pre-dispositions that are known to influence consumer behavior (e.g., mood). Similarly, personality traits have not been included in the current research. A useful segmentation variable in this area might be Parasuraman's Technology Readiness Index (Parasuraman 2000). For example, consumers who are less "technology ready" might be more willing to adopt innovations if they perceive a fit with their own image, i.e., the signal is more important for them than for consumers that are more "technology ready". Furthermore, this 
research does not take into account changes over time. Karahanna et al. (1999) have made a substantial contribution in this field by investigating pre- and post-adoption beliefs. However, as Karahanna et al. (1999) state, our knowledge about how these beliefs and attitudes change over time is still limited, indicating a need for further research in this area.

Finally, future research should focus on a broader range of services. However, it can be argued that other categories are even more embedded in social settings (e.g., mobile entertainment and communication services), which leads us to believe that investigation of these types of services should confirm our findings. Moreover, past research has mainly focused on functional aspects when studying adoption of new technology or services (e.g., Davis 1989), while socio-emotional aspects have been included implicitly (e.g., Rogers 1995). The relevance of image congruence in the current study signals the need for research regarding adoption theory that goes beyond functional relevance. In particular, more attention should be devoted to the role of social networks and their role in the adoption and diffusion of innovative networks.

\subsection{Managerial implications}

There are several managerial implications to be drawn from this study. First, the current research suggests that employing various consumption situations as a promotional tool might be very effective with respect to consumers whose selfimage is not consistent with the wireless service image. Instead of focusing on the overwhelming (functional) possibilities mobile services offer, managers should exploit the use of socio-emotional aspects when marketing wireless services. While most companies have focused on the individual, marketers should realize the importance of the social surroundings in the adoption process.

Moreover, techniques related to viral marketing might be useful in promoting wireless services. Using consumers to introduce other consumers to new services might be the most effective way to create consumer acceptance. Companies need to create opportunities for "wireless worth-of-mouth", for example by allowing users of a particular service to invite other potential customers for a free trial. Focusing on social networks to spread these innovations might be particularly helpful, as other interactive services such as SMS have been spread effectively through these networks.

Finally, given the impact of image congruence on the adoption of new services, marketers should consider segmenting their markets in terms of consumer image. Analyzing the firm's customer base may disclose different clusters of images. Developing and positioning new products or services close to these images 
may speed up the adoption process. For example, Nokia through their Nokia 5100 is targeting consumers with a sporty self-image. The phone is designed to resemble a 'six-pack' (i.e., well-defined abdominal muscles) and the promotional campaigns portray athletic people. The promotional slogan "shaped by performance" emphasizes the match between the athletic consumer and the phone design to an even greater extent. In general, Nokia claims that their phones are "designed to make an impression" (www.nokia.com). This strategy can certainly be extended to numerous innovative (wireless) services. 


\section{Chapter 5}

\section{Explaining Consumer Intentions to Use Service Innovations: Knowledge Acquisition Through Mobile Social Networks ${ }^{12}$}

Taking a social network perspective, the authors investigate consumers' intentions to use mobile service innovations. With a sociometric survey, they empirically assess how consumers integrate and connect through mobile social networks, as well as how their network position influences knowledge acquisition and intentions to use four innovative mobile services: multimedia messaging, gaming, information, and transactions. Both personal (i.e., opinion leadership and experience with the communication mode) and similarity attributes of social network members have a significant impact on network positions, though the members' need to belong to the social network moderates the latter relationships. In addition, network position attributes have divergent impacts on knowledge acquisition. In three of four mobile service categories, integration exhibits a negative effect on knowledge acquisition, whereas connectedness has a positive effect. Knowledge acquisition significantly influences intentions to use mobile services. Moreover, we demonstrate that carryover effects occur across the four service categories. Finally, the network's perceived ability to adopt innovative services has different impacts on usage intentions across the four service categories.

12 Next to Mirella Kleijnen, Ko de Ruyter, and Martin Wetzels, Annouk Lievens contributed to this research project. 


\subsection{Introduction}

Recent technological advances, such as short message services (SMS), offer new ways for consumers to interact and exchange information. For telecommunication providers, SMS drives market revenues, it accounts for as much as $80 \%$ of nonvoice revenues for the European market (Portioresearch 2005), and enjoys market growth of $80 \%$ in the United States (Informa Telecoms \& Media 2005). Telecom providers and various other industries are eager to tap into this communication channel for marketing purposes, but thus far, they have done so predominantly through bulk advertising. The increasing discontent consumers indicate with unsolicited commercial messages sent to their cell phones suggest however that this direct marketing strategy is ineffective (Barwise and Strong 2002). To develop more effective ways to target consumers, service providers have begun to explore the marketing potential of mobile social networks of consumer-to-consumer communication. For example, Vodafone pushes Multi-Media Messaging, an enriched form of texting that enables consumers to attach sounds, pictures, and videos to their text messages, by enticing SMS users to share and experiment collectively with this new service. Other mobile service providers have designed applications that allow customers to easily forward stock price SMS alerts to other consumers (e.g., www.huawei.com).

Particularly when it comes to service innovations, consumers consider interactions with their peers a valuable and reliable information source (Hennig-Thurau et al. 2001), but emerging literature on mobile communication focuses primarily on the individual rather than interactions between consumers or information exchange in mobile social networks (Igarashi et al. 2005). Furthermore, the scarce findings regarding social network effects on mobile services adoption seem equivocal. For example, Birke and Swann (2006) reveal that consumers coordinate their mobile operator choices with their peers, but do not do so when they choose mobile devices. In response to these characteristics of the industry and gaps in the literature, we attempt to offer a more in-depth understanding of service adoptions in mobile social networks by focusing on three important issues.

First, we develop a theoretical framework that identifies relevant antecedents and consequences of a consumer's position in a mobile social network. According to social network theory (e.g., Granovetter 1983; Rogers and Kincaid 1981), the information consumers derive from networks depends primarily on their position in the network, because the amount and heterogeneity of information they receive relates to their position. However, it remains unclear which factors define a person's network position (Klein et al. 2004). Drawing on prior research on organizational and social psychology, we suggest two relevant antecedent categories: (1) personal 
attributes (e.g., Robins et al. 2001) and (2) similarity attributes (e.g., Gibbons and Olk 2003). Furthermore, we incorporate the relevant marketing consequences of a consumer's network position, namely, knowledge acquisition and usage intentions. We also include a broad range of innovative mobile services in our empirical study to test the robustness of our model, ranging from mobile communication (MMS) to gaming, information, and transaction services. In addition, we assess not only the effect of knowledge about a service on usage of that particular service category but also the carry-over effects of knowledge about one category to other categories. Service usage intentions typically do not form in isolation; rather, consumers use information about comparable service innovations to choose new services. Therefore, to understand consumers' decisions fully, we cannot simply model singlecategory effects (Russell et al. 1999) but rather must consider knowledge transferability as well.

Second, prior research reveals the cross-sectional heterogeneity of relationships in social networks (Gibbons and Olk 2003; Igarashi et al. 2005). Whereas knowledge acquisition serves as an overriding cognitive rationale for consumers' participation in social networks, consumers still differ in their needs for interpersonal attachment (Bagozzi and Dholakia 2002). Therefore, we introduce consumers' need to belong as a relevant moderator that may account for diverging network relationships. Because consumers with a strong need to belong tend to express their identity through the social group in which they participate, this need should alter the impact of personal and similarity attributes on the consumer's position within the network.

Third, Igarashi et al. (2005) contend that the empirical modeling of mobile networks remains a major research challenge. In the current study, we empirically apply a social network analysis. With a few notable exceptions (e.g., Brown and Reingen 1987; Reingen and Kernan 1986), such analysis is rare in relation to consumer social networks. Although previous research illustrates that relationships are critical for knowledge and behavior, most studies ignore how these relationships form within the context of a social network structure and the consequences that follow there from (e.g., Bagozzi and Dholakia 2002; Wellman et al. 1996). Reingen and Kernan's (1986) call for analyses that address the sociostructural context of networks has remained unanswered in mobile communication contexts (Igarashi et al. 2005). We shed more light on this issue by assessing the structural properties of participants in social networks and the information they derive due to those properties. 


\subsection{Conceptual background: mobile social networks}

According to Granovetter (1983), people are embedded in concrete, ongoing structures of social relations, and the extent of their embeddedness influences their individual behavior. Therefore, an in-depth understanding of the convergence of mobile technology, consumer interactions, and resultant consumer decisions may best be acquired by adopting a social network perspective. We define a social network as "a set of people, organizations, or other social entities, connected by a set of socially meaningful relationships" (Lea et al. 2006, p. 121), in which members participate for a variety of reasons, ranging from sociopsychological needs (e.g., friendship) to more functionally oriented reasons, such as knowledge transfer. We focus specifically on social networks formed through asynchronous communication via a mobile platform using SMS. Because a cell phone has become an intimate, always available device, senders of SMS are confident messages get delivered to the intended recipient and experience an enhanced level of intimacy (Reid and Reid 2004). Improvements in its functionality and speed has helped texting mature into a communication channel that allows for conversations about various content, ranging from romance (Byrne and Findlay 2004) to information sharing (Ling 2005). Recent studies reveal that even close relationships employ SMS in addition to voice and face-to-face contacts (Igarashi et al. 2005; Reid and Reid 2004). These developments have led consumers to participate actively in dynamic, overlapping social groups (e.g., family, friends, colleagues) maintained by cell phones and increased the importance of mobile social networks (Palen 2002; Reid and Reid 2004).

However, research on mobile networks has not advanced beyond their simple existence and treats social structures within networks as virtual black boxes (Igarashi et al. 2005; Miyata et al. 2005). But knowledge of such structures is pivotal for exploring mobile networks as marketing channels. Prior research suggests that the accessibility and diversity of information consumers receive depends largely on their positions in various social networks (Granovetter 1983).

We focus on individual integration and connectedness, both relevant structural properties of the person's network position with respect to information exchange (Lievens et al. 1999). Both integration and connectedness pertain to the homogeneity versus heterogeneity of information a consumer receives (Rogers and Kincaid 1981). Specifically, individual integration reflects heterogeneity in information exchange (Lievens et al. 1999) and "the degree to which members of an individual's personal communication network are linked" (Rogers and Kincaid 1981, p. 179). When a consumer shares the same contacts with others with whom he or she communicates, information likely gets duplicated, so the exchanged information is homogeneous. In contrast, individual connectedness, the degree to which a 
person is linked to others within his or her (mobile) network (Rogers and Kincaid 1981, p. 178), can lead to a broader mobile network in terms of the number of personal interactions. The consumer communicates with more others and thereby obtains access to a greater amount of information. In the next section, we elaborate on the antecedents and consequences of the consumer's position in the mobile network by developing a set of hypotheses that reflect our conceptual framework (see Figure 5.1).

\subsection{Hypothesis development}

\subsubsection{Personal attributes}

Social network theory stresses the importance of personal attributes with regard to obtaining a certain position in a network (Ahuja et al. 2003; Ibarra 1993; Robins et al. 2001). As research on organizational groups illustrates (e.g., Weisband et al. 1995), individual attributes influence communication patterns and thus directly affect a person's network position. For example, organizational studies illustrate that people with higher status (based on power or knowledge) are more influential and interact more, which influences their network position (Ahuja et al. 2003; Ibarra 1993). Similarly, consumer innovation literature recognizes opinion leadership as a personal attribute that contributes to information exchange (Gilly et al. 1998), because opinion leaders attain higher social status in their social system through their knowledge and expertise in a certain domain (Venkatraman 1989). Because their information is highly credible (Gilly et al. 1998), consumers turn to opinion leaders for information about products or services to reduce their risk and uncertainty.

Similar patterns occur in mobile social networks; research on mobile communication confirms that consumers seek the opinions of particular members of their mobile networks regarding relevant topics (Ling 2005). By definition, opinion leaders communicate frequently about their domain of expertise and proactively spread information because of their intrinsic motivation to share knowledge and spread information (Gilly et al. 1998; Reinecke Flynn et al. 1996). For example, socially engaged and opinionated members text others in their social network to share their political views (Lin 2005). On the basis of their intrinsic motivation to share information, their desire to interact frequently, and the frequent requests for their advice, we posit that opinion leaders communicate with more other members in the network.

H1a Opinion leadership is associated with greater individual connectedness. 


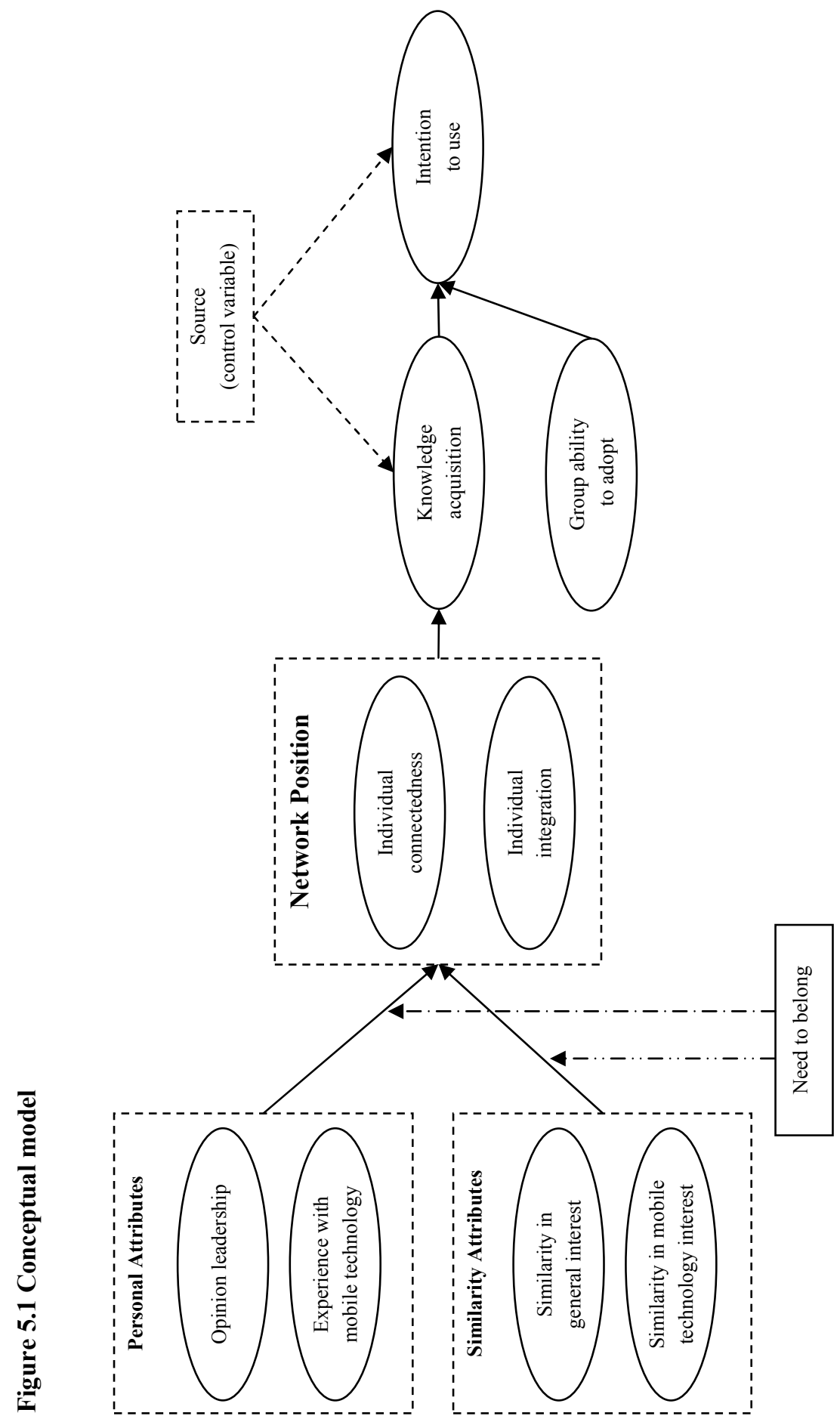


Moreover, opinion leadership is not a self-proclaimed state but rather is granted by other network members. Because opinion leadership usually is operationalized by the extent to which strong ties (i.e., friends and family) consult the opinion leader (Childers 1986; Reingen and Kernan 1986), those who communicate with the opinion leader likely communicate with one another, which implies a high level of integration. Gross (1971) also suggests that both opinion leaders and the information seekers who consult them are interested in communicating about a particular topic of interest. Therefore, opinion leaders likely trigger and facilitate communication among others with similar knowledge needs (Coulter et al. 2002). In line with Jones, Herschel, and Moesel (2003), we argue that opinion leaders are highly integrated within their social system.

\section{H1b Opinion leadership is associated with greater individual integration.}

In addition, a person's experience with the communication mode (in this case, mobile technology) may influence his or her position in the mobile social network. Recent mobile communication studies (James and Reischel 2001; MacKenzie and Zhang 2001) illustrate that novice consumers find communicating via SMS cumbersome because of their lack of speed or knowledge about its potential (e.g., predictive text input, emoticons). As Igarashi, Takai, and Yoshida (2005) suggest, channel properties can become impediments that consumers need to overcome to understand various elements, such as emotional cues. Experience with texting creates comfort with the technology and enables a consumer to express himor herself more accurately, which is necessary to establish a certain position in the network. Drawing on (e-)community literature (e.g., Rothaermel and Sugiyama 2001), we argue that experienced mobile technology users are more eager to explore new contacts, which suggests a higher level of connectedness. As their experience with the communication mode increases, people become less inhibited, more creative (Wellman et al. 1996), more socially engaged, and more willing to explore new contacts (Palen 2002). Research on mobile communication and dating (Byrne and Findlay 2004; Ling 2005) supports such claims; as teenagers become more experienced with the technology, they reach out more and are more likely to use SMS to make new contacts. Therefore, as experience with texting increases, people become more connected.

H2a Greater experience with the communication mode leads to greater individual connectedness.

Experienced SMS users also likely communicate with a more diverse range of contacts (Palen 2002; Rothaermel and Sugiyama 2001), including those that are 
not part of the group they know well. In contrast, less experienced users tend to communicate only with a very limited, select group of people and foster high-quality relationships within that group (Palen 2002). Within this familiar group, consumers share an interpretive context, so they may worry less about failing to express themselves correctly or being misunderstood due to the technology interface. Häkkilä and Chatfield (2005) highlight the importance of abbreviations and "SMS slang" and find that novice users must learn how to interpret such messages and respond appropriately. In turn, inexperienced consumers probably prefer to communicate with a well-known, intimate group of network members (Igarashi et al. 2005), which causes them to exhibit higher individual integration; experienced users, in contrast, move beyond these comfortable boundaries, which reduces their level of integration.

$H 2 b$ Greater experience with the communication mode leads to a lower level of individual integration.

\subsubsection{Similarity attributes}

Network studies often recognize similarity, or homophily, as an important antecedent of relational ties (Brass et al. 2004; McPherson et al. 2001), because people prefer to interact with those whose salient attributes are similar to their own, perhaps because similarity eases communication and fosters trust and reciprocity (Brass et al. 2004). Prior research focuses primarily on demographics, such as gender, age (Mehra et al. 1998), and socioeconomic status (Rothaermel and Sugiyama 2001). However, to provide a strong basis for self-identification with other network members (Bowler and Brass 2006), the salient attributes should move beyond demographics (e.g., Gibbons and Olk 2003; Gilly et al. 1998). In studies on social groups, shared interests, values, and passion represent the common denominators that cause consumers to interact (Bowler and Brass 2006; Rubin 1980). Therefore, we suggest that similar interests help determine the place a consumer obtains in a mobile network. Emerging studies on mobile communication and social networks also suggest that a sense of generally shared interests, such as common goals and values, drive mobile network formation (Igarashi et al. 2005; Ito and Okabe 2005) and promote communication and information exchange.

In addition to similarity in terms of general interests (i.e., what network members talk about), we investigate similarity in technology interests, or how and through which medium network members prefer to communicate. Mobile communication research indicates that regardless of the message, consumers choose particular communication channels simply because they are intrinsically motivated by their genuine interest in a specific channel (e.g., Spitzberg 2006). Similar patterns are likely to occur for mobile enthusiasts. Carroll et al. (2002) conclude that youngsters 
become part of mobile social networks because they consider mobile communication technology "their stuff," meaning they enjoy the technology itself and look for others that share this interest to communicate via the mobile platform. Therefore, a person can obtain a certain network position within the mobile network on the basis of the network members' shared appreciativeness of the mobile platform as a communication tool.

We suggest that similarity in general interest and similarity in technology interests affect a person's network position in a comparable manner. Similarity in interests fosters new relationships, or as McPherson et al. (2001) state, it breeds connection, because it offers consumers the opportunity for social identification (Gibbons and Olk 2003). Perceived similarities with others stimulate consumers to establish relationships, such that similar interests lead to greater individual connectedness. These people with similar interests are also likely to interact together, as they seemingly share the same interests. So when consumers perceives similarities, they increase the level of interaction with these similar others-birds of a feather flocking together (McPherson et al. 2001). In turn, homophily should affect individual integration positively.

H3 Perceived similarity in general interests leads to a higher level of (a) individual connectedness and (b) individual integration.

H4 Perceived similarity in mobile technology interests leads to a higher level of (a) individual connectedness and (b) individual integration.

\subsubsection{From network position to intention to use}

Consumers must acquire a satisfactory amount of information about an innovative service before they are able and willing to use them (Herr et al. 1991; Moorman et al. 2004). They often obtain such information from the social network (Nyblom et al. 2003); as Murray (1991) states, information acquired from social sources serves as the most important driver of usage intentions. Consumers learn from the information they obtain from their social network, which influences their service innovation usage (Ellison and Fudenburg 1993).

Communication within mobile social networks no longer consists of simply coordination-related messages (“where are you?") but rather entails a variety of conversation topics beyond socially oriented content (Ling 2005). Ling (2005) illustrates that as many as $30 \%$ of messages sent and received by consumers relate to substantive information sharing. However, according to social network theory, the heterogeneity and accessibility of this information depends heavily on a person's position in the mobile social network. Therefore, the levels of individual integration and connectedness relate, respectively, to the heterogeneity of the information and to the amount and accessibility of information the person retrieves from the network. 
A highly integrated member, whose network peers also communicate with one another (Rogers and Kincaid 1981), exchanges less heterogeneous information, so we expect knowledge acquisition to relate negatively to the level of individual integration. Granovetter's (1983) strength of weak ties theory supports our claim in arguing that persons with stronger ties (highly integrated) lack information from distant parts of their social system and may access only information from the small group of people around them. In contrast, consumers with weak ties enjoy a wide range of contacts and therefore likely obtain more non-redundant and diverse information. For individual connectedness, we suggest a positive relationship with knowledge acquisition, because greater connectivity implies more interactions with a diverse range of network members (Lievens et al. 1999). Because the information is more readily accessible (Scott 1991), consumers can acquire more knowledge.

H5 A higher level of individual connectedness is associated with a higher level of knowledge acquisition regarding innovative services.

H6 A higher level of individual integration is associated with a lower level of knowledge acquisition regarding innovative services.

H7 Greater knowledge acquisition leads to a higher intention to use innovative services.

We further recognize that being part of a group can influence a consumer's individual behavior. Prior research suggests that group characteristics contribute to individual consumer decision making, specifically about innovations (Munshi 2004). Research on group influences, such as group climate (Zhou 2003) and efficacy (Perry-Smith and Shalley 2003), indicates that such influences must be included in investigations of individual member's innovative behavior. We investigate the influence of a member's perception of the group's ability to adopt in particular. According to social cognitive theory, people exhibit the same type of behavior they observe in others (Bandura 1986), and Perry-Smith and Shally (2003) specifically argue that creativity (i.e., being innovative) is a social process in which surroundings, including social network members, provide important stimuli. Therefore, we posit that usage intentions rely not only on the specific knowledge a person collects about an innovation through information exchanges within the social network but also on the group's ability to deal with innovations.

H8 A group's ability to adopt increases members' intentions to use innovative services.

As we noted previously, we must also consider the carry-over effects of knowledge acquisition. Consumers typically do not decide to use products and 
services in isolation. Gregan-Paxton and Moreau (2003) suggest that consumers transfer knowledge from one category to the next, so their inferences about related product or service categories assist their decision making. Moreau et al. (2001) also show that knowledge about a particular category affects the decision to adopt a related innovation, especially if the innovation is continuous. To understand consumers' decisions, we cannot simply model single-category effects (Russell et al. 1999).

To address the carry-over effects of knowledge as well, we investigate a range of mobile service innovations. Recent research demonstrates that mobile service innovations occur in four categories (e.g., Nysveen et al. 2005a) on a continuum from incremental (MMS) to disruptive (financial transactions) (Ondrus and Pigneur 2005). On the continuum, the first category is communication, represented by the recent extension of text-based messaging to MMS, which enables consumers to transmit and receive animated text, sound, pictures and video. As our second category, we use mobile gaming, which enables consumers to play interactive, multiplayer games with other remote mobile users through their cell phones (Kleijnen et al. 2004). The third category, mobile information, involves information services, such as weather forecasts, traffic information, and sport results, sent to cell phones. Finally, we recognize mobile transaction services, with which consumers can conduct transactions, such as mobile banking and brokerage (Müller-Veerse et al. 2001). Although these service categories entail obvious differences (e.g., with respect to level of interactivity), they also share similarities that might cause consumer knowledge about one category to affect their intention to use another. For example, knowledge about service protocols, procedures, and payment options might be similar across categories and help consumers draw analogies from one to the other. Therefore, we investigate whether knowledge about service A (e.g., MMS) drives consumers' intention to use service B (e.g., gaming).

H9 Greater knowledge acquisition regarding MMS increases intentions to use (a) mobile gaming, (b) mobile information, and (c) mobile transactions; greater knowledge acquisition regarding mobile gaming increases intentions to use (d) mobile information and (e) mobile transactions; and greater knowledge acquisition regarding mobile information increases intentions to use (f) mobile transactions.

\subsubsection{Moderator: Need to belong}

Mobile social networks are social phenomena, similar to communities, which means that some consumers, by nature, are more prone to participate (e.g., Bagozzi and Dholakia 2002) because of their need to belong (Arndt et al. 2002). The need to belong is an innate desire to form sustainable, interpersonal relationships and feel 
part of a social group (Baumeister and Leary 1995). Consumers with a strong need to belong tend to express and enhance their identities through the social groups in which they participate (Arndt et al. 2002). Knutsen and Lyytinen (2005) also recognize that need to belong prompts participation in mobile social networks, which provides the gratifications associated with group membership, participation, and identity. Consequently, consumers with a high need to belong worry about their position in their social network (Pickett et al. 2004) and place greater importance on the attributes that drive this position. The need to belong therefore likely moderates the impact of both personal and similarity attributes on a person's network position.

First, we argue that the need to belong moderates the relationship between opinion leadership and network position because it stimulates activities that might satisfy the need (Baumeister and Leary 1995). Consumers with a high need to belong actively strategize and use their personal attributes to obtain a fulfilling network position; for example, they might exploit their knowledge as opinion leaders to enhance their position. Thomas-Hunt et al. (2003) show that people can improve their social positions by emphasizing their unique knowledge, and we similarly argue that consumers with a strong need to belong exploit their opinion leader status and feel great motivation to communicate their knowledge to create highly desired social contacts. That is, opinion leaders with a stronger need to belong undertake more efforts to become more connected within their social network, and the positive effect of opinion leadership on connectedness gets strengthened by this need to belong, as does the positive relationship between opinion leadership and integration. When consumers have a strong need to belong, they strive to embed themselves within a strongly integrated network, with a high level of individual integration, to enhance their feelings of intimacy and belonging (Miyata et al. 2005).

H10 Need to belong strengthens the positive relationship between opinion leadership and the levels of (a) individual connectedness and (b) individual integration.

Second, consumers with a strong need to belong attend closely to social cues, e.g., expression of emotion and conversational tone (Pickett et al. 2004). Their ability to comprehend social cues leverages their experience with mobile communication and heightens their understanding of communication processes compared with consumers with a low need to belong. Therefore, consumers with a high need to belong benefit more from their experience and exhibit stronger learning curves in terms of expressiveness and communication abilities. In turn, we expect that the need to belong strengthens the relationship between experience and connectedness. In contrast, the negative relationship between experience with the communication 
mode and the level of individual integration probably gets attenuated (i.e., becomes less negative) by the need to belong, because consumers with stronger needs are less concerned about creating more heterogeneity in their network (Hornsey and Jetten 2004). Because these consumers desire a more homogenous network, they also prefer a higher level of integration than consumers with a low need to belong.

H10 Need to belong (c) strengthens the positive relationship between experience with the communication mode and the level of individual connectedness but (d) attenuates the negative relationship between experience with the communication mode and the level of individual integration.

Third, similarity becomes an even more important driver of network position (McPherson et al. 2001), because the need to belong implies a desire for meaningful relationships rather than just frequent contact with another person (Baumeister and Leary 1995), and similarity fosters bonding. A relational setting is essential to a person who needs to belong and demands a certain extent of similarity. For example, social research in the field of friendships clearly illustrates that relationships flourish on the basis of similarities and that dissimilarities can destroy friendships (Gibbons and Olk 2003). The positive effect of similarity in both general interests and mobile technology interests should have a stronger impact on the network position of a consumer with a high need to belong, because similarity serves as a strong base for identification and self-expressiveness within the social network (Arndt et al. 2002). Consequently, consumers with a high need to belong strive to leverage their similarity by not only creating a highly connected network but also enhancing their strong homogenous communication within a highly integrated network.

H10 Need to belong strengthens the relationship between (e) similarity in general interests and the level of individual connectedness, ( $f$ ) similarity in general interests and the level of individual integration, $(g)$ similarity in mobile technology interests and the level of individual connectedness, and (h) similarity in mobile technology interests and the level of individual integration. 


\subsection{Empirical research}

\section{Measure development}

We collected data for this study through a written questionnaire, which contains items derived from an extensive literature study and that use multiple-item, Likerttype scales. A qualitative pretest consisting of in-depth, personal interviews of 20 respondents enabled us to assess the clarity and quality of the questionnaire. On the basis of these interviews, we critically reviewed the scales that we had adapted to the context in terms of their applicability and wording, and we reformulated items as necessary.

We used existing scales for experience, need to belong, usage intention, and opinion leadership (see Appendix B). However, we devoted special attention to developing a measure for similarity, because previous studies tend to employ "hard" criteria, such as age and gender, but do not include a similarity scale for more "soft" criteria, such as similarity in interests. Therefore, we turned to image congruence literature and its scales to measure similarities in images between products and users (Sirgy et al. 1997), which we transformed to fit the purposes of our study. Our measure of knowledge acquisition is based on a scale by Lievens et al. (1999), modified to make the items context specific to the service features about which consumers collect knowledge. We identified specific issues through literature reviews and our qualitative interviews with the 20 respondents who also pretested our questionnaire. Several issues emerged: service quality (e.g., Chae et al. 2002), user friendliness (e.g., Nysveen et al. 2005a; Pagani 2004), costs (e.g., Kleijnen et al. 2007; Pagani 2004), performance (e.g., Chae et al. 2002), possibilities (e.g., Nysveen et al. 2005a; Pagani 2004), and risks (e.g., Kleijnen et al. 2007). To assess the carry-over effects of knowledge, we measured both knowledge acquisition and intention specifically for each mobile service category (MMS, gaming, information, and transactions). Finally, we measured each person's perception of the group's ability to adopt with a scale based on Riggs and Knight's (1994) work, which we adapted, on the basis of qualitative interviews, to measure the construct at hand.

Both individual integration and individual connectedness measures rely on communication frequencies within the network (Lievens et al. 1999; Scott 1991). Each respondent indicated his or her communication frequency with every other person in the network, which also gave us the network properties. Following Lievens et al. (1999), we operationalize individual integration as the properties of a person's extant ties, which also mirrors Scott's (1991) description of individual integration as "the number of lines in a graph, expressed as a proportion of the maximum possible number of lines." We defined individual connectedness as the number of members to whom the focal member is adjacent and calculate the degree 
of connection (point degree) by the number of nonzero entries for that person in the row or column entry in the adjacency matrix (Scott 1991). Finally, we included a control for other sources of information that consumers might use to obtain information. From a provided list of sources (Wendel and Dellaert 2005), consumers indicated on a scale of 1 (none at all) to 7 (very much) how much information they obtained about mobile innovations from these sources. We included the average score as our control variable.

We also conducted a quantitative pretest with 203 business and economics students, evenly divided in terms of gender, whose ages vary between 18-33 years. We used SPSS for the exploratory factor analyses and deleted those items with loadings below .65. In Appendix B we provide a complete overview of the final items and sources for each variable.

\section{Sample}

A common method of collecting data in social network studies uses "sampling of referral chains" (Reingen and Kernan 1986). Therefore, we randomly approached people, whose referrals we used to create a snowball sample. In practice, we asked each respondent to list the names of the persons s/he considered part of her or his SMS network. We then contacted these persons and asked them for similar lists, which we used to contact those mentioned persons. We obtained four different networks $\left(\mathrm{n}_{1}=33 ; \mathrm{n}_{2}=23 ; \mathrm{n}_{3}=27 ; \mathrm{n}_{4}=21\right)$, which we aggregated into one data set whose total sample consists of 105 respondents. Although it is likely that an SMS network is not a closed network, we obtained relatively closed networks through our three waves of data collection; in the last wave, we retrieved less than $5 \%$ of new names. The rate of refusal was $1 \%$, and the percentage of persons we could not reach was also approximately $1 \%$. These numbers fall within the reasonable limits mentioned by Reingen and Kernan (1986). Furthermore, we asked our respondents whether they believed the network was complete; they responded on a scale of 1 to 7 , in which 1 represents totally disagree, 4 is the neutral point, and 7 equals totally agree. The resultant averages illustrate the completeness of the sampled networks (network $1, \mu=5.9$; network $2, \mu=6.3$; network $3, \mu=6.1$; network $4, \mu=6.6$ ). Finally, $60 \%$ of the sample are women, and the age range of the total sample varies from 17 to 50 years of age, with $50 \%$ younger than or 25 and $50 \%$ older than 25 years of age. 


\subsection{Analysis results}

\section{Network position}

To obtain respondents' network positions, we followed the procedure suggested by Lievens et al. (1999). We use the UCINET V statistical package, a program specifically designed to extract network measures (Borgatti et al. 1999). Three levels of analysis exist within networks (Rogers and Agarwala-Rogers 1976; Rogers and Kincaid 1981; Tichy and Fombrun 1979): individual, group, and system. We focus on the individual level (Knoke and Kuklinski 1982). Through the questionnaire, we collect what Scott (1991) describes as valued, undirected relational data. To calculate the network properties, we make the relations within the communication networks symmetrical using the average value algorithm (i.e., average value of column and row values for an individual respondent, $\mathrm{D}(\mathrm{i}, \mathrm{j})=((\mathrm{D}(\mathrm{i}, \mathrm{j})+\mathrm{D}(\mathrm{j}, \mathrm{i})) / 2)$ after we verified the degree of identity between the original matrix and its transpose (Zegers and ten Berghe 1985). The matrix correlation of the original communication matrix and its transpose produce the coefficient of identity for each SMS network, and the sufficiently high degree of identity $\left(\mathrm{symm}_{1}=92.69 \%\right.$; $\mathrm{symm}_{2}=95.65 \%$; symm $_{3}=95.98 \% ;$ symm $_{4}=97.40 \%$ ) provides a rationale for making the communication matrices symmetrical. Next, we dichotomized the communication matrices. For establishing the cut-off value, we took several criteria into consideration. Scott (1991) stresses that presence of communication itself can already establish a reasonable cut-off value, a line of argumentation that is also followed by Igarashi, Takai, and Yoshida (2005) in their study on mobile communication networks. Additionally, both communication patterns and the network averages are considered (Lievens et al. 1999). Combined, these criteria lead to a cut-off value of 1 SMS per week per person, i.e., 1 indicates a tie of any strength whereas 0 indicates no tie. Consequently, we dichotomize each communication matrix by replacing values of one or more SMS per week with 1 and maintaining zero values as 0 .

For each person in the network, we extract a personal communication matrix from the dichotomized communication matrix. To calculate the density of the resulting submatrix, we use the centralization command of UCINET, which represents the level of individual integration. In other words, starting from a personal communication network, we calculate the number of links among members and divide that number by the total number of possible links (Lievens et al. 1999). To calculate individual connectedness, we measure the number of nonzero entries for a person in the associated row or column entry in the communication matrix (Scott 1991). Because our data are binary, the degree of connectedness is the column or row sum for a focal respondent. Moreover, because we have made our data symmetrical, no differences occur between row and columns entries. 
After we derive the network variables using UCINET IV, we export them to an SPSS file, together with the measures for the other constructs. Then, we standardize all variables, which serve as input for our analysis.

\section{Reliability and validity}

We use confirmatory factor analysis (CFA) to assess the psychometric properties of the measures with multiple indicators (Anderson and Gerbing 1988; Brown 2006). We employ MPlus 4.1 with an MLMV estimator to establish all pairwise CFAs and assess unidimensionality, reliability, and (within-method) construct validity (Anderson and Gerbing 1988; Fornell and Larcker 1981). Our results confirm the unidimensionality, reliability, and convergent and discriminant validity of our measures. We also inspect the composite scale reliability (CR) and average variance extracted (AVE) to assess the reliability of each construct (Fornell and Larcker 1981). All measures exceed the cut-off values of .70 for CR and .50 for AVE (see Appendix B). To evaluate convergent validity, we inspect the standardized loadings of the measures on their respective constructs (Anderson and Gerbing 1988; Bollen 1989) and find that all loadings except one (.694) are greater than the conservative cut-off value of .70 (Fornell and Larcker 1981). Next, we assess discriminant validity by conducting pairwise CFAs for all constructs (see Table 5.1). The confidence intervals for the correlations between all construct pairs indicate that 1 is not included in any confidence interval (Anderson and Gerbing 1988; Hatcher 1994). ${ }^{13}$ Therefore, all constructs exhibit satisfactory discriminant validity.

13 We use CFA to test for discriminant validity in a design with two factors for all constructs in our study. For a design with two latent variables, the variances of the factors are fixed at 1, which enables us to estimate the correlation (and standard error) between factors. We allow for single-item measures by fixing the error term of the indicator (Linda Muthén, pers. comm., November 6, 2006). 


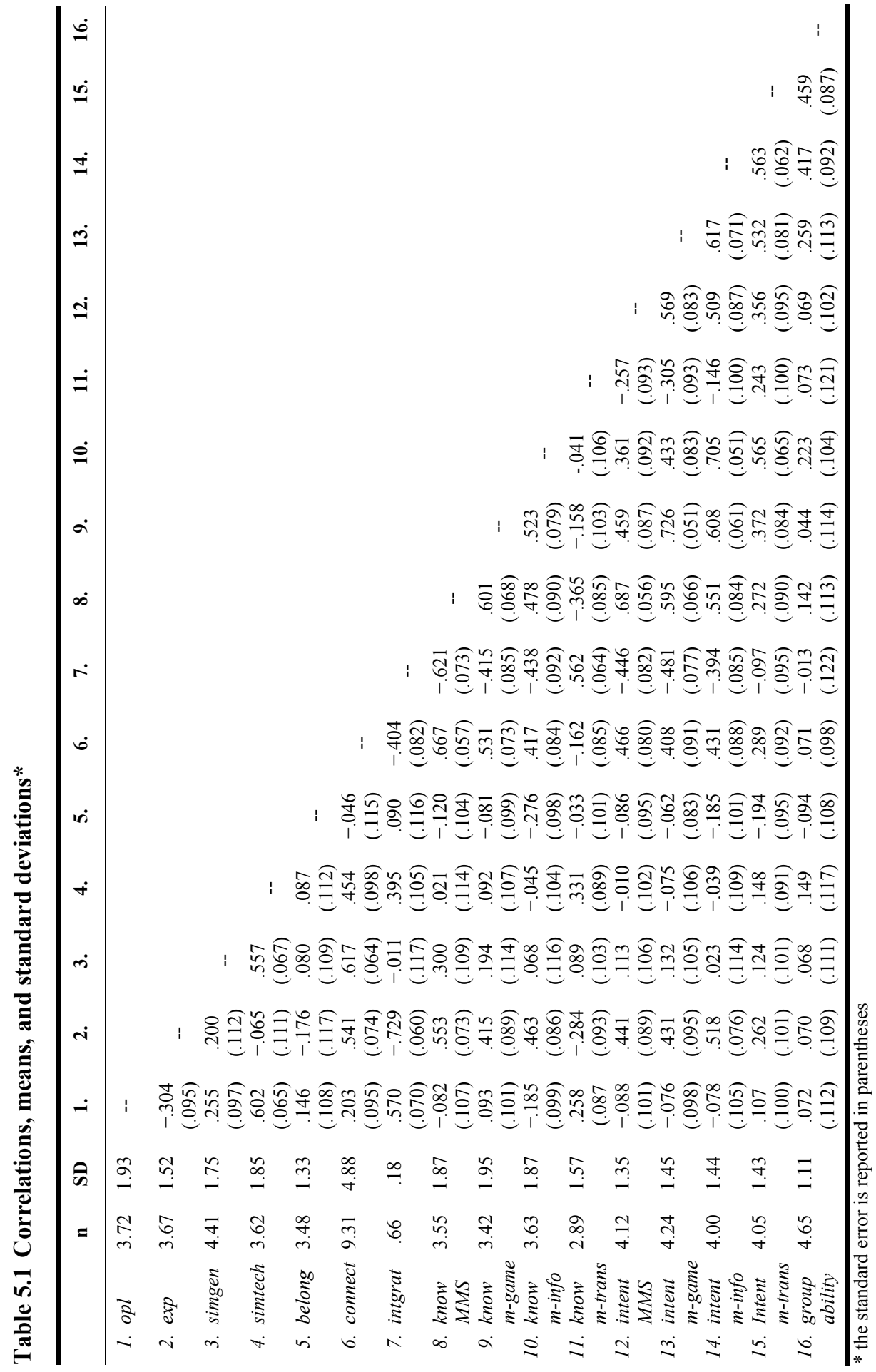




\section{Seemingly Uncorrelated Regression}

We use seemingly unrelated regression (SUR), as implemented in STATA release 9, to test the hypotheses derived from our conceptual framework (cf. Zellner 1962; Zellner 1963). If the disturbance terms ( $\varepsilon_{\mathrm{i}}$ in regression terms) of the regression equations in multiple equation systems are correlated, SUR provides more efficient estimates than ordinary least squares. Breusch and Pagan's (1980) $\chi^{2}$ test of independence confirms that the estimated disturbance terms are correlated at a significance level of $5 \%\left(\chi^{2}=127.97, p<.001\right)$. Our analysis is based on 101 observations; we omit four observations on the basis of their Mahalanobis distance (Barnett and Lewis 1994; Tabachnik and Fidell 1996). For all endogenous variables in the model, the F-test is significant at 5\%, and the variance explained can be considered large as it ranges from .27 to .74 (Cohen 1988). We provide a complete overview of these results in Table 5.2 .

\section{Results core model}

To draw conclusions regarding each hypothesis, we examine the unstandardized regression coefficients of the individual structural paths. Opinion leadership exhibits the expected positive effect on integration ( $\mathrm{H} 1 \mathrm{~b}, b=.03, p<.001$ ), but we find no significant effects with regard to connectedness (H1a, n.s.). For experience with the communication mode, we find the expected positive relationship with connectedness (H2a, $b=.31, p<.001)$ and a significant negative relationship with integration (H2b, $b=-.07, p<.001)$. Similarity in general interests has a significant positive effect on connectedness (H3a, $b=.23, p<.001)$ but no significant relationship with integration (H3b, n.s.). For similarity in mobile technology interests, we confirm positive relationships with both connectedness (H4a, $b=.12, p=.003)$ and integration (H4b, $b=.02, p=.001)$.

To a large extent, we confirm the relationships pertaining to our outcome variables which were estimated for each setting. This suggests our model is fairly robust for the different mobile innovation contexts. For individual connectedness, we find the expected positive relationship with knowledge acquisition for MMS (H5a, $b=.93, p<.001$ ), gaming (H5b, $b=.87, p<.001$ ), and information (H5c, $b=$ $.41, p=.009$ ). However, we find no significant relationship with transactions (H5d). Also, between individual integration and knowledge acquisition, we find the expected negative relationship for three of the four mobile service categories, namely, MMS (H6a, $b=-3.81, p<.001$ ), gaming (H6b, $b=-1.77, p=.028$ ), and information (H6c, $b=-.3 .56, p<.001$ ). For transactions, we find a significant, but contrary to our expectations, positive effect (H6d, $b=4.49, p<.001$ ). Knowledge acquisition also positively influences intentions to use all four mobile service categories: MMS (H7a, $b=.50, p<.001)$, gaming (H7b, $b=.42, p<.001)$, informa- 
tion $(\mathrm{H} 7 \mathrm{c}, b=.31, p<.001)$, and transactions (H7d, $b=.29, p<.001)$. Finally, people's perceptions of the group's ability to adopt influences their usage intentions. Although we find no significant effect for MMS (H8a, n.s.), the results are significant for gaming (H8b, $b=.27, p=.001)$, information (H8c, $b=.35, p<.001)$, and transactions ( $\mathrm{H} 8 \mathrm{~d}, b=.36, p<.001)$. No significant effects with regard to alternative sources as a control variable emerge.

To assess the carry-over effects of knowledge, we constrain the coefficients for ability and knowledge to equality across the four model equations and perform a Wald test of the equality of these parameters. Our results show that for both ability $\left(F_{3,952}=4.41, p<.001\right)$ and knowledge acquisition $\left(F_{3,952}=2.79, p<.039\right)$, the null hypothesis may be rejected at $\alpha=.05$. For the specific relationships, our findings illustrate that carry-over effects exist: Intention to use gaming is partly explained by knowledge about MMS (H9a, $b=.19, p=.001$ ), and knowledge about both MMS (H9b, $b=.12, p=.018)$ and gaming (H9d, $b=.20, p<.001)$ have significant effects on intentions to use information. Finally, we no longer find a significant effect of knowledge about MMS on usage intentions toward transactions (H9c), but we do uncover the significant influence of knowledge about gaming $(\mathrm{H} 9 \mathrm{e}, b=.14, p=$ .022 ) and information (H9f, $b=.25, p<.001)$ on intention to use transactions.

Table 5.2 Overview results seemingly unrelated regression

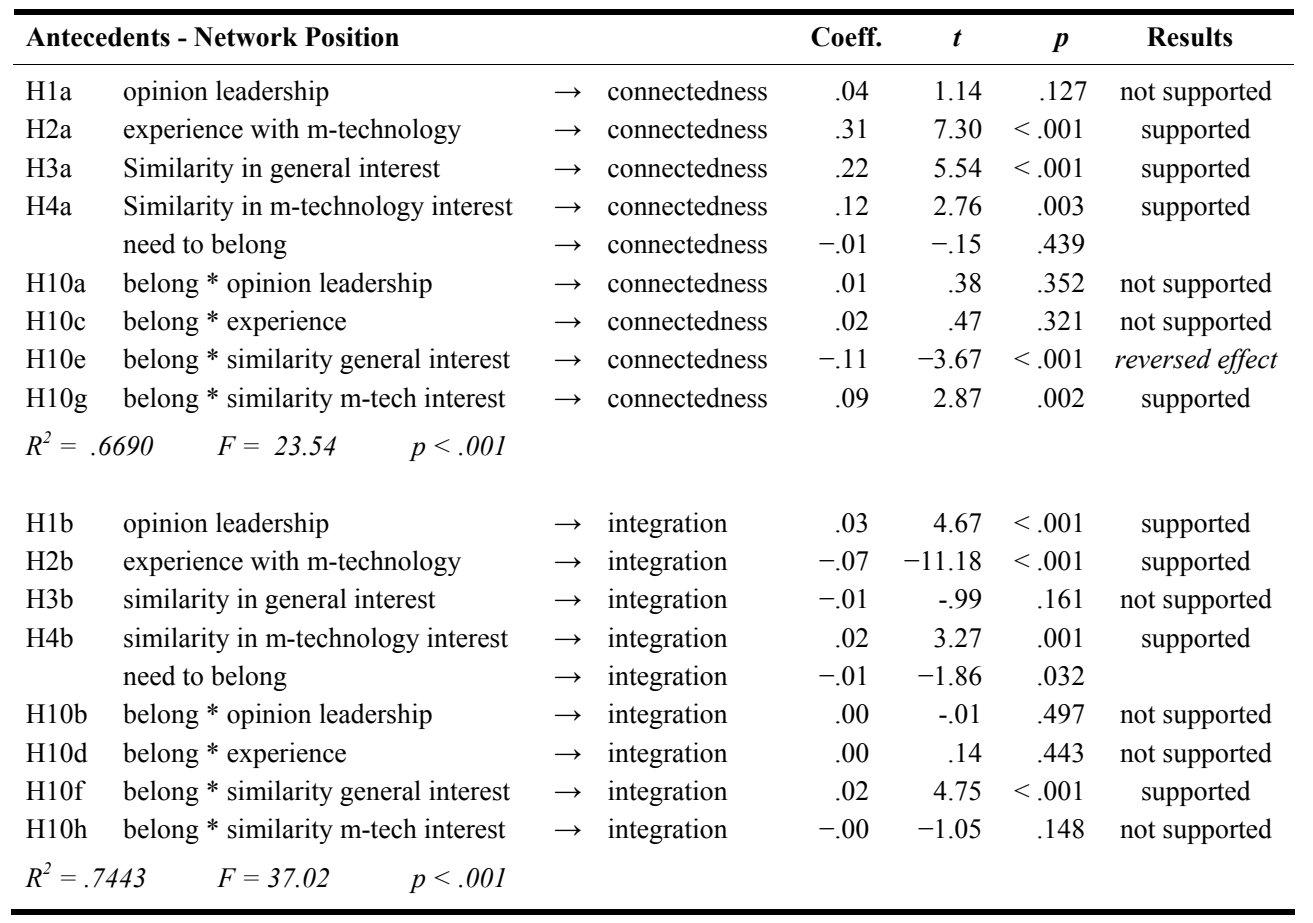


Table 5.2 Continued: overview results seemingly unrelated regression

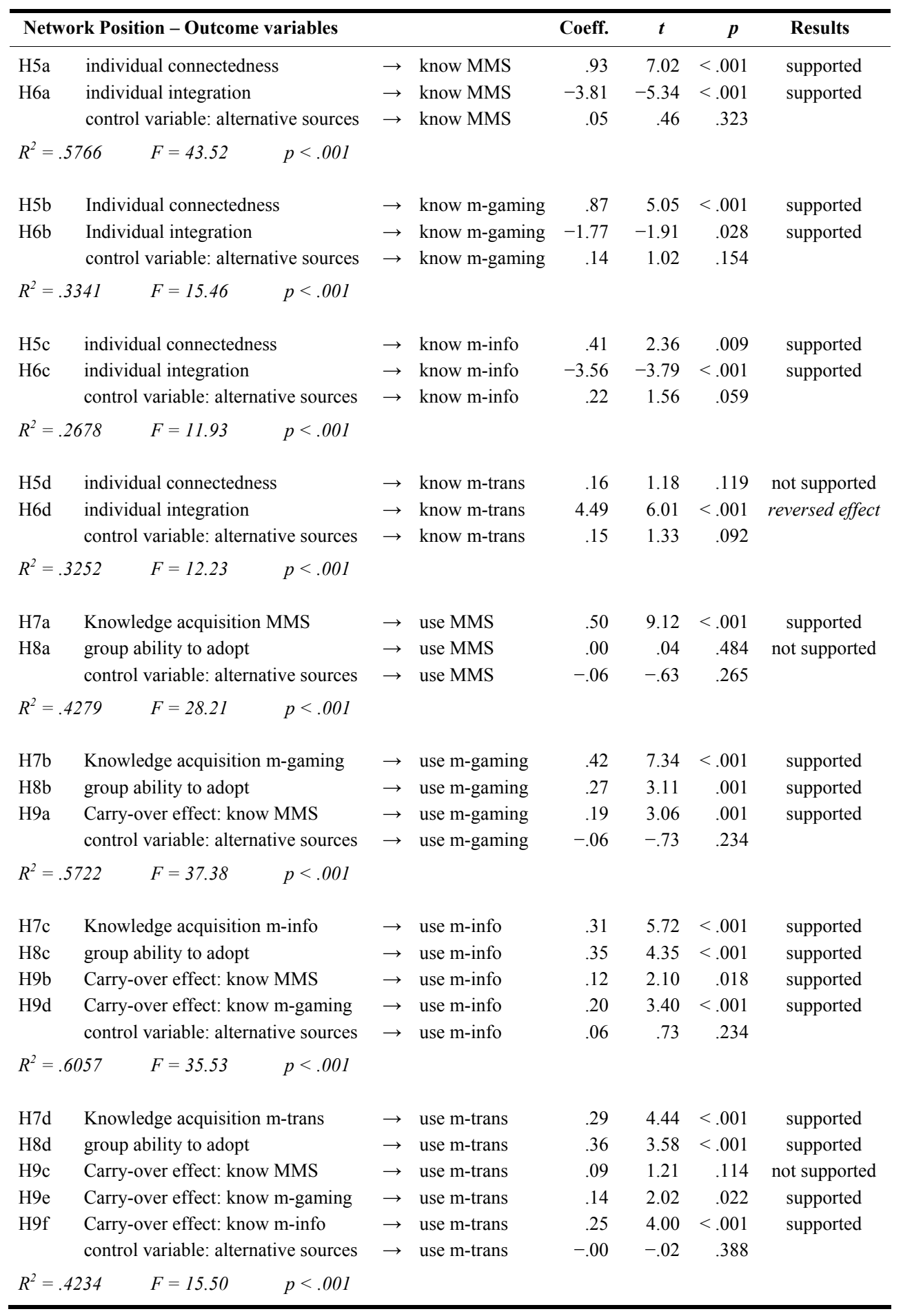




\section{Need to belong}

Although significant moderating effects exist, some relationships differ from our hypotheses. With regard to the personal attributes opinion leadership (H10a, H10b) and experience (H10c, H10d), we find no significant interaction effects with the need to belong. In the interaction between the need to belong and similarity attributes, we reveal mixed results, such that the relationship between similarity in general and individual integration grows stronger (H10f, $b=.02, p<.001)$ with a greater need to belong, but it attenuates the relationship with individual connectedness, in contrast with our prediction (H10e, $b=-.11, p<.001$ ). Finally, the need to belong strengthens the relationship between similarity in mobile technology interests and connectedness ( $\mathrm{H} 10 \mathrm{~g}, b=.09, p=.002)$, but we find no significant interaction effect in the relationship with integration (H10h, n.s.).

\subsection{Discussion}

Within the context of an SMS-based social network, we offer a more profound understanding of consumer decisions about mobile service in three ways. First, we provide a theoretical framework that distinguishes relevant antecedents and consequences of a consumer's position in a mobile social network. Second, we assess this network position through a social network approach that enables us to consider the specific structural properties of each person within his or her mobile social network. Third, we illustrate the moderating role of need to belong and thus offer more indepth insight into the relationships.

Our analysis shows strong support for our conceptual model, which identifies specific personal and similarity attributes as antecedents of network position. Opinion leaders have specific structural characteristics; they show high levels of individual integration but an insignificant level of connectedness, possibly as a result of the commonly acknowledged domain-specific character of opinion leaders' expertise (Reinecke Flynn et al. 1996). Opinion leaders' knowledge may be too specific to interest all members in a network; as Engel et al. (1990) note, they likely communicate first and foremost with others who exhibit the same involvement in the product category. In addition, opinion leaders tend to be conservative and position themselves as similar to the group in which they are imbedded (Venkatraman 1989). Therefore, opinion leadership leads to a higher level of individual integration but not to a higher level of connectedness. With regard to experience, we find an expected negative relationship with individual integration and positive relationship with individual connectedness. These confirmations indicate that experienced consumers of texting services move freely through mobile social networks (James and Reischel 
2001; MacKenzie and Zhang 2001), connect easily with others through this means of communication, and "cross bridges" to other, less familiar groups.

Similarity in mobile technology interests, as we expected, drives both individual connectedness and individual integration, but similarity in general interests has only a positive effect on individual connectedness and no significant influence on individual integration. Therefore, to establish interaction, it appears commonalities among persons are necessary. These commonalities can be rather superficial in nature, especially in computer-mediated environments (Bryant et al. 2006), though a higher level of individual integration, which implies a network of strong ties, might require a more profound, intrinsically oriented interest that provides a stronger basis for self-identification (Bowler and Brass 2006). Similarity in mobile technology interests can provide such as base, because sharing an intrinsic enjoyment in communicating through a mobile channel creates affective and social intimacy that fosters strong ties (Hu et al. 2004).

With regard to the effects of network position on knowledge acquisition, we find interesting differences across the four types of mobile service innovations. In line with our expectations, a negative relationship occurs between the level of individual integration and knowledge acquisition for three of four contexts, but for mobile transactions, we find a positive relationship. Moreover, though we find a positive relationship between connectedness and knowledge acquisition with regard to MMS, gaming, and information, we find no significant relationship when it comes to mobile transaction services. Because transactions represents the most disruptive innovation of our four categories (Ondrus and Pigneur 2005) and the failure of transaction services can have important consequences (e.g., money loss) (Suoranta and Mattila 2004), consumers may value the credibility of their knowledge sources especially highly. Levin and Cross (2004) argue that strong ties represent useful knowledge sources because they tend to be trustworthy, so people learn from such ties. A strongly tied information-providing party also might be more willing to expend efforts to help the receiving party understand the information (Hansen 1999; Levin and Cross 2004).

Finally, we confirm the positive relationship between knowledge acquisition and intentions to use innovative services and test the carry-over effects of knowledge about different service types. Rosa and Porac (2002) indicate that consumers use (service) categories as knowledge-organizing structures, so preexisting knowledge of one category helps determine their preference for another. Similar transferability appears in research on innovations (e.g., Liao and Cheung 2001; Wu and Wang 2005) and brand extensions (e.g., Grønhaug et al. 2002). We detect comparable patterns, in which intentions to use mobile gaming services depend not only on knowledge about mobile gaming but also on knowledge about MMS. This effect may occur because MMS and gaming services share some characteristics that allow 
for carry-over effects; for example, both can be classified as interactive and hedonic in nature (Nysveen et al. 2005a). Similarly, knowledge about MMS and mobile gaming influence intentions to use mobile information services. Finally, the intention to use mobile transaction services may be explained by people's knowledge about other service categories, with the exception of MMS, likely because communication and transactions are the least similar of the categories (Moreau et al. 2001). In general, MMS is an incremental service innovation that simply extends the media richness of existing written communications (Müller-Veerse et al. 2001), whereas the other innovations create new categories of the mobile service field, and transaction services are the most innovative (Ondrus and Pigneur 2005). Also, MMS pertains to interactions between persons, whereas transactions relate more to personto-machine interactions. Finally, as well as being less interactive by nature, transaction services deliver mostly utilitarian value (Kleijnen et al. 2007), whereas communication services often seem hedonic or experiential.

Furthermore, the effect of a person's perception of the group's ability to adopt is not significant in the MMS context, but we find significant relationships in the remaining three settings. Again, this result might occur because MMS is an incremental innovation, particularly in comparison with the other service categories. Therefore, consumers rely less on the competencies of their surroundings. However, as the service categories become more innovative, consumers become more insecure (Christensen 1997). Despite the knowledge they have acquired through the network, they retain their uncertainties and look for additional signals to make a decision (Kirmani and Rao 2000). In such situations, the competencies of the group to which the consumer belongs serve as additional positive stimuli in their decisions to use mobile service innovations. Social cognitive theory supports this assertion (Bandura 1986) in its suggestion that people reflect on their own behavior by assessing the behavior of their group members and proactively adjust their own behavior and decisions accordingly. Overall, the results with regard to the core model illustrate the importance of mobile networks in spreading information and their influence on consumer usage decisions.

When we investigate the moderating effects of the need to belong, we find that it does not moderate the relationships between personal attributes and the mobile network position but does affect the relationship between the similarity attributes and mobile network position. The consistency of these findings with regard to personal attributes seems to suggest that consumers with a high need to belong focus on others' attributes to enhance their network position rather then their own characteristics, possibly because they are less self-involved and have a more external-oriented focus. The need to belong enhances a person's sensitivity to external social cues (Pickett et al. 2004), so they become especially attentive to the characteristics of others that would foster relationships. This attentiveness might be 
caused by their need for reciprocity (Baumeister and Leary 1995) rather than a simple affiliation with another person.

With regard to similarity attributes and network position, we find interesting effects. The need to belong strengthens the effect between similarity in mobile technology interest and individual connectedness but attenuates the relationship between similarity in general interest and individual connectedness. In other words, for consumers with a high need to belong, similarities in how they communicate stimulate more connections within the network, perhaps because they recognize specific interests as an easy means to connect to many people in the network. Research on technology-mediated environments (e.g., Spitzberg 2006) also suggests that a shared interest in interacting through a specific medium facilitates interactions, regardless of the people's other common goals or values.

However, we find a different effect for integration, in that the need to belong strengthens the effect of similarity in general on individual integration but has no effect on the relationship between similarity in technology interests and integration. This finding might indicate a consumer strategy to "increase the odds," in that people with a high need to belong seek interpersonal contacts and relationships but want to form these bonds rather easily and readily (Baumeister and Leary 1995). Consumers with a higher need to belong also go to greater lengths to secure social contacts by lowering their threshold for acceptable interactions (Rudich and Vallacher 1999). Because general interests comprise a broader range of possible matches, they increase the chances of recognition and affiliation and therefore satisfy the need to belong more easily.

\subsection{Limitations and suggestions for further research}

We attempt to capture the nature of communication networks, especially mobile social networks, and though we find interesting results, we also acknowledge some limitations to our study. One such limitation is the cross-sectional nature of the research. Networks tend to be dynamic and develop over time (Burkhardt 1994; Lievens et al. 1999), so it would be interesting to research communication networks over time and pay particular attention to the roles of network members. These roles might change as the network develops, possibly because members gain more experience within the network or because knowledge within the network is finite, so members must move outside it for information.

In addition, we focus solely on mobile social networks, though consumers likely have several means to communicate and use a range of communication formats (Igarashi et al. 2005; Miyata et al. 2005). Younger generations in particular tend to use multiple channels to maintain and enhance their relationships. Further 
research therefore should investigate how consumers use various communication channels in combination, to what extent each channel influences the consumer's position in the network, whether separate networks appear in each channel, and whether these networks eventually converge.

We also focus on cognition-oriented variables as outcome variables and specifically on the network as a source of information. Networks may serve as sources for more affect-oriented variables by creating affect, influencing opinions, and changing the attitudes of consumers. Innovation research notes the relevance of such attitudinal constructs; researchers might consider incorporating these issues in studies of communication networks.

Our study also suggests different findings for the different mobile service innovations we investigated. It would be interesting to investigate the underlying variables that cause these differences. We suggest that trust and credibility underlie the significant differences, as do Levin and Cross (2004), so follow-up studies could address the influences of these variables more explicitly. An additional explanation might consider the extent to which innovation is incremental versus disruptive. Research highlights these differences, and we offer explanations for some of our findings on the basis of the nature of the innovation. Because that nature may influence the extent to which knowledge affects intentions, additional research should study the effects innovation type has on a consumer's need for information.

Finally, we study information transfer within a network without specifying the exact nature or origin of messages. Our results suggest that viral marketing techniques can be highly effective, but specific viral effects are often hard to predict (Scharl et al. 2005). More insights on message content and format could lead to a better understanding of what kind of messages (e.g., mobile infomercials versus funoriented messages) create the highest level of attention or attain the best "forwarding rate."

\subsection{Managerial implications}

Miyata et al. (2005) stress the importance of mobile social networks for communicating and forwarding information about products and services and urge companies to obtain a deeper understanding of how mobile communities spread such information. Companies might identify mobile networks from consumer databases and target these networks with specific marketing techniques. Although telecom providers have excellent tools to track and observe mobile communication behavior (e.g., SMScounter by Palm, http://software.palminfocenter.com; SMSCount, http://handheld.softpedia.com), they have few notions about how to transfer this 
knowledge into successful marketing strategies (Ahonen 2002). Our study suggests several managerial implications in this regard.

According to our findings, SMS is an important communication platform, excellently suited to spread information about (mobile) service innovations. By tracking SMS exchanges among consumers (i.e., how many text messages are sent to and received from a particular contact), telecom providers can determine each consumer's structural properties and identify those who are most likely to spread information about innovative service offerings (i.e., highly connected, loosely integrated consumers). While keeping in mind existing rules and legal privacy regulations, companies can approach mobile networks and boundary spanners within those networks to make them special offers.

We also identify several antecedents that affect a consumer's network position and thus the spread of information. Opinion leadership and experience with mobile technology precede connectedness, and experience also drives integration. Therefore, companies should collect information about their consumers to identify opinion leaders and experienced mobile communicators and entice them to spread information about service innovations. Companies can stimulate the spread of knowledge through incentives, such as free trials of services. For example, offering free trials of mobile games and extended invitations to try other mobile services may spread the new service effectively throughout the mobile social networks. Also, offering free forwards might be a worthwhile investment. Mobile service providers have experimented with providing consumers the opportunity to forward MMSs for free to friends and family to create more awareness about their possibilities. Universal Studios similarly introduced BoreMeMobile (www.borememobile.com), which enables consumers to download movie previews on their cell phone and forward this content for free to other consumers. Such offers stimulate interest and knowledge in not only a mobile service innovation but also the studio's latest new movies. As a means to provide information to consumers, the commercial use of SMS has grown increasingly important, and as more and more companies use viral marketing techniques to create consumer awareness of and knowledge about their products, mobile word of mouth might become the next tool for introducing new services, replacing face-to-face and even phone-to-phone communications.

Companies can enhance information forwarding by simplifying information transfer within the mobile social network. For example, they might incorporate "click-to-forward" options (Ahonen 2002) in their mobile message designs to enable the easy transfer of information. When consumers use informational services (e.g., weather, traffic), the messages contain not only the requested information but also an easy, one-button, one-click forward option they may use to spread the message to other members of their network. Other consumers thus become aware of the 
informational services available, as well as the levels of detail, accuracy, and relevancy of the information.

Because similarity attributes affect people's mobile network positioning, companies might consider marketing to bring consumers with similar interests together. As Smith (2002) points out, consumers have trouble organizing their own communication platforms, so companies should step in to create ways for consumers with shared interests to meet in mobile communities. Creating such platforms for sharing (Ahonen 2002) might entail posting messages or parking files, which allow the community to communicate simultaneously with bundles of contacts and thus facilitate knowledge sharing. For example, Nokia provides members of its community with free access to mobile platforms, as well as added features both in the mobile space and through online tools. Nokia thus hopes to create a technological platform for information exchange in the broadest sense of the word. Also, companies could stimulate the spread of innovations by offering deals for "buddies," in which members receive a bonus for introducing their friends and other network members to new innovations.

We must note the differences in service categories in our findings, with the recognition that more disruptive innovations or those that entail more sensitive trust issues cause consumers to consult their stronger ties. For such services, companies should identify specifically the strong ties in the network and provide them with information and incentives.

Finally, companies could benefit from consumer segmentation strategies according to their need to belong. Consumers with a high need to belong foster their connections with other network members though similar mobile technology interests and therefore are likely very sensitive to initiatives such as mobile communities, which enable these consumers to find similar others who enjoy communicating through mobile channels. Initiatives comparable to MSN mobile or playtxt (www.playtxt.net) help mobile enthusiasts find other proximate mobile users, whether that proximity is based on geographic location, gender, age, or interests. Such initiatives open the mobile space and make it easy to find other mobile users who enjoy communicating in this way. 


\section{Chapter 6}

\section{Conclusion}

This final chapter provides an overview of the most important conclusions of this dissertation. After a short synopsis of the four empirical studies, the findings and their implications are presented. Three main themes emerging from these studies are addressed; mobile service characteristics, consumer characteristics, and the social environment. Finally, possible avenues for further research are discussed. 
"If a man can write a better book, preach a better sermon, or make a better mousetrap than his neighbor, though he builds his house in the woods, the World will make a beaten path to his door."

Ralph Waldo Emerson (1803-1882)

\subsection{Synopsis}

The quote by Emerson is a rather simplistic view of bringing innovations to the market, as mobile service innovations have demonstrated so eloquently. While various companies and business analysts proclaim the great potential of mobile services, consumers are not in a hurry to adopt these innovative services. The aim of this dissertation was to create insights in the motivations that drive consumers' intentions to use these services from various perspectives. Empirical research on consumer behavior with regard to mobile service adoption is still relatively scarce. To advance our insights with regard to consumer decision making, and the use of mobile service innovations in particular, the objective of this dissertation was formulated as follows:

What factors contribute to consumers' intentions to use innovative mobile services?

This research theme was addressed by four consecutive studies, which were discussed in chapters two through five. In chapter two, we investigated the importance of traditional service innovation characteristics that were complemented with context specific characteristics. By means of conjoint analysis and simulations an importance hierarchy was derived. Additionally, through cluster analysis, we nuanced these results for different consumer segments. Chapter three discussed the impact of mobile service characteristics on mobile value creation and how this value consequently affects consumers' intention to use the mobile channel. Hereby, we also accounted for the moderating effect of time consciousness on the relationships between mobile value and its antecedents. In chapter four and five we addressed more socially-related issues with regard to mobile service usage. More specifically, chapter four focused on the role of image congruence in determining consumer evaluations of mobile services, whereby we accounted for the moderating effects of the consumption situation consumers find themselves in while using the mobile service. Chapter five investigated how consumers obtain a certain position in their mobile social network. We actively assessed the individual's network position and how this position is created, as well as how it leads to knowledge creation and usage intentions with regard to a diverse range of innovative mobile services. 
In sum, we addressed a broad range of antecedents that contribute to explaining consumers' intentions to use mobile service innovations. Hereby, we mainly considered three themes: 1) mobile service characteristics, 2) consumer characteristics, and 3) the social environment. This final chapter provides an overview of the most important results and an outlook on future research.

\subsection{Discussion}

While each of the four studies set out to accomplish specific goals, there are apparent common themes across these studies. In the following, we provide an overview of the most eminent results regarding these themes.

\subsubsection{Mobile service characteristics}

In our first study (Chapter 2), we investigated a range of mobile service characteristics that we initially derived from Rogers' innovation characteristics with focus on mobile gaming services. This resulted in the following services characteristics: relative advantage, compatibility, complexity, communicability, perceived risk, navigation, critical mass, and payment options. The results of the conjoint analysis and simulations illustrated that perceived risk is by far the most important characteristic within the derived hierarchy, followed by complexity and compatibility. These findings were further differentiated for different consumer segments, whereby we distinguished three different segments: Game Players, Value Seekers, and Risk Avoiders. Game Players mostly focus on factors that seem highly relevant for the particular service category at hand: mobile gaming. Communicability, payment options, and navigation appear to be most important for these consumers. Value Seekers are mostly driven by the added value of mobile services (relative advantage) and the fit to their current living style and value system. Risk Avoiders concentrate on perceived risk as well as complexity; they seem to be most concerned about whether or not the mobile service will actually deliver on its promise.

The second study (Chapter 3 ) further examined these mobile service characteristics and posed these factors as contributors to the mobile channel's value. We focused on utilitarian value perceptions in particular and classified three benefits and two cost factors. The concept of relative advantage was disaggregated into two relevant benefits: time convenience and service control. This is in line with research on innovations, which encourages more concrete conceptualizations of relative advantage in relation to its context (e.g., Moore and Benbasat 1991). Additionally, service compatibility was included as a benefit. As for costs, we recognized perceived risk as a relevant factor, as well as cognitive effort, which relates to the complexity involved with understanding mobile services. With the exception of 
service compatibility, all antecedents were relevant predictors of mobile service value, which in turn strongly affected consumer usage intentions. In line with previous research on innovation theory that recognizes relative advantage as a dominant factor (e.g., Tornatzky and Klein 1982), we found that time convenience is the most important benefit. Our findings also confirm prior beliefs with regard to the importance of time-related gains with regard to mobile services, and utilitarianoriented services in particular (Mort and Drennan 2005).

Striking is the fact that while in the first study inhibitors of mobile services had the strongest influence on mobile service evaluations, the second study revealed that benefits contributed more strongly to mobile value perceptions. This is in line with findings of ATKearney (2005), who in their yearly monitor studies on mobile services find that consumers' perceptions of impediments such as perceived risk are diminishing over time. This might lead to a less pronounced impact of these factors on mobile value creation.

\subsubsection{Consumer characteristics}

Several researchers point out the importance of studying consumer characteristics in relation to the use of innovations (e.g., Dabholkar and Bagozzi 2002; Meuter et al. 2005). In our first study, we used consumer characteristics, next to mobile service characteristics, to distinguish between consumer segments. We included opinion leadership, innovativeness, and Internet experience. Only the latter two showed significant differences between the segments, whereby the game player segment can be characterized as the most innovative. This finding can be explained by the fact that at the time of the study mobile gaming was truly in its infant stages and considered as a highly innovative service (The Economist 2000). Risk avoiders on the other hand can be characterized by a low level of internet experience. This is in line with previous research (Anckar and D'Incau 2002; Dholakia et al. 2005; Suoranta et al. 2005), which suggests that consumers that have experience with other technology-mediated interfaces (e.g., Internet) are more likely to have a positive attitude towards new technology-mediated channels, while consumers with less experience are more concerned about problems that might arise during the use of such an interface. These results are indicative of the fact that different consumers contribute different levels of importance to evaluative criteria when assessing mobile services.

In consecutive studies, we therefore also accounted for relevant consumer characteristics, whereby we focused on moderating effects of personality characteristics in explaining heterogeneity in predictor-criterion relationships. As argued by Dabholkar and Bagozzi (2002) and Hung et al. (2003), it is important to investigate such moderating effects in order to comprehensively understand evaluations of service transactions mediated by (mobile) technology. Moreover, focusing on personality characteristics as explanatory variables for such heterogeneity is 
considered much more meaningful than more traditional demographic variables such as age or gender (Dabholkar and Bagozzi 2002; Mort and Drennan 2005). In the second study (Chapter 3), we explained mobile value creation from a consumer's perspective. In focusing on the time-related gains that can arise from utilitarianoriented services, we considered the fact that consumers differ in their awareness of how they spend their time (Francis-Smythe and Robertson 1999). Our results demonstrated significant interactions between this personality trait we refer to as time consciousness and the antecedent-value relationships. More specifically, as expected, consumers with a higher time consciousness illustrated a stronger positive relationship between time convenience and value than those with a lower level, and the relationships between costs (perceived risk and cognitive effort) and mobile value were attenuated. Only for user control we found results counter to our expectations. The relationship between user control and mobile value was attenuated rather than strengthened, which might be explained by the fact that user control implies that the consumer is (partly) responsible for the outcome of the service. In this case, consumers might experience inefficiencies due to lack of role clarity with regard to their responsibilities as co-producers of the service, or they may feel they do not possess sufficient knowledge to undertake the role expected of them. This in turn might cause a less efficient delivery of the service, which is not in line with the needs of more time-conscious consumers.

In the last study (Chapter 5), we investigated the mobile social network. In determining the consumer's network position, we found that particularly the relationships between similarity attributes and the consumer's network position were moderated by the consumer's need to belong. Need to belong positively moderated the relationship between similarity in mobile technology interests and individual connectedness, while the relationship between similarity in general interest and individual connectedness, contrary to our expectations, was affected negatively. Additionally, for consumers with a high need to belong, similarity in mobile technology became a more important driver of connectedness, rather than integration. Spitzberg (2006) also suggests that when individuals share a preference for communicating via a particular medium (i.e., similarity in mobile technology interests), this enhances interaction between these individuals, apart from of other common goals or values. Most likely, these consumers use this similarity attribute, that strongly pertains to the way consumers communicate with each other, as a swift tactic to connect to other individuals, thereby satisfying their need for a minimum level of interaction (Rudich and Vallacher 1999). Finally, need to belong strengthened the effect of similarity in general interests on individual integration. This effect seems to imply that consumers with a high need to belong strategize to increase the odds in fostering bonds with other individuals. While we normally expect more profound interests to be the basis of strongly integrated networks, consumers with a 
high need to belong will settle for less and accept less profound and more general similarities of interest as a basis for interaction. This is line with Baumeister and Leary (1995), who pose that individuals with a high need to belong seek out interpersonal contacts and relationships, but that these bonds should be formed rather easily and readily.

\subsubsection{The role of the social environment}

Theory on consumer decision making has a long tradition of including the social environment as an essential factor in the decision making process (e.g., Ajzen 1991; Ajzen and Fishbein 1980; Tajfel and Turner 1986), particularly with regard to innovations in particular (e.g., Chang and Cheung 2001; Cheung et al. 2000; Karahanna and Limayem 2000; Taylor and Todd 1995). While the results of our first study seemed to suggest that social factors are not as dominant as we expected, emerging studies in the field of mobile services advocate otherwise (Dickinger et al. 2006; Nysveen et al. 2005a). Particularly the fit with a consumer's lifestyle is suggested to be of importance, as well as the way a consumer can use mobile services as a means of self-expressiveness. The second study illustrated that service compatibility was not a significant factor in valuing the mobile channel, however, we approached this project from a strongly utilitarian-oriented perspective. Considering the results of other researches in the mobile service field and the longstanding evidence of social-driven motivations as an important factor in consumers' evaluations, the third study (Chapter 4), takes a different approach in addressing this issue. In this study, we do not look at the fit of the mobile services with consumers' habits from a functional perspective, but instead investigate the fit of such services with the individual's image. Previous research already posed that the image as such can function as an important signal for consumers in forming their service evaluations. Our findings further advance these insights by illustrating that it is not only the image of the service itself, but the image congruence between the mobile service and the consumer that affects consumer elevations of these services. Further investigation of different consumption situations elicits some interesting findings with regard to the impact of image congruence on consumer evaluations. In case of a high congruence level, the impact of image congruence on consumer attitude and intention to use mobile services was fairly stable across different situations. However, for consumers whose self-image is inconsistent with the mobile service image, we found that the influence of friends is stronger than that of their colleagues, i.e., friends are more likely to induce a positive evaluation in case of incongruence than colleagues. Apparently, friends are able to provide strong signals with regard to the mobile service that might overrule any incongruency effects, which is in line with findings of Herr et al. (1991). In their research they discovered that the social environment can induce favorable attitudes, even when extensive, diagnostic 
attribute information is available that would lead to less positive evaluations. In sum, our third study suggested a strong impact from the social environment and the signals or cues it provides to aid consumers in their decision making process. However, we cannot make any inferences on how and what information is transferred. This issue is addressed in the final research project, study 4.

Study four (Chapter 5), takes a social network perspective and addresses how consumers obtain a certain position in a particular type of network, the mobile social network. With the current technological as well social developments, such networks are becoming increasingly important as a means of communication and information exchange (Igarashi et al. 2005). Our results showed that both personal attributes (e.g., Robins et al. 2001) and similarity attributes (e.g., Gibbons and Olk 2003) have a significant influence on the consumer's network position. More importantly, we found that this network position, expressed by individual connectedness and integration within the mobile social environment, significantly contributes to consumers' knowledge acquisition (Ellison and Fudenburg 1993). This knowledge acquisition in turn positively affected consumers' usage intentions towards mobile service innovations. Hereby it is important to note that not only the knowledge about the service innovation itself, but also knowledge about related mobile service innovations is important, as we found significant carry-over effects of various types of knowledge (Rosa and Porac 2002). In addition to this, we found that the innovative climate of the social network (group ability to adopt) also significantly influenced these usage intentions. In fact, as the mobile service innovation became more disruptive (Ondrus and Pigneur 2005), the role of this group trait became more important. In sum, we can conclude that the mobile social environment has a profound direct (through group ability) and indirect (by serving as an information source) effect on consumer decision making with regard to mobile service innovations.

\subsection{Perspective on future research}

This dissertation has left several avenues of research unexplored. Firstly, we focused on one particular aspect of the adoption process by trying to explain consumers' intention to use mobile service innovations. Recent research has hinted at the fact that these factors might not be stable across different stages of the adoption process. More particularly, while many studies consider possession of an innovation as adoption, few studies shed light on what happens after the initial obtainment (products) or trial period (services) of these innovations. The few studies that have investigated continued usage of innovations illustrate that there are significant differences between pre- and post-adoption beliefs (Karahanna et al. 1999). While 
consumers have certain pre-usage criteria, as were also investigated in this study, evaluation after purchase or usage might be induced by a different set of variables (Gardial et al. 1994). Research on consumer adoption has left this issue virtually unexplored.

Furthermore, this thesis focused on consumers' intention to use, rather than consumers' resistance to mobile service innovations. While most studies in the adoption field focus on factors that contribute to the "positive" adoption decision, understanding why customers resist innovations is at least as important (Midgley and Dowling 1993; Szmigin and Foxall 1998). As several researchers point out, it is not appropriate to conclude that consumer resistance is simply the obverse of adoption (Gatignon and Robertson 1989; Herbig and Day 1992; Ram and Sheth 1989). Consumer resistance can unfold itself in various forms of behavior, e.g., postponing the adoption decision, rejecting the innovation, or even actively opposing innovations (e.g., boycotts). Innovation literature has largely ignored this behavior when explaining adoption decisions, even though several researchers have suggested the drivers of such behavior to be different than those of positive usage decisions (e.g., Garcia and Atkin 2002; Ram 1987). Therefore, more insights with regard to this issue are needed.

Additionally, more research should be devoted to multi-channel strategies. More and more service companies are pursuing a multi-channel strategy. However, little is known about the effects of such a strategy as research in this area is still in its infant stages (Montoya-Weiss et al. 2003). Especially when studying the mobile service delivery channel, more attention should be devoted to this multi-channel perspective, as the mobile channel is often offered as an additional, rather than a main channel (Hourahine and Howard 2004; Nysveen et al. 2005b). In the second study we partly focused on this issue and found the inclusion of different channels when studying consumers' behavioral intention towards the mobile channel to be relevant. Consumers evaluate the mobile channel relative to other channels available to them, even though they do not fulfill exactly the same needs. As many companies are opting for multi-channel solutions to serve a broad range of consumers via their preferred service delivery channel, more research is required to fully understand the effects different channels have on each other. Research seems to suggest that they can co-exist, and that a multi-channel strategy is beneficial for the company. More insights are needed however in the complementary or cannibalizing effects of channels. Investigating conditions or situations that cause consumers to switch to other channels could increase our understanding of consumers' multi-channel usage. In relation to this, more knowledge should be obtained on how companies can utilize each channel for different functions. Certain channels might be more suitable as selling points, others for relationship management. How to optimize each channel's utilities might be an interesting point for further research. This is in line with 
Venkatesan and Kumar (2004) who call for research on how companies can effectively communicate with consumers across different channels and can optimize their resources accordingly.

Also within the field of social networks, knowledge creation, and usage decisions, many opportunities for research still remain. For one, we need to stress the importance of longitudinal research in this area, as networks tend to be dynamic social phenomena (Burkhardt 1994; Lievens et al. 1999). While there are many practical restrains in collecting such data, insights about how consumer social networks develop over time can advance our understanding of human interaction and consumer decision making based on these interactions substantially. Crosssectional research does not allow us to assess any changes in functional and structural characteristics that are likely to appear over time. For example, as the experience of network members increases, the role of opinion leadership in determining a consumer's network position is prone to change. Also, while the mobile channel has started out as a social communication channel, its functionality is growing in diversity, and information exchange is becoming an important part of its utility. Reciprocal effects in information seeking and information giving are currently not addressed, while it is likely that these informational roles of consumers can vary over time. Consumers that are seeking for information at one time might, in turn, become information givers once they acquire a certain status in the social network, based on their newly acquired knowledge.

Moreover, in our social network study we focused solely on the consumers' mobile social network. However, it is likely that consumers interact with others via various communication networks, whether it being human-to-human, interpersonal interaction or technology-mediated interaction. Research on technology-mediated communication illustrates that social networks emerging via such communication tools (e.g., Internet) can exists in their own right. These networks might consist of individuals that at the moment of engaging in the network are strangers to the individual who they never have met and never will meet face-to-face, nor are they part of other social networks these consumer engage in (Garton et al. 1997). However, considering current trends in the convergence of technological platforms, it is likely that several social networks are going to overlap (Igarashi et al. 2005; Miyata et al. 2005). Consumers are using technology to build social networks that exist separately from their face-to-face networks, but they also use technology to support already existing relationships (Igarashi et al. 2005). Moreover, relationships might migrate from one setting to another (e.g., relationships that start online and are continued in a face-to-face setting). Our research is only a first attempt to gain insights on how a certain type of social network contributes to consumer decision making, but how various networks act together, their separate and joint effects on various relevant variables in explaining consumer decisions, are left untouched. 
Finally, future social network studies would benefit from addressing various levels of the network structural characteristics. In the current studies, even within the network study, our analysis has always focused on the consumer as the unit of analysis. When explaining consumers' innovation evaluations, we did not address the structural characteristics of the social network as a whole (for an overview, see: Garton et al. 1997; Scott 1991). Investigating such characteristics could still add considerably to our understanding of individual consumer evaluations of innovations. For example, research suggests that more cohesive social groups are more subject to groupthink (Baron 2005; Janis 1972). This would imply that even though a consumer, based on his or her individual network characteristics, is expected to create knowledge that leads to a positive evaluation of a certain innovation, the structural characteristics of the group might cause the consumer to conform to the group consensus, even if this consensus implies a negative evaluation of the innovation. This suggests that by assessing group-level phenomena we could still significantly add to explaining consumer evaluations of mobile service innovations. 
Appendices 


\section{Appendix A Value creation: \\ Questionnaire items and measurement properties}

\begin{tabular}{|c|c|c|c|}
\hline CR & AVE & SL & Construct / Source / Items \\
\hline \multirow[t]{5}{*}{.95} & .83 & & Time convenience (Mathwick et al. 2001) \\
\hline & & .91 & Using mobile transactions is an efficient way to manage my time \\
\hline & & .85 & Using mobile transactions would be convenient for me \\
\hline & & .94 & Using mobile transactions would allow me to save time \\
\hline & & .92 & Using mobile services would make transactions less time consuming \\
\hline \multirow[t]{5}{*}{.93} & .77 & & User control (Mathwick and Rigdon 2004) \\
\hline & & .83 & $\begin{array}{l}\text { Using mobile services for my transactions allows me to make a lot of decisions } \\
\text { on my own }\end{array}$ \\
\hline & & .90 & I have a lot to say about what happens during the mobile transaction \\
\hline & & .87 & I have flexibility when using mobile transactions \\
\hline & & .91 & I have control over the transaction when using the mobile channel \\
\hline \multirow[t]{4}{*}{.89} & .72 & & Service compatibility (Meuter et al. 2005) \\
\hline & & .81 & Using the $\mathrm{m}$-channel for transactions fits my service needs \\
\hline & & .87 & $\begin{array}{l}\text { Using the m-channel is compatible with the way I normally perform my } \\
\text { service transactions }\end{array}$ \\
\hline & & .86 & The use of mobile transaction services is in line with my service preferences \\
\hline \multirow[t]{14}{*}{.87} & .70 & & $\begin{array}{l}\text { Perceived risk: financial risk, performance risk and security risk constitute } \\
\text { first-order factors for the second-order factor risk }\end{array}$ \\
\hline & & .75 & Financial risk \\
\hline & & .86 & Performance risk \\
\hline & & .91 & Security risk \\
\hline & & & Financial risk (Stone and Gronhaug 1993) \\
\hline & & .75 & Using mobile transactions would cost me money \\
\hline & & .81 & $\begin{array}{l}\text { If I used mobile transactions I would be concerned that the financial invest- } \\
\text { ment I would make would not be wise }\end{array}$ \\
\hline & & .85 & $\begin{array}{l}\text { If I would use mobile transactions I would be concerned that I really would get } \\
\text { not my money's worth }\end{array}$ \\
\hline & & .83 & Using mobile transactions could involve important financial losses \\
\hline & & & Performance risk (Stone and Gronhaug 1993) \\
\hline & & .90 & $\begin{array}{l}\text { As I consider using mobile transactions I worry about whether the service will } \\
\text { really perform as well as it is supposed to }\end{array}$ \\
\hline & & .92 & $\begin{array}{l}\text { The thought of using mobile transactions causes me to be concerned for how } \\
\text { really reliable the service will be }\end{array}$ \\
\hline & & .87 & $\begin{array}{l}\text { If I were to use mobile transactions I become concerned that the service will } \\
\text { not provide the level of benefits I would be expecting }\end{array}$ \\
\hline & & .91 & $\begin{array}{l}\text { The thought of using mobile transactions causes me to be concerned for how } \\
\text { really dependable the service will be }\end{array}$ \\
\hline
\end{tabular}




\section{CR AVE SL Construct/Source/Items}

Security risk (Pavlou and Chellappa 2001)

.81 I have confidence in the security of my mobile transactions $\left(^{*}\right)$

.81 I am confident that the private information I provide during my mobile transactions will only reach the relevant persons, and nobody else $\left(^{*}\right)$

.73 I believe the information I provide during my mobile transactions will not be manipulated by inappropriate parties $(*)$

.71 I believe that inappropriate parties may store the information I provide during my mobile transactions

.75 I believe the information I provide during my mobile transactions will not exposed to inappropriate parties $\left({ }^{*}\right)$

.83 I am worried about the security of financial transactions via my mobile phone

.73 I will be uncomfortable making use of mobile payments

.76 The transmission of data over my mobile phone will be unsafe

.78 I am worried that information will be delivered to wrong persons

Cognitive effort (Dabholkar and Bagozzi 2002)

.87 Likely, it will be uncomplicated to use mobile transactions $(*)$

.91 Likely, it will take a lot of effort to understand how to use mobile transactions

.91 I believe it will be difficult to learn how mobile transactions work

.95

Perceived value mobile channel (Voss et al. 2003)

.79 Ineffective - Effective

.83 Not functional - Functional

.84 Impractical - Practical

.84 Useless - Useful

.83 Not sensible - Sensible

.84 Inefficient - Efficient

.86 Unproductive - Productive

84 Bad-Good

Perceived value electronic channel (Voss et al. 2003)

.92 Ineffective - Effective

.92 Not functional - Functional

.89 Impractical - Practical

.90 Useless - Useful

.84 Not sensible - Sensible

.91 Inefficient - Efficient

.91 Unproductive - Productive

$.92 \mathrm{Bad}-\mathrm{Good}$

Perceived value retail channel (Voss et al. 2003)

.84 Ineffective - Effective

.87 Not functional - Functional

.86 Impractical - Practical

.86 Useless - Useful

.85 Not sensible - Sensible

.84 Inefficient - Efficient

.85 Unproductive - Productive

.79 Bad-Good 


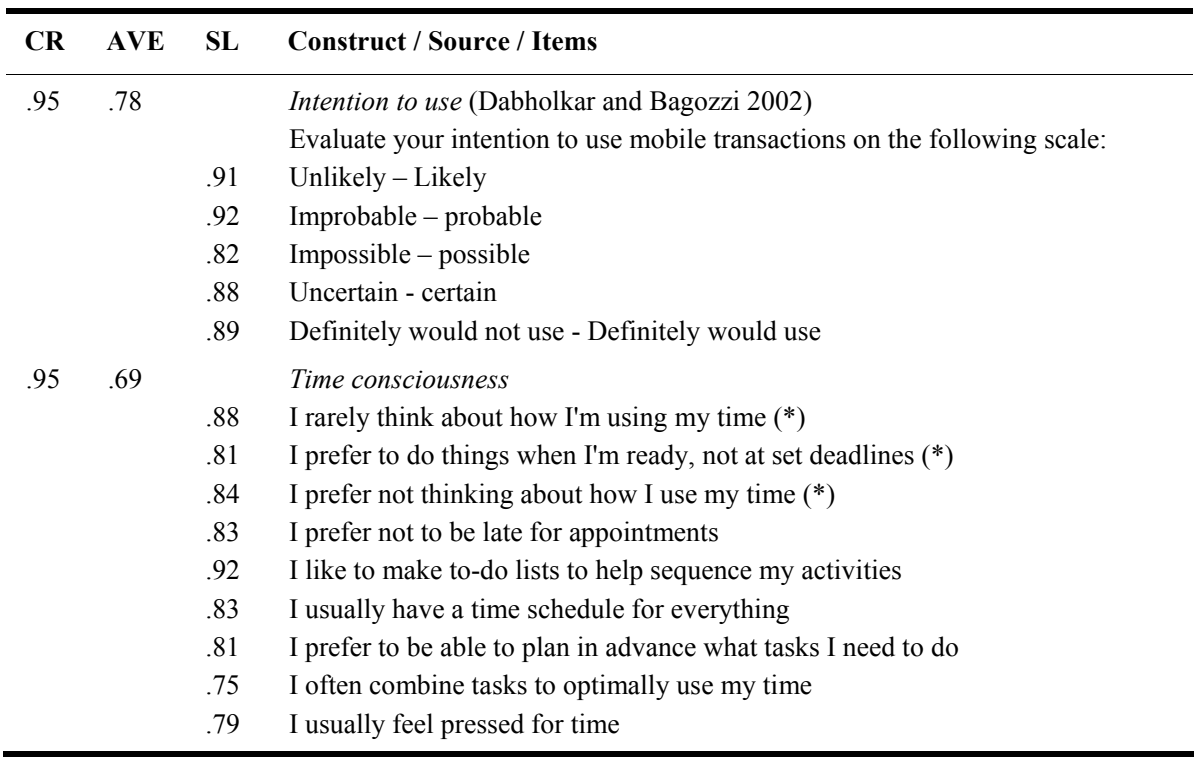

Notes: $\mathrm{SL}=$ standardized loadings; $\mathrm{CR}=$ composite reliability; and AVE = average variance extracted. Items are measure on a 7-point scale; 1 represents totally disagree, 4 is the neutral point, and 7 equals totally agree, unless indicated otherwise.

* Reverse-scored item. 


\section{Appendix B Mobile social networks: Questionnaire items and measurement properties}

\begin{tabular}{|c|c|c|c|}
\hline CR & AVE & SL & Construct / Source / Items \\
\hline \multirow[t]{8}{*}{.99} & .91 & & Opinion leadership (Dishaw and Strong 1999; Igbaria and IIvari 1995) \\
\hline & & .96 & I believe in sharing with others what I know about mobile services \\
\hline & & .97 & I enjoy being asked about mobile services \\
\hline & & .96 & It is important to share one's opinion about mobile services with others \\
\hline & & .95 & I enjoy discussing mobile services \\
\hline & & .97 & I like to help others make decisions about mobile services \\
\hline & & .96 & $\begin{array}{l}\text { My friends think of me as a knowledgeable source of information about mobile } \\
\text { services }\end{array}$ \\
\hline & & .91 & My friends ask for my opinion about mobile services \\
\hline \multirow[t]{3}{*}{.93} & n.a. & & Experience with mobile technology (SMS)** \\
\hline & & .93 & How frequently do you use m-technology to communicate with other people? \\
\hline & & .94 & How much experience do you have with communicating via m-technology? \\
\hline \multirow[t]{8}{*}{.98} & .88 & & Similarity in general interests (Sirgy et al. 1997) \\
\hline & & & In general, the interests of the group of people I communicate with via SMS \\
\hline & & .92 & $\ldots$ are not consistent with my own interests $(*)$ \\
\hline & & .91 & $\ldots$ reflect my own interests \\
\hline & & .97 & $\ldots$ are similar to my own interests \\
\hline & & .93 & $\ldots$ are very different from my own interests $(*)$ \\
\hline & & .95 & $\ldots$ are interests I can identify with \\
\hline & & .96 & In general, the group and I have common interests \\
\hline \multirow[t]{8}{*}{.99} & .93 & & Similarity in mobile technology interests (Sirgy et al. 1997) \\
\hline & & & $\begin{array}{l}\text { The interest in mobile technology of the group of people I communicate with } \\
\text { via SMS ... }\end{array}$ \\
\hline & & .98 & $\ldots$ is not consistent with my own interest in mobile technology $\left({ }^{*}\right)$ \\
\hline & & .97 & $\ldots$ reflects my own interest in mobile technology \\
\hline & & .97 & $\ldots$ is similar to my own interest in mobile technology \\
\hline & & .97 & $\ldots$ is very different from my own interests in mobile technology $(*)$ \\
\hline & & .93 & $\ldots$ is an interest I can identify with \\
\hline & & .96 & The group and I have a common interest in mobile technology \\
\hline \multirow[t]{7}{*}{.98} & .89 & & Knowledge acquisition (Lievens et al. 1999) \\
\hline & & .95 & I have increased my knowledge base about the quality of MMS \\
\hline & & .95 & ...... on the user friendliness of MMS \\
\hline & & .97 & $\ldots \ldots$ on the costs of MMS \\
\hline & & .96 & ...... concerning the performance of MMS \\
\hline & & .91 & ...... concerning the possibilities of MMS \\
\hline & & .95 & ...... about the risks of MMS \\
\hline
\end{tabular}




\begin{tabular}{|c|c|c|c|}
\hline CR & AVE & SL & Constuct / Source / Items \\
\hline \multirow[t]{8}{*}{.99} & .93 & & Knowledge acquisition cont. \\
\hline & & & I have increased my knowledge base...... \\
\hline & & .96 & ...... about the quality of mobile gaming \\
\hline & & .97 & $\ldots \ldots$ on the user friendliness of mobile gaming \\
\hline & & .96 & ...... on the costs of mobile gaming \\
\hline & & .97 & ...... concerning the performance of mobile gaming \\
\hline & & .97 & ...... concerning the possibilities of mobile gaming \\
\hline & & .94 & ...... about the risks of mobile gaming \\
\hline \multirow[t]{6}{*}{.98} & .90 & .97 & ...... about the quality of mobile information \\
\hline & & .95 & $\ldots \ldots$ on the user friendliness of mobile information \\
\hline & & .91 & $\ldots \ldots$ on the costs of mobile information \\
\hline & & .96 & ...... concerning the performance of mobile information \\
\hline & & .94 & ...... concerning the possibilities of mobile information \\
\hline & & .97 & ..... about the risks of mobile information \\
\hline \multirow[t]{6}{*}{.98} & .91 & .95 & ...... about the quality of mobile transactions \\
\hline & & .97 & $\ldots \ldots$ on the user friendliness of mobile transactions \\
\hline & & .95 & $\ldots \ldots$ on the costs of mobile transactions \\
\hline & & .97 & ...... concerning the performance of mobile transactions \\
\hline & & .98 & ...... concerning the possibilities of mobile transactions \\
\hline & & .90 & $\ldots . .$. about the risks of mobile transactions \\
\hline
\end{tabular}

Intention to use (Kleijnen et al. 2007)

Evaluate your intention to use $M M S$ on the following scale:

.82 Unlikely - Likely

.91 Improbable - probable

.88 Impossible - possible

.87 Uncertain - certain

.89 Definitely would not use - Definitely would use

Evaluate your intention to use mobile gaming on the following scale:

.89 Unlikely - Likely

.90 Improbable - probable

.82 Impossible - possible

.89 Uncertain - certain

.84 Definitely would not use - Definitely would use

Evaluate your intention to use mobile information on the following scale:

.88 Unlikely - Likely

.87 Improbable - probable

.86 Impossible - possible

.89 Uncertain - certain

.90 Definitely would not use - Definitely would use

Evaluate your intention to use mobile transactions on the following scale:

.98 Unlikely - Likely

.87 Improbable - probable

.87 Impossible - possible

.90 Uncertain - certain

.84 Definitely would not use - Definitely would use 


\begin{tabular}{|c|c|c|c|}
\hline $\mathbf{C R}$ & AVE & SL & Constuct / Source / Items \\
\hline \multirow[t]{12}{*}{.93} & .61 & & Need to belong (Leary et al. 2001) \\
\hline & & .79 & If other people don't seem to accept me, I don't let it bother me \\
\hline & & .83 & I try hard not to do things that will make people avoid or reject me \\
\hline & & .82 & I want other people to accept me \\
\hline & & .76 & I do not like being alone \\
\hline & & .65 & Being apart from my friends for long periods of time does not bother me $\left(^{*}\right)$ \\
\hline & & .83 & I have a strong "need to belong" \\
\hline & & .77 & It bothers me a great deal when I am not included in other people's plans \\
\hline & & .80 & My feelings are easily hurt when I feel that others do not accept me \\
\hline & & & $1=$ not at all characteristic of me; \\
\hline & & & $4=$ very characteristic of me; \\
\hline & & & $7=$ extremely characteristic of me \\
\hline \multirow[t]{6}{*}{.85} & .52 & & Individual perception of the group's ability to adopt (Riggs and Knight 1994) \\
\hline & & .69 & $\begin{array}{l}\text { The group I communicate with has a higher ability to adopt new mobile } \\
\text { services then others }\end{array}$ \\
\hline & & .73 & This group is not very able to adopt new mobile services $(*)$ \\
\hline & & .68 & $\begin{array}{l}\text { The members of this SMS group have the skills needed to adopt new mobile } \\
\text { services }\end{array}$ \\
\hline & & .75 & This group is not very effective in terms of adopting new mobile services $(*)$ \\
\hline & & .76 & The members of this group are very good at adopting new mobile services \\
\hline
\end{tabular}

Notes: $\mathrm{SL}=$ standardized loadings; $\mathrm{CR}=$ composite reliability; and $\mathrm{AVE}=$ average variance extracted. Items are measure on a 7-point scale, 1 represents totally disagree, 4 the neutral point, and 7 totally agree, unless indicated otherwise.

* Reverse-scored item.

** Cronbach's alpha 



\section{References}


Aaker, David A. (1991), Managing Brand Equity: Capitalizing on the Value of a Brand Name. New York: Free Press.

Adriaenssens, Charles (2001), "The Potential for M-Commerce in Retail Financial Services," in: Mobile Commerce - Connecting with the Future, Mike Elysée and Charlie Henderson and Nicholas A. Hopwood and John Machin and Malcolm Marshall, Eds. London, UK: Technology Publishing Ltd.

Adrian, Bradford (2001), "Wireless Financial Services Delivery: A Cloud of Hype," Gartner Research Report.

Agarwal, Manoj K. and Paul E. Green (1991), "Adaptive Conjoint Analysis Versus Self-Explicated Models: Some Empirical Evidence," International Journal of Research in Marketing, 8 (June), 141146.

Agarwal, Ritu and Jayesh Prasad (1998a), "Are Individual Differences Germane to the Acceptance of New Information Technologies?," Decision Sciences, 30 (2), 361-391.

Agarwal, Ritu and Jayesh Prasad (1998b), "A Conceptual and Operational Definition of Personal Innovativeness in the Domain of Information Technology," Information Systems Research, 9 (2), 204-215.

Ahonen, Tomi T. (2002), M-Profits: Making Money from $3 g$ Services. Chichester, England: John Wiley \& Sons, LDT.

Ahuja, Manju K., Dennis F. Galletta, and Kathleen M. Carley (2003), "Individual Centrality and Performance in Virtual R\&D Groups: An Empirical Study," Management Science, 49 (1), 21-38.

Ajzen, Icek (1991), "The Theory of Planned Behavior," Organizational Behavior and Human Decision Processes, 50 (2), 179-211.

Ajzen, Icek and Martin Fishbein (1980), Understanding Attitudes and Predicting Social Behavior. Engelwood Cliffs, NJ: Prentice Hall, Inc.

Anckar, Bill and Davide D'Incau (2002), "Value-Added Services in Mobile Commerce: An Analytical Framework and Empirical Findings from a National Consumer Survey," Journal of Information Technology Theory \& Application, 4 (1), 43-64.

Anderson, James C. and David W. Gerbing (1988), "Structural Equation Modeling in Practice: A Review and Recommended Two-Step Approach," Psychological Bulletin, 103 (3), 411-423.

Ariely, Dan (2000), "Controlling the Information Flow: Effects on Consumers' Decision Making and Preferences," Journal of Consumer Research, 27, 233-248.

Arndt, Jamie, Jeff Greenberg, Jeff Schimel, Tom Pyszczynski, and Sheldon Solomon (2002), "To Belong or Not to Belong, That Is the Question: Terror Management and Identification with Gender and Ethnicity," Journal of Personality and Social Psychology, 83 (1), 26-43.

ATKearney (2005), "Mobinet Index," ATKearney and Judge Institute of Management, Cambridge University, http://www.atkearney.com.

\section{B}

Bagozzi, Richard P. (1992), "The Self Regulation of Attitudes, Intentions, and Behavior," Social Psychology Quarterly, 55, 178-204.

Bagozzi, Richard P. and Utpal M. Dholakia (2002), "Intentional Social Action in Virtual Communities," Journal of Interactive Marketing, 16 (2), 2-21.

Bahli, Bouchaib and Younes Benslimane (2004), "An Exploration of Wireless Computing Risks," Information Management \& Computer Security, 12 (2/3), 245-254. 
Baier, Daniel and Wolfgang Gaul (2001), "Marketing Simulations Using a Probabilistic Ideal Vector Model for Conjoint Data," in: Conjoint Measurement: Methods and Applications, Anders Gustafsson and Andreas Herrmann and Frank Heber, Eds. ( $2^{\text {nd }}$ ed.) Berlin: Springer-Verlag.

Balabanis, George and Stefanos Vassileiou (1999), "Some Attitudinal Predictors of Home-Shopping through the Internet," Journal of Marketing Management, 15 (5), 361-385.

Balasubramanian, Sridhar, Robert A. Peterson, and Sirkka L. Jarvenpaa (2002), "Exploring the Implications of M-Commerce for Markets and Marketing," Journal of the Academy of Marketing Science, 30 (4), 348-361.

Baldi, Stefan and Heike Pyu-Pyu Thaung (2002), “The Entertaining Way to M-Commerce: Japan's Approach to the Mobile Internet - a Model for Europe?,” Electronic Markets, 12 (1), 6-13.

Bandura, Albert (1986), Social Foundations of Thought and Action. Engelwood Cliffs, NJ: Prentice Hall.

Barnard, Chris, Elena Carreri, Pim Bilderbeek, Barbara Blesio, Daniele Bonfanti, and Tim Sheedy (2001), "Banking on Mobile: Prospects for Western Europe," IDC Research Report, 1-58.

Barnes, Stuart J. (2002), "The Mobile Commerce Value Chain: Analysis and Future Developments," International Journal of Information Management, 22 (2), 91-108.

Barnett, Vic and Toby Lewis (1994), Outliers in Statistical Data. Chichester: John Wiley \& Sons.

Baron, Robert S. (2005), "So Right It's Wrong: Groupthink and the Ubiquitous Nature of Polarized Group Decision Making," in: Advances in Experimental Social Psychology, Mark P. Zanna, Ed. Vol. 37. San Diego, CA: Elsevier Academic Press.

Barwise, Patrick and Colin Strong (2002), "Permission-Based Mobile Advertising," Journal of Interactive Marketing, 16 (1), 14-24.

Basso, Monica (2001), “Mobile Portals: Five Critical Success Factors,” ZDNet Wireless Update.

Bateson, John E. G. and Michael K. Hui (1987), "Perceived Control as a Crucial Perceptual Dimension of the Service Experience: An Experimental Study," in: Add Value to Your Service, C.F. Surprenant, Ed. Chicago: American Marketing Association.

Baumeister, Roy F. and Mark R. Leary (1995), "The Need to Belong: Desire for Interpersonal Attachments as a Fundamental Human Motivation," Psychological Bulletin, 117 (3), 497-529.

BBC (2000), “A Simple Guide to M-Commerce," BBC News Business Section, Retrieved February 18, 2004 from the World Wide Web: http://news.bbc.co.uk/2001/hi/business/992292.stm.

Becker, Gary S. and Casey B. Mulligan (1997), "The Endogenous Determination of Time Preference," The Quarterly Journal of Economics, 112 (3), 729-758.

Becker, Ursula, Robert Mutschler, and Bettina Christi (2002), "Efficient Multichannel Banking," Forrester Research TechStrategy Report, 1-28.

Belk, Russel W., Kenneth D. Balm, and Robert N. Mayer (1982), "Developmental Recognition of Consumption Symbolism,” Journal of Consumer Research, 9 (June), 4-17.

Berman, Barry and Shawn Thelen (2004), "A Guide to Developing and Managing a Well-Integrated Multi-Channel Retail Strategy," International Journal of Retail \& Distribution Management, 32 (3), 147-156.

Bhattacherjee, Anol (2000), "Acceptance of E-Commerce Services: The Case of Electronic Brokerage," IEEE Transactions of Systems, Man and Cybernetics, 30 (4), 411-420.

Birke, Daniel and G. M. Peter Swann (2006), "Network Effects and the Choice of Mobile Phone Operator," Journal of Evolutionary Economics, 16 (1-2), 65-84.

Bollen, Kenneth A. (1989), Structural Equations with Latent Variables. New York: John Wiley \& Sons.

Bolton, Ruth N. and James H. Drew (1991), "A Multi-Stage Model of Customers' Assessments of Service Quality and Value,” Journal of Consumer Research, 17 (4), 375-384.

Borgatti, Stephen P., Martin G. Everett, and Lin Freeman (1999), Ucinet V. Software for Social Network Analysis. Harvard, MA: Analytical Technologies.

Bowler, Wm. Matthew and Daniel J. Brass (2006), "Relational Correlates of Interpersonal Citizenship Behavior: A Social Network Perspective,” Journal of Applied Psychology, 91 (1), 70-82. 
Brady, Michael K., Gary A. Knight, J. Joseph Cronin, G. Thomas Hult, and Bruce D. Keillor (2005), "Removing the Contextual Lens: A Multinational, Multi-Setting Comparison of Service Evaluation Models," Journal of Retailing, 81 (3), 215-230.

Brass, Daniel J., Joseph Galaskiewicz, Henrich R. Greve, and Wenpin Tsai (2004), "Taking Stock of Networks and Organizations: A Multilevel Perspective,” Academy of Management Journal, 47 (6), 795-817.

Breusch, Trevor S. and Adrian Rodney Pagan (1980), "The Lagrange Multiplier Test and Its Applications to Model Specification in Econometrics," The Review of Economic Studies, 47 (1), 239-253.

Brodsky, Ira (2001), "Europe's Wireless Industry Is on the Brink of Disaster," Network World, 18 (22), 51.

Brokat Technologies (2001), "From Wireless Technology to User-Centric M-Commerce: How to Profit from the Paradigm Shift," Brokat Technologies Business White Paper.

Brown, Jacqueline J. and Peter H. Reingen (1987), "Social Ties and Word-of-Mouth Referral Behavior," Journal of Consumer Research, 14, 350-362.

Brown, Timothy A. (2006), Confirmatory Factor Analysis for Applied Research. New York: The Guilford Press.

Bruner II, Gordon C. and Paul J. Hensel (1998), Marketing Scales Book: A Compilation of Multi-Item Measures ( $2^{\text {nd }}$ ed.). Chicago, Ilinois USA: American Marketing Association.

Bryant, J. Alison, Ashley Sanders-Jackson, and Amber M. K. Smallwood (2006), "IMing, Text Messaging, and Adolescent Social Networks," Journal of Computer-Mediated Communication, 11 (2), article 10. http://jcmc.indiana.edu/vol11/issue12/bryant.html.

Buellingen, Franz and Martin Woerter (2004), "Development Perspectives, Firm Strategies and Applications in Mobile Commerce," Journal of Business Research, 57 (12), 1402-1408.

Burkhardt, Marlene E. (1994), "Social Interaction Effects Following a Technological Change: A Longitudinal Investigation," Academy of Management Journal, 37 (4), 869-898.

Bush, Alan J. and Joseph F. Hair Jr. (1985), “An Assessment of the Mall Intercept as a Data Collection Method," Journal of Marketing Research, 32 (November), 385-391.

Byrne, Ruth and Bruce Findlay (2004), "Preference for SMS Versus Telephone Calls in Initiating Romantic Relationships," Australian Journal of Emerging Technologies and Society, 2 (1), 48-61.

\section{C}

Calinski, T. and J. Harabasz (1974), "A Dendrite Method for Cluster Analysis," Communications in Statistics, 3, 1-27.

Carlson, John R. and Robert W. Zmud (1999), "Channel Expansion Theory and the Experimental Nature of Media Richness Perceptions," Academy of Management Journal, 42 (2), 153-170.

Carroll, Jennie, Steve Howard, Frank Vetere, Jane Peck, and John Murphy (2002), "Just What Do the Youth of Today Want? Technology Appropriation by Young People," in: Proceedings of the 35th Hawaii International Conference on System Sciences.

Cattin, Philippe and Dick R. Wittink (1982), “Commercial Use of Conjoint Analysis: A Survey,” Journal of Marketing, 46 (3), 44-53.

Chae, Minhee, Jimwoo Kim, Hoyoung Kim, and Hosung Ryu (2002), "Information Quality for Mobile Internet Services: A Theoretical Model with Empirical Validation," Electronic Markets, 12 (1), 3846.

Chang, Man Kit and Waiman Cheung (2001), "Determinants of the Intention to Use the Internet/WWW at Work: A Confirmatory Study,” Information \& Management, 39 (1), 1-14.

Chang, Tung-Zong and Albert R. Wildt (1994), "Price, Product Information, and Purchase Intention: An Empirical Study," Journal of the Academy of Marketing Science, 22 (1), 16-27. 
Chau, Patrick Y.K. (1996), "An Empirical Assessment of a Modified Technology Acceptance Model," Journal of Management Information Systems, 13 (2), 185-204.

Cheung, Waiman, Man Kit Chang, and Vincent S. Lai (2000), "Prediction of Internet and World Wide Web Usage at Work: A Test of an Extended Triandis Model," Decision Support Systems, 30 (1), 83100.

Childers, Terry L. (1986), "Assessment of the Psychometric Properties of an Opinion Leadership Scale," Journal of Marketing Research, 23 (May), 184-188.

Childers, Terry L., Christopher L. Carr, Joann Peck, and Stephen Carson (2001), "Hedonic and Utilitarian Motivations for Online Retail Shopping Behavior," Journal of Retailing, 77 (4), 511-535.

Chin, Wynne W. (1998), "The Partial Least Squares Approach to Structural Equation Modeling," in: Modern Business Research Methods, George A. Marcoulides, Ed. Mahwah, NJ: Lawrence Erlbaum Associates.

Chin, Wynne W. (2001), PLS-Graph User's Guide Version 3.0. Houston, TX: C.T. Bauer College of Business, University of Houston.

Chin, Wynne W., Barbara L. Marcolin, and Peter R. Newsted (2003), “A Partial Least Squares Latent Variable Approach for Measuring Interaction Effects: Results from a Monte Carlo Simulation Study and an Electronic-Mail Emotion/Adoption Study," Information Systems Research, 14 (2), 189-217.

Christensen, Clayton M. (1997), Innovator's Dilemma: When New Technologies Cause Great Firms to Fail. Cambridge, MA: Harvard Business School Publishing.

Churchill, Gilbert A. Jr. (1979), "A Paradigm for Developing Better Measures of Marketing Constructs,” Journal of Marketing Research, 16 (February), 64-73.

Citrin, Alka Varma, David E. Sprott, Steven N. Silverman, and Donald E. Stem Jr. (2000), "Adoption of Internet Shopping: The Role of Consumer Innovativeness," Industrial Management \& Data Systems, 100 (7), 294-300.

Cohen, Jacob (1988), Statistical Power Analysis for the Behavioral Sciences $\left(2^{\text {nd }}\right.$ ed.). Hillsdale, NJ: Lawrence Earlbaum Associates.

Conte, Jeffrey M., John E. Mathieu, and Frank J. Landy (1998), "The Nomological and Predictive Validity of Time Urgency," Journal of Organizational Behavior, 19 (1), 1-13.

Coulter, Robin A., Lawrence Feick, and Linda L. Price (2002), "Cosmetics Opinion Leadership among Women in the New Hungary,” European Journal of Marketing, 36 (11/12), 1287-1308.

Cronin, J. Joseph, Michael K. Brady, and G. Thomas Hult (2000), "Assessing the Effects of Quality, Value, and Customer Satisfaction on Consumer Behavioral Intentions in Service Environments," Journal of Retailing, 76 (2), 193-218.

\section{D}

Dabholkar, Pratibha A. and Richard P. Bagozzi (2002), "An Attitudinal Model of Technology-Based Self-Service: Moderating Effects of Consumer Traits and Situational Factors," Journal of the Academy of Marketing Science, 30 (3), 184-201.

Davis, Fred D. (1989), "Perceived Usefulness, Perceived Ease of Use, and Usage of Information Technology: A Replication," MIS Quarterly, 13 (3), 319-339.

Davis, Fred D., Richard P. Bagozzi, and Paul R. Warshaw (1989), "User Acceptance of Computer Technology: A Comparison of Two Theoretical Models," Management Science, 35 (8), 982-1003.

Davison, John, Duncan Brown, and Ann Walsh (2000), "Mobile E-Commerce: Market Strategies," Ovum Report, available at http://www.ovum.com.

de Ruyter, Ko and Martin G.M. Wetzels (1998), "On the Complex Nature of Patient Evaluations of General Practice Service,” Journal of Economic Psychology, 19, 565-590. 
de Ruyter, Ko, Martin G.M. Wetzels, and Mirella H.P. Kleijnen (2001), "Customer Adoption of EServices: An Experimental Study," International Journal of Service Industry Management, 12 (2), 184-207.

DeCarlo, Lawrence T. (1997), "On the Meaning and Use of Kurtosis," Psychological Methods, 2 (3), 292-307.

DeMaris, Alfred (1992), Logit Modeling: Practical Applications. Newbury Park, CA: Sage Publications.

DeSarbo, Wayne S., Lenard Huff, Marcelo M. Rolandelli, and Jungwhan Choi (1994), "On the Measurement of Perceived Service Quality,” in: Service Quality, Roland T. Rust and Richard L. Oliver, Eds. Thousand Oaks: Sage Publications.

DeSarbo, Wayne S., Michel Wedel, Marco Vriens, and Venkatram Ramaswamy (1992), "Latent Class Metric Conjoint Analysis," Marketing Letters, 3 (3), 273-288.

Dey, Anind K., Gregory D. Abowd, and Daniel Salber (2001), “A Conceptual Framework and a Toolkit for Supporting the Rapid Prototyping of Context-Aware Applications," Human-Computer Interaction, 16, 97-166.

Dholakia, Ruby Roy, Miao Zhao, and Nikhilesh Dholakia (2005), "Multichannel Retailing: A Case Study of Early Experiences," Journal of Interactive Marketing, 19 (2), 63-74.

Dickinger, Astrid, Mitra Arami, and David Meyer (2006), "Reconsidering the Adoption Process: Enjoyment and Social Norms-Antecedents of Hedonic Mobile Technology Use," European Journal of Information Systems (forthcoming).

Dishaw, Mark T. and Diane M. Strong (1999), "Extending the Technology Acceptance Model with TaskTechnology Fit Constructs," Information \& Management, 36 (1), 9-21.

Dolan, Daniel P. (2000), “The Big Bumpy Shift: Digital Music via Mobile Internet," First Monday, 5 (12).

Dolich, Ira J. (1969), “Congruence Relationships between Self Images and Product Brands,” Journal of Marketing Research, 6 (February), 80-84.

Dorsch, Michael J. and R. Kenneth Teas (1992), “A Test of the Convergent Validity of Self-Explicated and Decompositional Conjoint Measurement," Journal of the Academy of Marketing Science, 20 (1), $37-48$.

Dowling, Graham R. and Richard Staelin (1994), “A Model of Perceived Risk and Intended RiskHandling Activity,” Journal of Consumer Research, 21 (1), 119-135.

Du, Heather and Fabio Crestani (2003), "Spoken Versus Written Queries for Mobile Information" in: Mobile and Ubiquitous Information Access, Fabio Crestani and Mark Dunlop and Stefano Mizzaro, Eds. Berlin / Heidelberg: Springer Verlag.

Duda, Richard O. and Peter E. Hart (1973), Pattern Classification and Scene Analysis. New York: Wiley.

\section{E}

Ellison, Glenn and Drew Fudenburg (1993), "Rules of Thumb for Social Learning," Journal of Political Economy, 101 (4), 612-643.

Engel, James F., Roger D. Blackwell, and Paul W. Miniard (1990), Consumer Behavior (6 ${ }^{\text {th }}$ ed.). Chicago: Dryden Press.

Ericksen, Mary K. and M. Joseph Sirgy (1992), "Employed Females Clothing Preference, Self-Image Congruence, and Career Anchorage," Journal of Applied Social Psychology, 22 (5), 408-422.

Escalas, Jennifer Edson and James R. Bettman (2003), "You Are What They Eat: The Influence of Reference Groups on Consumers' Connections to Brands," Journal of Consumer Psychology, 13 (3), 339-348.

Everitt, Brian S., Sabine Landau, and Morven Leese (2001), Cluster Analysis (4 ${ }^{\text {th }}$ ed.). London: Arnold. 


\section{$\mathbf{F}$}

Falk, R. F. and N.B. Miller (1992), A Primer on Soft Modeling. Akron, OH: The University of Akron Press.

Fang, K. (1998), “An Analysis of Electronic-Mail Usage," Computers in Human Behavior, 14 (2), 349374.

Ferguson, George A. (1976), Statistical Analysis in Psychology \& Education (4 ${ }^{\text {th }}$ ed.). New York: McGraw-Hill.

Fiore, Ann Marie, Jihyun Kim, and Hyun-Hwa Lee (2005), "Effect of Image Interactivity Technology on Consumer Responses toward the Online Retailer," Journal of Interactive Marketing, 19 (3), 38-53.

Fishbein, Martin and Icek Ajzen (1975), Belief, Attitude, Intention and Behavior. Reading, MA: AddisonWesley.

Fornell, Claes (1992), “A National Customer Satisfaction Barometer: The Swedish Experience," Journal of Marketing, 56 (1), 6-21.

Fornell, Claes and David F. Larcker (1981), "Evaluating Structural Equation Models with Unobservable Variables and Measurement Error," Journal of Marketing Research, 18 (Augustus), 39-50.

Francis-Smythe, Jan A. and Ivan T. Robertson (1999), "Time-Related Individual Differences," Time \& Society, 8 (2), 273-292.

\section{G}

Games, Paul A. and James F. Howell (1976), "Pairwise Multiple Comparison Procedures with Unequal N's and/or Variances," Journal of Educational Statistics, 1 (Summer), 113-125.

Garcia, Rosanna and Tom Atkin (2002), "Co-Opetition for the Diffusion of Resistant Innovations: A Case Study in the Global Wine Industry," Institute for Global Innovation Management Working Paper, 05$002,1-22$.

Gardial, Sarah Fischer, D. Scoot Flemons, Robert B. Woodruff, David W. Schumann, and Mary Jane Burns (1994), "Comparing Consumers' Recall of Prepurchase and Postpurchase Product Evaluation Experiences," Journal of Consumer Research, 20 (March), 548 - 560.

Garton, Laura, Caroline Haythornthwaite, and Barry Wellman (1997), "Studying Online Social Networks," Journal of Computer-Mediated Communication, 3 (1), http://jcmc.indiana.edu/vol3/ issue1/garton.html.

Gatignon, Hubert and Thomas S. Robertson (1989), "Technology Diffusion: An Empirical Test of Competitive Effects," Journal of Marketing, 53 (1), 35-49.

George, Jennifer M. and Gareth R. Jones (2000), "The Role of Time in Theory and Theory Building," Journal of Management, 26 (4), 657-684.

Gerstheimer, Oliver and Christian Lupp (2004), "Needs Versus Technology - the Challenge to Design Third-Generation Mobile Applications," Journal of Business Research, 57 (12), 1409-1415.

Gibbons, Deborah and Paul M. Olk (2003), "Individual and Structural Origin of Friendship and Social Position among Professionals," Journal of Personality and Social Psychology, 84 (2), 340-351.

Gilly, Mary C., John L. Graham, Mary Finley Wolfinbarger, and Laura J. Yale (1998), “A Dyadic Study of Interpersonal Information Search," Journal of the Academy of Marketing Science, 26 (2), 83-100.

Gold, Steve (2001), "Mobile Gaming: Savior of Europe's Wireless Nets?," Newsbytes.

Graeff, Timothy R. (1997), "Consumption Situations and the Effect of Brand Image on Consumers' Brand Evaluations," Psychology \& Marketing, 14 (1), 49-70.

Graeff, Timothy R. (1996), "Using Promotional Messages to Manage the Effects of Brand and Self-Image on Brand Evaluations," Journal of Consumer Marketing, 13 (3), 4-18. 
Granovetter, Mark (1983), "The Strength of Weak Ties: A Network Theory Revisited," Sociological Theory, 1, 201-233.

Green, Paul E. (1984), "Hybrid Models for Conjoint Analysis: An Expository Review," Journal of Marketing Research, 21 (May), 155-159.

Green, Paul E., Kristiaan Helsen, and Bruce Shandler (1988), "Conjoint Internal Validity under Alternative Profile Presentations,” Journal of Consumer Research, 15 (3), 392-397.

Green, Paul E. and Abba M. Krieger (1988), "Choice Rules and Sensitivity Analysis in Conjoint Simulators," Journal of the Academy of Marketing Science, 16 (1), 114-128.

Green, Paul E. and Abba M. Krieger (1991), "Segmenting Markets with Conjoint Analysis," Journal of Marketing, 55 (October), 20-31.

Green, Paul E. and V. Srinivasan (1978), "Conjoint Analysis in Consumer Research: Issues and Outlook," Journal of Consumer Research, 5 (September), 103-123.

Green, Paul E. and V. Srinivasan (1990), "Conjoint Analysis in Marketing: New Developments with Implications for Research and Practice,” Journal of Marketing, 54 (October), 3-19.

Green, Paul E. and Abba M. Krieger (1996), "Individualized Hybrid Models for Conjoint Analysis," Management Science, 42 (6), 850-868.

Green, Paul E., Abba M. Krieger, and Manoj K. Agarwal (1991), “Adaptive Conjoint Analysis: Some Caveats and Suggestions," Journal of Marketing Research, 28 (May), 215-222.

Green, Paul E. and Vithala R. Rao (1971), "Conjoint Measurement for Quantifying Judgement Data," Journal of Marketing Research, 8 (August), 355-263.

Gregan-Paxton, Jennifer and Page Moreau (2003), "How Do Consumers Transfer Existing Knowledge? A Comparison of Analogy and Categorization Effects," Journal of Consumer Psychology, 13 (4), $422-430$.

Grewal, Rajdeep, Raj Mehta, and Frank R. Kardes (2000), "The Role of the Social-Identity Function of Attitudes in Consumer Innovativeness and Opinion Leadership," Journal of Economic Psychology, 21 (3), 233-252.

Grønhaug, Kjell, Leif Hem, and Rune Lines (2002), "Exploring the Impact of Product Category Risk and Consumer Knowledge in Brand Extensions," Journal of Brand Management, 9 (6), 463-476.

Gross, Edwin J. (1971), “Opinion Leaders, a Study in Communication,” Journal of Marketing Research, 8 (February), 131-132.

Grubb, Edward L. and Harrison L Grathwohl (1967), "Consumer Self-Concept, Symbolism and Market Behavior: A Theoretical Approach,” Journal of Marketing, 31 (October), 22-27.

\section{H}

Hagerty, Michael R. (1985), "Improving the Predictive Power of Conjoint Analysis: The Use of Factor Analysis and Cluster Analysis,” Journal of Marketing Research, 22 (May), 168-184.

Hair Jr., Joseph F., Rolph E. Anderson, Ronald L. Tatham, and William C. Black (1995), Multivariate Data Analysis with Readings ( $4^{\text {th }}$ ed.). Englewood Cliffs, New Jersey: Prentice-Hall, Inc.

Häkkilä, Jonna and Craig Chatfield (2005), “'It's Like If You Opened Someone Else's Letter'-User Perceived Privacy and Social Practices with SMS Communication," in: Proceedings of MobileHCI’05. Salzburg, Austria.

Hansen, Morten T. (1999), "The Search-Transfer Problem: The Role of Weak Ties in Sharing Knowledge across Organization Subunits," Administration Science Quarterly, 44 (March), 82-111.

Hatcher, Larry (1994), Step by Step Approach to Using the SAS System for Factor Analysis and Structural Equation Modeling. Cary, NC: SAS Institute Inc.

Hennig-Thurau, Thorsten, Gianfranco Walsh, and Oliver Wruck (2001), "An Investigation into the Factors Determining the Success of Service Innovations - the Case of Motion Pictures," Academy of Marketing Science Review, 1 (6), http://www.amsreview.org/articles/hennig06-2001.pdf. 
Herbig, Paul A. and Ralph L. Day (1992), "Customer Acceptance: The Key to Successful Introductions of Innovations," Marketing Intelligence \& Planning, 10 (1), 4-15.

Herr, Paul M., Frank R. Kardes, and John Kim (1991), "Effect of Word-of-Mouth and Product-Attribute Information on Persuasion: An Accessibility-Diagnosticity Perspective," Journal of Consumer Research, 17 (March), 454-462.

Hoffman, Donna L. and Thomas P. Novak (1996), "Marketing in Hypermedia Computer-Mediated Environments: Conceptual Foundations," Journal of Marketing, 60 (Winter), 50-68.

Hogg, Margaret K., Alastair J. Cox, and Kathy Keeling (2000), “The Impact of Self-Monitoring on Image Congruence and Product/Brand Evaluation," European Journal of Marketing, 34 (5/6), 641-666.

Holbrook, Morris B. (1999), Consumer Value: A Framework for Analysis and Research. New York: Routledge.

Hornsey, Matthew J. and Jolanda Jetten (2004), "The Individual within the Group: Balancing the Need to Belong with the Need To Be Different," Personality and Social Psychology Review, 8 (3), 248-264.

Hosmer, David W. and S. Lemeshow (2000), Applied Logistic Regression ( $2^{\text {nd }}$ ed.). New York: John Wiley \& Sons.

Hourahine, Ben and Melanie Howard (2004), "Money on the Move: Opportunities for Financial Service Providers in the 'Third Space'," Journal of Financial Services Marketing, 9 (1), 57-67.

Howell, Jane M. and Bruce J. Aviolo (1993), “Transformational Leadership, Transactional Leadership, Locus of Control, and Support for Innovation: Key Predictors of Consolidated-Business-UnitPerformance," Journal of Applied Psychology, 78 (6), 891-902.

Hu, Yifeng, Jacqueline Fowler Wood, Vivian Smith, and Nalova Westbrook (2004), "Friendships through IM: Examining the Relationship between Instant Messaging and Intimacy," Journal of ComputerMediated Communication, 10 (1), article 6, http://jcmc.indiana.edu/vol10/issue11/hu.html.

Huber, J.C., Dick R. Wittink, J.A. Fiedler, and R.L. Miller (1993), "The Effectiveness of Alternative Preference Elicitation Procedures in Predicting Choice," Journal of Marketing Research, 30 (February), 105-114.

Hulland, John (1999), "Use of Partial Least Squares (PLS) in Strategic Management Research: A Review of Four Recent Studies," Strategic Management Journal, 20 (February), 195-204.

Hung, Shin-Yuan, Cheng-Yuan Ku, and Chia-Ming Chang (2003), "Critical Factors for the Adoption of WAP Services: An Empirical Study,” Electronic Commerce Research and Applications, 2 (1), 42-60.

Ibarra, Herminia (1993), "Network Centrality, Power, and Innovation Involvement: Determinants of Technical and Administrative Roles," Academy of Management Journal, 36 (3), 471-501.

Igarashi, Tasuku, Jiro Takai, and Toshikazu Yoshida (2005), "Gender Differences in Social Network Development via Mobile Phone Text Messages: A Longitudinal Study," Journal of Social and Personal Relationships, 22 (5), 691-713.

Igbaria, M. and J. IIvari (1995), "The Effects of Self-Efficacy on Computer Usage," International Journal of Management Science, 23 (6), 587-605.

Informa Telecoms \& Media (2005), "Mobile Messaging," Informa Telecoms \& Media Research Report, retrieved from www.informatm.com.

Ito, Mizuko and Daisuke Okabe (2005), "Intimate Connections: Contextualizing Japanese Youth and Mobile Messaging," in: The inside Text: Social, Cultural and Design Perspectives on SMS, Richard Harper and Leysia Palen and Alex S. Taylor, Eds. Amsterdam: Kluwer Academic Publishers. 
Jaccard, James, Robert Turrisi, and Choi K. Wan (1990), Interaction Effects in Multiple Regression. Beverly Hills: Sage.

Jackson, Cynthia M., Simeon Chow, and Robert A. Leitch (1997), "Toward an Understanding of the Behavioral Intention to Use an Information System," Decision Sciences, 28 (2), 357-389.

James, Christina L. and Kelly M. Reischel (2001), "Text Input Formobile Devices: Comparing Model Prediction Toactual Performance," in: Proceedings of CHI2001, AMC New York, 365-371.

James, J. (2001), "Mobile Gaming: An Introduction to the Mobile Gaming Market," Mobile Streams.

Janis, Irving (1972), Victims of Groupthink: A Psychological Study of Foreign-Policy Decisions and Fiascoes. Boston: Houghton Mifflin.

Jarvenpaa, Sirkka L., Karl Reiner Lang, Yoko Takeda, and Virpi Kristiina Tuunainen (2003), "Mobile Commerce at Cross Roads," Communications of the ACM, 46 (12), 41-45.

Johnson, Richard M. (1987), "Adaptive Conjoint Analysis," In: Proceedings of the Sawtooth Software Conference on Perceptual Mapping, Conjoint Analysis and Computer Interviewing, Ketchum, ID: Sawtooth Software, Inc., 253-265.

Johnson, Richard M. (1991), "Comment on 'Adaptive Conjoint Analysis: Some Caveats and Suggestions'," Journal of Marketing Research, 28 (May), 223-225.

Jones, Nory B., Richard T. Herschel, and Douglas D. Moesel (2003), "Using 'Knowledge Champions' to Facilitate Knowledge Management," Journal of Knowledge Management, 7 (1), 49-77.

\section{$\mathbf{K}$}

Kaasinen, Elija, Matti Aaltone, Juha Kolari, Suvi Melakoski, and Timo Laakko (2000), "Two Approaches to Bringing Internet Services to WAP Devices," Computer Networks, 33, 231-246.

Kai-ming Au, Alan and Peter Enderwick (2000), "A Cognitive Model on Attitude towards Technology Adoption," Journal of Managerial Psychology, 15 (4), 266-282.

Kamakura, Wagner A. (1988), "A Least Squares Procedure for Benefit Segmentation with Conjoint Experiments," Journal of Marketing Research, 25 (May), 157-167.

Karahanna, Elena and Moez Limayem (2000), "E-Mail and V-Mail Usage: Generalizing across Technologies," Journal of Organizational Computing and Electronic Commerce, 10 (1), 49-66.

Karahanna, Elena and Detmar W. Straub (1999), "The Psychological Origins of Perceived Usefulness and Ease-of-Use," Information \& Management, 35 (4), 237-250.

Karahanna, Elena, Detmar W. Straub, and Norman L. Chervany (1999), "Information Technology Adoption across Time: A Cross-Sectional Comparison of Pre-Adoption and Post-Adoption Beliefs," MIS Quarterly, 23 (2), 183-213.

Kaufman, Carol Felker, Paul M. Lane, and Jay D. Lindquist (1991), "Exploring More Than 24 Hours a Day: A Preliminary Investigation of Polychronic Time Use," Journal of Consumer Research, 18 (December), 392-401.

Keppel, G. (1991), Design and Analysis: A Researcher's Handbook. Englewood Cliffs, New Jersey: Prentice-Hall.

Keryer, Ph. and T. Nara (2001), "i-Mode: A Successful Launch of the Mobile Internet Market," Alcatel Telecommunications Review, retrieved November 11, 2001 from the World Wide Web: http://www.alcatel.de/atr/hefte/2001i_2001/gb/pdf_gb/2012keryergb.pdf.

Kirmani, Amna and Akshay R. Rao (2000), "No Pain, No Gain: A Critical Review of the Literature on Signaling Unobservable Product Quality," Journal of Marketing, 64 (April), 66-79. 
Kleijnen, Mirella H.P., Ko de Ruyter, and Martin G.M. Wetzels (2007), “An Assessment of Value Creation in Mobile Service Delivery and the Moderating Role of Time Consciousness," Journal of Retailing, 83 (1), 33-46.

Kleijnen, Mirella H.P., Ko de Ruyter, and Martin G.M. Wetzels (2004), “Consumer Adoption of Wireless Services: Discovering the Rules, While Playing the Game,” Journal of Interactive Marketing, 18 (2), 51-61.

Klein, Katherine J., Beng-Chong Lim, Jessica L. Saltz, and David M. Mayer (2004), "How Do They Get There? An Examination of the Antecedents of Centrality in Team Networks," Academy of Management Journal, 47 (6), 952-963.

Knoke, David and James H. Kuklinski (1982), Network Analysis. Thousand Oaks: Sage Publications.

Knutsen, Lars A. and Kalle Lyytinen (2005), "The Difference Is in Messaging: Specifications, Properties and Gratifications Affecting the Japanese Wireless Service Evolution," Sprouts: Working Papers on Information Environments, Systems and Organizations, 5 (3), 117-136.

Koranteng, Juliana (2000), “Dial “M” For E-Commerce,” Advertising Age International, May, 1-24.

\section{L}

Laforet, Sylvie and Xiaoyan Li (2005), “Consumers' Attitudes Towards Online and Mobile Banking in China," International Journal of Bank Marketing, 23 (5), 362-380.

Landon Jr., E. Laird (1974), "Self-Concept, Ideal Self-Concept and Consumer Purchase Intentions," Journal of Consumer Research, 1 (September), 44-51.

Lea, Bih-Ru, Wen-Bin Yu, Nisha Maguluru, and Michael Nichols (2006), "Enhancing Business Networks Using Social Network Based Virtual Communities," Industrial Management \& Data Systems, 106 (1), 121-138.

Leary, Mark R., Catherine A. Cottrell, Lisa S. Schreindorfer, and Kristine M. Kelly (2001), "Individual Differences in the Need to Belong: Mapping the Nomological Network," Unpublished manuscript, Wake Forest University, Winston-Salem, NC.

Lee, Morna S.Y., Peter J. McGoldrick, Kathleen A. Keeling, and Joanne Doherty (2003), "Using ZMET to Explore Barriers to the Adoption of 3G Mobile Banking Services," International Journal of Retail \& Distribution Management, 31 (6/7), 340-348.

Lee, Young E. and Izak Benbasat (2004), “A Framework for the Study of Customer Interface Design for Mobile Commerce," International Journal of Electronic Commerce, 8 (3), 79-103.

Levin, Daniel Z. and Rob Cross (2004), "The Strength of Weak Ties You Can Trust: The Mediating Role of Trust in Effective Knowledge Transfer,” Management Science, 50 (11), 1477-1490.

Liao, Ziqi and Michael Tow Cheung (2001), “," Information \& Management, 38 (5), 299-306.

Lievens, Annouk, Ko de Ruyter, and Jos G.A.M. Lemmink (1999), "Learning During New Banking Service Development: A Communication Approach to Marketing Departments," Journal of Service Research, 2 (2), 145-163.

Lin, Angel (2005), "Gendered, Bilingual Communication Practices: Mobile Text-Messaging among Hong Kong College Students," Fibreculture Journal 6, http://journal.fibreculture.org/issue6/issue6_lin.html.

Ling, Rich (2005), "The Socio-Linguistics of SMS: An Analysis of SMS Use by a Random Sample of Norwegians," in: Mobile Communications: Renegotiation of the Social Sphere, Rich Ling and Per E. Pedersen, Eds. London: Springer.

Lynch, John G., Jr. and Dan Ariely (2000), "Wine Online: Search Costs Affect Competition on Price, Quality, and Distribution,” Marketing Science, 19 (1), 83-103. 


\section{M}

MacKenzie, I. Scott and Shawn X. Zhang (2001), “An Empirical Investigation of the Novice Experience with Soft Keyboards," Behaviour \& Information Technology, 20, 411-418.

Mahler, Alwin and Everett M. Rogers (1999), “The Diffusion of Interactive Communication Innovations and the Critical Mass: The Adoption of Telecommunication Services by German Banks," Telecommunications Policy, 23 (10/11), 719-740.

Martineau, Pierre (1958), "The Personality of the Retail Store," Harvard Business Review, 36 (JanuaryFebruary), 47-55.

Mathwick, Charla, Naresh Malhotra, and Edward Rigdon (2001), "Experiential Value: Conceptualization, Measurement and Application in the Catalog and Internet Shopping Environment," Journal of Retailing, 77 (1), 39-56.

Mathwick, Charla and Edward Rigdon (2004), "Play, Flow, and the Online Search Experience," Journal of Consumer Research, 31 (2), 324-332.

Matthews, Karen A. (1982), "Psychological Perspectives on the Type a Behavior Pattern," Psychological Bulletin, 91 (2), 293-323.

May, Paul (2001), Mobile Commerce - Breakthroughs in Application Development: Opportunities, Applications and Technologies of Wireless Business. Cambridge UK: Cambridge University Press.

McPherson, Miller, Lynn Smith-Lovin, and James M. Cook (2001), "Birds of a Feather: Homophily in Social Networks," Annual Review of Sociology, 27, 415-444.

Mehra, Ajay, Martin Kildurff, and Daniel J. Brass (1998), “At the Margins: A Distinctiveness Approach to the Social Identity and Social Networks of Underrepresented Groups," Academy of Management Journal, 41 (4), 441-452.

Metha, Raj, William L. Moore, and Teresa M. Pavia (1992), “An Examination of the Use of Unacceptable Levels in Conjoint Analysis," Journal of Consumer Research, 19 (December), 470-476.

Meuter, Matthew L., Mary Jo Bitner, Amy L Ostrom, and Stephen W. Brown (2005), "Choosing among Alternative Service Delivery Modes: An Investigation of Customer Trial of Self-Service Technologies," Journal of Marketing, 26 (April), 61-83.

Meuter, Matthew L., Amy L Ostrom, Robert I. Roundtree, and Mary Jo Bitner (2000), "Self-Service Technologies: Understanding Customer Satisfaction with Technology-Based Service Encounters," Journal of Marketing, 64 (3), 50-64.

Midgley, David F. and Grahame R. Dowling (1993), "A Longitudinal Study of Product Form Innovation: The Interaction between Predispositions and Social Messages," Journal of Consumer Research, 19 (March), 611-625.

Milligan, Glenn W. and Martha C. Cooper (1985), "An Examination of Procedures for Determining the Number of Clusters in a Data Set,” Psychometrika, 50 (2), 159 -179.

Milligan, Glenn W. and Martha C. Cooper (1987), "Methodology Review: Clustering Methods," Applied Psychological Measurement, 11 (44), 329-354.

Miyata, Kakuko, Barry Wellman, and Jeffrey Boase (2005), "The Wired - and Wireless - Japanese: Webphones, Pcs and Social Networks," in: Mobile Communications: Re-Negotiation of the Social Sphere, Rich Ling and Per E. Pedersen, Eds. London: Springer.

Mojena, Richard (1977), "Hierarchical Grouping Methods and Stopping Rules: An Evaluation," Computer Journal, 20 (4), 359-363.

Montoya-Weiss, Mitzi M., Glenn B. Voss, and Dhruv Grewal (2003), "Determinants of Online Channel Use and Overall Satisfaction with a Relational, Multichannel Service Provider," Journal of the Academy of Marketing Science, 31 (4), 448-458.

Moore, David J. and Pamela M. Homer (2003), "Self-Brand Connections: An Exploratory Study into Construct Validity and Gender Effects," Advances in Consumer Research, 32, Barbara K. Kahn and Mary Frances Luce. Valdosta, GA: Association for Consumer Research. 
Moore, Gary C. and Izak Benbasat (1991), "Development on an Instrument to Measure the Perceptions of Adopting an Information Technology Innovation," Information Systems Research, 2 (3), 192-222.

Moore, Geoffrey A. (2002), Crossing the Chasm: Marketing and Selling High-Tech Products to Mainstream Consumers. New York, NY: Harper Collins Publishers.

Moore, William L. and Richard J. Semenik (1988), "Measuring Preferences with Hybrid Conjoint Analysis: The Impact of Different Number of Attributes in the Master Design," Journal of Business Research, 16 (3), 261-274.

Moorman, Christine, Kristin Diehl, David Brinberg, and Blair Kidwell (2004), "Subjective Knowledge, Search Locations, and Consumer Choice," Journal of Consumer Research, 31 (3), 673-680.

Moreau, C. Page, Donald R. Lehmann, and Arthur B. Markman (2001), "Entrenched Knowledge Structures and Consumer Response to New Products," Journal of Marketing Research, 38 (1), 14-29.

Morello, Gabriele (2000), "Time Orientation across Cultures: A Comparative Study in Italy, Cuba and Spain," in: Proceedings of the International Conference ISIDA, April 6-8, 2000, 81-100.

Mort, Gillian S. and Judy Drennan (2005), "Marketing M-Services: Establishing a Usage Benefit Typology Related to Mobile User Characteristics," Journal of Database Marketing \& Customer Strategy Management, 12 (4), 327-341.

Müller-Veerse, Falk (2000), "Mobile Commerce," Research Report Durlacher Research Ltd, retrieved May 20, 2001 from the World Wide Web: http://www.durlacher.com.

Müller-Veerse, Falk, Bodo Kohlenbach, Dirk Bout, Shum Singh, Gennady Golub, Jukka Häyrynen, Sasu Laitinen, and Erkko Autio (2001), "UMTS - an Investment Perspective," Research Report Durlacher Research Ltd. in cooperation with Eqvitec and HuT, retrieved December 20, 2001, http://www.durlacher.com.

Munshi, Kaivan (2004), "Social Learning in a Heterogeneous Population: Technology Diffusion in the Indian Green Revolution,” Journal of Development Economics, 73 (1), 185- 213.

Murray, Keith B. (1991), "A Test of Services Marketing Theory: Consumer Information Acquisition Activities," Journal of Marketing, 55 (January), 10-25.

$\mathbf{N}$

Netemeyer, Richard G., William O. Bearden, and Subhash Sharma (2003), Scaling Procedures: Issues and Applications. Thousand Oaks, CA: Sage Publications.

Newell, Frederick and Katherine N. Newell-Lemon (2001), Wireless Rules. New York: McGraw-Hill.

Ngai, E.W.T., T.C.E. Cheng, S. Au, and Kee-Hung Lai (2006), "Mobile Commerce Integrated with RFID Technology in a Container Depot," Decision Support Systems, forthcoming.

Noble, Stephanie M., David A. Griffith, and Marc G. Weinberger (2005), "Consumer Derived Utilitarian Value and Channel Utilization in a Multi-Channel Retail Context," Journal of Business Research, 58 (12), $1643-1651$.

Nokia (2001), "Nokia Wireless Application Protocol Technology Enables Highly Secured Mobile Transactions for Deutsche Bank," Nokia Case Study, retrieved April 10, 2002 from the World Wide Web: www.nokia.com.

Nunnally, Jum C. and Ira H. Bernstein (1994), Psychometric Theory. New York: McGraw-Hill.

Nyblom, Jukka, Steve P. Borgatti, Juha Roslakka, and Mikko A. Salo (2003), "Statistical Analysis of Network Data - an Application to Diffusion of Innovation," Social Networks, 25 (2), 175-195.

Nyshadham, Easwar A. (2000), "Privacy Policies of Air Travel Web Sites: A Survey and Analysis," Journal of Air Transport Management, 6 (3), 143-152.

Nysveen, Herbjørn, Per E. Pedersen, and Helge Thorbjørnsen (2005a), "Intentions to Use Mobile Services: Antecedents and Cross-Service Comparisons," Journal of the Academy of Marketing Science, 33 (3), 330-346. 
Nysveen, Herbjørn, Per E. Pedersen, Helge Thorbjørnsen, and Pierre Berthon (2005b), "Mobilizing the Brand: The Effects of Mobile Services on Brand Relationships and Main Channel Use," Journal of Service Research, 7 (3), 257-276.

\section{O}

Okazaki, Shintaro (2004), "How Do Japanese Consumers Perceive Wireless Ads? A Multivariate Analysis," International Journal of Advertising, 23 (4), 429-454.

Okazaki, Shintaro (2005), "New Perspectives on M-Commerce Research," Journal of Electronic Commerce Research, 6 (3), 160 - 164.

Olson, Jerry C. (1972), "Cue Utilization of the Quality Perception Process: A Cognitive Model and an Empirical Test," unpublished doctorial dissertation, Purdue University.

Ondrus, Jan and Yves Pigneur (2005), "A Disruption Analysis in the Mobile Payment Market," in: Proceedings of the 38th Annual Hawaii International Conference on System Sciences. Hawaii, USA.

Onkvisit, Sak and John Shaw (1987), "Self-Concept and Image Congruence: Some Research and Managerial Implications," Journal of Consumer Marketing, 4 (1), 13-23.

Ortt, Roland, J. (1998), "Videotelephony in the Consumer Market," Doctoral dissertation, Delft University of Technology.

\section{P}

Pagani, Margaritha (2004), "Determinants of Adoption of Third Generation Mobile Multimedia Services," Journal of Interactive Marketing, 18 (3), 46-59.

Palen, Leysia (2002), "Mobile Telephony in a Connected Life," Communications of the ACM, 45 (3), 7882.

Parasuraman, A. (2000), "Technology Readiness Index (TRI): A Multiple-Item Scale to Measure Readiness to Embrace New Technologies," Journal of Service Research, 2 (4), 307-320.

Parasuraman, A. and Dhruv Grewal (2000), "The Impact of Technology on the Quality-Value-Loyalty Chain: A Research Agenda," Journal of the Academy of Marketing Science, 28 (1), 168-174.

Pastore, Michael (2000), "M-Commerce? Maybe M-Games? Yes," M-commerce Times.

Pavlou, Paul A. and Ramnath K. Chellappa (2001), "The Role of Perceived Privacy and Perceived Security in the Development of Trust in Electronic Commerce Transactions," Working Paper ebizlab, Submitted to the Special Issue of ISR on "Electronic Commerce Metrics".

Pedhazur, Elazar (1997), Multiple Regression in Behavioral Research: Explanation and Prediction. Singapore: Wadsworth/Thomson Learning.

Perdue, Barbara C. and John O Summers (1986), "Checking the Success of Manipulations in Marketing Experiments," Journal of Marketing Research, 23 (November), 317-326.

Perry-Smith, Jill E. and Christina E. Shalley (2003), "The Social Side of Creativity: A Static and Dynamic Social Network Perspective,” Academy of Management Review, 28 (1), 89-106.

Pickett, Cynthia L., Wendi L. Gardner, and Megan Knowles (2004), "Getting a Cue: The Need to Belong and Enhanced Sensitivity to Social Cues," Personality and Social Psychology Bulletin, 30 (9), 10951107.

Plouffe, Cristopher R., Mark Vandenbosch, and John Hulland (2001), "Intermediating Technologies and Multi-Group Adoption: A Comparison of Consumer and Merchant Adoption Intentions toward a New Electronic Payment System,” Journal of Product Innovation Management, 18 (2), 65-81.

Portio Research (2005), "Mobile Messaging Future 2005-2010,” Portio Research Report, June 27, 1-150. 
Proshansky, Harold M., William H. Ittelson, and Leanne G. Rivlin (1974), "Freedom of Choice and Behavior in a Physical Setting," in: Environmental Psychology, Harold M. Proshansky and et al., Eds. New York: Holt, Rinehart \& Winston.

Pullman, Madeleine E., Kimberly J. Dodson, and William L. Moore (1999), “A Comparison of Conjoint Methods When There Are Many Attributes," Marketing Letters, 10 (2), 125-138.

Punj, Girish and David W. Stewart (1983), "Cluster Analysis in Marketing Research: Review and Suggestions for Application,” Journal of Marketing Research, 20 (May), 134-148.

\section{R}

Ram, Sundaresan (1987), “A Model of Innovation Resistance,” Advances in Consumer Research, 14 (1), 208-211.

Ram, Sundaresan and Jagdish N. Sheth (1989), "Consumer Resistance to Innovations: The Marketing Problem and Its Solutions," Journal of Consumer Marketing, 6 (2), 5-14.

Reid, Fraser J.M. and Donna J. Reid (2004), “Text Appeal: The Psychology of Sms Texting and Its Implications for the Design of Mobile Phone Interfaces," Campus-Wide Information Systems, 21 (5), 196-200.

Reinecke Flynn, Leisa, Ronald E. Goldsmith, and Jacqueline K. Eastman (1996), “Opinion Leaders and Opinion Seekers: Two New Measurement Scales," Journal of the Academy of Marketing Science, 24 (2), 137-147.

Reingen, Peter H. and Jerome B. Kernan (1986), “Analysis of Referral Networks in Marketing: Methods and Illustration,” Journal of Marketing Research, 23 (November), 370-378.

Riggs, Matt L. and Patrick A. Knight (1994), "The Impact of Perceived Group Success-Failure on Motivational Beliefs and Attitudes: A Causal Model,” Journal of Applied Psychology, 79 (5), 755 766.

Robins, Garry, Peter Elliott, and Philippa Pattison (2001), "Network Models for Social Selection Processes," Social Networks, 23 (1), 1-30.

Rogers, Everett M. (1995), Diffusion of Innovations (4 ${ }^{\text {th }}$ ed.). New York: The Free Press.

Rogers, Everett M. and Rekha Agarwala-Rogers (1976), Communication in Organizations. London: The Free Press, Collier Macmillan.

Rogers, Everett M. and D. Lawrence Kincaid (1981), Communication Networks: Toward a New Paradigm for Research. New York: The Free Press.

Rosa, José Antonio and Joseph F. Porac (2002), "Categorization Bases and Their Influence on Product Category Knowledge Structures,” Psychology \& Marketing, 19 (6), 503-532.

Rothaermel, Frank T. and Stephen Sugiyama (2001), "Virtual Internet Communities and Commercial Success: Individual and Community-Level Theory Grounded in the Atypical Case of Timezone.Com," Journal of Management Information Systems, 27 (3), 297-312.

Roulac, Stephen E. (2001), "Retail Real Estate in the 21st Century: Information + Time Consciousness + Unintelligent Stores = Intelligent Shopping? Not!," The Journal of Retail Estate Research, 9 (1), 125150.

Rubin, Zick (1980), Children's Friendships. Sommerset: Fontana Publishing.

Rudich, Eric A. and Robin R. Vallacher (1999), "To Belong or to Self-Enhance? Motivational Bases for Choosing Interaction Partners," Personality and Social Psychology Bulletin, 25 (11), 1387-1404.

Russell, Gaby J., S. Ratneshwar, Allan D. Shocker, David Bell, Anand Bodapati, Alex Degeratu, Lutz Hildebrandt, Namwoon Kim, R. Ramaswami, and Venkatash H. Shankar (1999), "Multiple-Category Decision-Making: Review and Synthesis," Marketing Letters, 10 (3), 319-332. 


\section{$\mathbf{S}$}

Sawtooth Software (1997), ACA System 4.0 Manual. Sequim, WA: Sawtooth Software, Inc.

Sawtooth Software (1993), "Adaptive Conjoint Analysis," ACA Technical Paper, Sequim, Washington: Sawtooth Software, Inc.

Scharl, Arno, Astrid Dickinger, and Jamie Murphy (2005), "Diffusion and Success Factors of Mobile Marketing," Electronic Commerce Research and Applications, 4 (2), 159-173.

Schlosser, Francine K. (2002), "So, How Do People Really Use Their Handheld Devices? An Interactive Study of Wireless Technology Use,” Journal Organizational Behavior, 23 (4), 401-423.

Schmitt, Bernd H. and Clifford J. Shultz II (1995), "Situational Effects on Brand Preferences for Image Products," Psychology \& Marketing, 12 (5), 433-446.

Schoder, Detlef (2000), "Forecasting the Success of Telecommunication Services in Presence of Network Effects," Information Economics and Policy, 12 (2), 181-200.

Scott, John (1991), Social Network Analysis. London: Sage Publications.

Shah, James (2003), "The Motivational Looking Glass: How Significant Others Implicitly Affect Goal Appraisals," Journal of Personality and Social Psychology, 85 (3), 424-439.

Shankar, Venkatesh, Tony O'Driscoll, and David Reibstein (2003), "Rational Exuberance: The Wireless Industry's Killer B," Strategy \& Business, 31 (Summer), 68-77.

Shih, Chuan-Fond and Alladi Venkatesh (2004), "Beyond Adoption: Development and Application of a Use-Diffusion Model," Journal of Marketing, 68 (January), 59-72.

Siau, Keng, Ee-Peng Lim, and Zixing Shen (2001), "Mobile Commerce: Promises, Challenges, and Research Agenda," Journal of Database Management, 12 (3), 4-13.

Simonoff, Jeffrey S. (1998), "Logistic Regression, Categorical Predictors, and Goodness-of-Fit: It Depends on Who You Ask," American Statistician, 52 (1), 10-15.

Sirgy, M. Joseph (1982), "Self-Concept in Consumer Behavior: A Critical Review," Journal of Consumer Research, 9 (December), 287-300.

Sirgy, M. Joseph (1985), "Using Self-Congruity and Ideal Congruity to Predict Purchase Motivation," Journal of Business Research, 13 (3), 195-206.

Sirgy, M. Joseph, Dhruv Grewal, and Tamara Mangleburg (2000), "Retail Environment, Self-Congruity, and Retail Patronage: An Integrative Model and a Research Agenda," Journal of Business Research, 49 (2), 127-138.

Sirgy, M. Joseph, Dhruv Grewal, Tamara F. Mangleburg, Jae-ok Park, Kye-Sung Chon, C.B. Claiborne, J.S. Johar, and Harold Berkman (1997), "Assessing the Predictive Validity of Two Methods of Measuring Self-Image Congruence," Journal of the Academy of Marketing Science, 25 (3), 229-241.

Smith, Michael D. (2002), "The Impact of Shopbots on Electronic Markets," Journal of the Academy of Marketing Science, 30 (4), 446-454.

Snyder, Mark (1979), "Self-Monitoring Processes," Advances in Experimental Social Psychology, 12, 86-128.

Snyder, Mark and Steve Gangestad (1986), "On the Nature of Self-Monitoring: Matters of Assessment, Matters of Validity," Journal of Personality and Social Psychology, 51 (1), 125-139.

Spitzberg, Brain H. (2006), "Preliminary Development of a Model and Measure of Computer-Mediated Communication (CMC) Competence," Journal of Computer-Mediated Communication, 11 (2), http://jcmc.indiana.edu/vol11/issue12/spitzberg.html.

Srinivasan, V. (1988), "A Conjunctive-Compensatory Approach to the Self-Explication of Multiattributed Preferences,” Decision Sciences, 19 (Spring), 295-305.

Steiger, James H. (1980), "Tests for Comparing Elements of a Correlation Matrix," Psychological Bulletin, 97 (2), 245-251.

Stone, Robert N. and Kjell Grønhaug (1993), "Perceived Risk: Further Considerations for the Marketing Discipline," European Journal of Marketing, 27 (3), 39-50. 
Stringer, Mark and Jessica Ward (2001), "Who Wants to Play? Beginning Research into Mobile Gaming," retrieved November 20, 2001 from the World Wide Web: http://www.viktoria.se/ play/ubigame/papers/stringer.pdf.

Suoranta, Mari and Minna Mattila (2004), "Mobile Banking and Consumer Behaviour: New Insights into the Diffusion Pattern,” Journal of Financial Services Marketing, 8 (4), 354-366.

Suoranta, Mari, Minna Mattila, and Juha Munnukka (2005), "Technology-Based Services: A Study on the Drivers and Inhibitors of Mobile Banking," International Journal of Management and Decision Making, 6 (1), 33-46.

Sutherland, Ed (2001), "Wireless Gaming," M-Commerce Times.

Sweeney, Jillian C., Geoffrey N. Soutar, and Lester W. Johnson (1999), "The Role of Perceived Risk in the Quality-Value Relationship: A Study in a Retail Environment,” Journal of Retailing, 75 (1), 77 105.

Szmigin, Isabelle and Gordon Foxall (1998), “Three Forms of Innovation Resistance: The Case of Retail Payment Methods," Technovation, 18 (6/7), 459-468.

\section{T}

Tabachnik, Barbara G. and Linda S. Fidell (1996), Using Multivariate Statistics. New York: Harper Collins.

Tajfel, Henri and John C. Turner (1986), “The Social Identity Theory of Intergroup Behavior,” in: Psychology of Intergroup Relations, Stephen Worchel and William G. Austin, Eds. Chicago: NelsonHall.

Taylor, Shirley and Peter Todd (1995), "Decomposition and Crossover Effects in the Theory of Planned Behavior: A Study of Consumer Adoption Intentions," International Journal of Research in Marketing, 12 (2), 137-155.

Tenenhaus, Michel, Vincenzo Esposito Vinzi, Yves-Marie Chatelin, and Carlo Lauro (2005), "PLS Path Modeling," Computational Statistics \& Data Analysis, 48 (1), 159-205.

The Economist (2000), "The Wireless Gamble," The Economist, October 12, 2000, retrieved April 24, 2001 from the World Wide Web: http://www.economist.com.

Thomas-Hunt, Melissa C., Tonya Y. Ogden, and Margaret A. Neale (2003), "Who's Really Sharing? Effects of Social and Expert Status on Knowledge Exchange within Groups," Management Science, 49 (4), 464-477.

Tichy, Noel and Charles Fombrun (1979), "Network Analysis in Organizational Settings," Human Relations, 32 (11), 923-965.

Toothaker, Larry E. (1992), Multiple Comparison Procedures. Newbury Park, CA: Sage Publications.

Tornatzky, L.G. and K.J. Klein (1982), "Innovation Characteristics and Innovation AdoptionImplementation: A Meta-Analysis of Findings," IEEE Transactions on Engineering Management, 29 (1), 28-45.

Turban, Efraim and David King (2003), Introduction to E-Commerce. Upper Saddle River, NJ: Prentice Hall.

$\mathbf{U}$

UMTS Forum (2000), "Enabling UMTS / Third Generation Services and Applications," UMTS Forum Report 11, retrieved June 20, 2001 from the World Wide Web: http://www.umts-forum.org. 
van der Heijden, Hans (2005), "Mobile Decision Support for in-Store Purchase Decisions," Decision Support Systems, 42, 656-663.

van der Heijden, Hans and Lotte Sangstad Sørensen (2003), "Measuring Attitudes Towards Mobile Information Services: An Empirical Validation of the Hed/Ut Scale," In: Proceedings of the European Conference on Information Systems (ECIS), Naples, Italy.

Venkatesan, Rajkumar and V. Kumar (2004), "A Customer Lifetime Value Framework for Customer Selection and Resource Allocation Strategy," Journal of Marketing, 68 (October), 106-125.

Venkatesh, Viswanath and Fred D. Davis (2000), "A Theoretical Extension of the Technology Acceptance Model: Four Longitudinal Field Studies,” Management Science, 46 (2), 186-204.

Venkatraman, Meera P. (1989), "Opinion Leaders, Adopters, and Communicative Adopters: A Role Analysis," Psychology \& Marketing, 6 (1), 51-68.

Viquez, Frank (2001), "Mobile Commerce: Analyzing Emerging Opportunities in Technologies, Applications, Markets and Trends," Allied Business Intelligence Inc. Strategic Research Report, 1225.

Voss, Kevin E., Eric R. Spangenberg, and Bianca Grohmann (2003), "Measuring the Hedonic and Utilitarian Dimensions of Consumer Attitude," Journal of Marketing Research, 40 (August), 310320.

Vriens, Marco, Michel Wedel, and Tom Wilms (1996), "Metric Conjoint Segmentation Methods: A Monte Carlo Comparison," Journal of Marketing Research, 33 (February), 73-85.

\section{W}

Ward, Lynn (2003), "Is M-Commerce Dead and Buried?," E-Commerce Times, 05/09/03, retrieved from the WWW, May 2, 2006: http://www.ecommercetimes.com/story/21464.html.

Wedel, Michel and Jan-Benedict E.M. Steenkamp (1989), "A Fuzzy Clusterwise Regression Approach to Benefit Segmentation," International Journal of Research in Marketing, 6 (March), 241-258.

Weisband, Suzanne P., Sherry K. Schneider, and Terry Connolly (1995), "Computer-Mediated Communication and Social Information: Status Salience and Status Differences," Academy of Management Journal, 38 (4), 1124-1151.

Wellman, Barry, Janet Salaff, Dimitrina Dimitrova, Laura Garton, Milena Gulia, and Caroline Haythornthwaite (1996), "Computer Networks as Social Networks: Collaborative Work, Telework, and Virtual Community," Annual Review of Sociology, 22, 213-238.

Wendel, Sonja and Benedict G.C. Dellaert (2005), "Situation Variation in Consumers' Media Channel Consideration," Journal of the Academy of Marketing Science, 33 (4), 575-584.

Wiley, James B. and James Low (1983), "A Monte Carlo Simulation Study of Two Approaches for Aggregating Conjoint Data," Journal of Marketing Research, 20 (November), 405-416.

Williams, E.J. (1959), "The Comparison of Regression Variables," Journal of the Royal Statistical Society, Series B, 21, 396-399.

Wittink, Dick R. and Philippe Cattin (1989), "Commercial Use of Conjoint Analysis: An Update," Journal of Marketing, 53 (July), 91-96.

Wu, Jen-Her and Shu-Ching Wang (2005), "What Drives Mobile Commerce? An Empirical Evaluation of the Revised Technology Acceptance Model," Information \& Management, 42 (5), 719-729. 
Yuan, Yufei and Jason J. Zhang (2003), "Towards an Appropriate Business Model for M- Commerce," International Journal of Mobile Communications, 1 (1/2), 35-56.

$\mathbf{Z}$

Zegers, Frits E. and Jos M. ten Berghe (1985), "A Family of Association Coefficients for Metric Scales," Psychometrika, 50 (1), 17-24.

Zellner, Arnold (1962), "An Efficient Method of Estimating Seemingly Unrelated Regressions and Tests for Aggregation Bias," Journal of the American Statistical Association, 57 (June), 348-368.

Zellner, Arnold (1963), "Estimators for Seemingly Unrelated Regression Equations: Some Exact Finite Sample Results," Journal of the American Statistical Association, 58 (December), 977-992.

Zhou, Jing (2003), "When the Presence of Creative Coworkers Is Related to Creativity: Role of Supervisor Close Monitoring, Developmental Feedback, and Creative Personality," Journal of Applied Psychology, 88 (3), 413-422. 



\section{Nederlandse Samenvatting}


Recente ontwikkelingen zoals de introductie van mobiele technologieën creëren nieuwe winstmogelijkheden voor bedrijven. Ondanks deze optimistische verwachtingen is de doorbraak van mobiele diensten in Europa en de VS nog lang niet gerealiseerd en is nauwelijks vergelijkbaar met het succes van bijvoorbeeld i-mode in Japan. Succesvolle integratie van mobiele diensten in het dienstenaanbod van bedrijven hangt dan ook sterk af van de adoptie van dergelijke diensten door de consument. Empirisch onderzoek naar het gedrag van consumenten in relatie tot de adoptie van mobiele diensten is nog steeds schaars. De centrale doelstelling in dit proefschrift is dan ook te onderzoeken welke factoren een invloed hebben op de consumentenintenties om innovatieve mobiele diensten te gebruiken. Hiertoe formuleren we de volgende onderzoeksvragen:

1. Wat is het effect van technologische kenmerken van mobiele diensten op de intentie van consumenten om dergelijke diensten te gebruiken? (hoofdstuk 2)

2. hoe wordt waarde gecreëerd voor het mobiele kanaal en welke rol speelt de mate van tijdsbewustheid van de consument hierbij een rol? (hoofdstuk 3 )

3. Welke rol speelt de mate van congruentie tussen het imago van de mobiele dienst en dat van de consument in het consumenten-adoptieproces? (hoofdstuk 4)

4. Hoe creëert een consument een bepaalde positie in zijn mobiele sociale netwerk en hoe draagt de informatie verkregen via dat netwerk bij tot zijn gebruiksintenties? (hoofdstuk 5)

\section{De adoptie van mobiele diensten: eerst het spel, dan de knikkers}

In hoofdstuk 2 onderzoeken we de adoptie van mobiele games op basis van een extensie van Rogers' innovatie-adoptietheorie. Hierbij breiden we het model niet alleen uit met contextspecifieke factoren gerelateerd aan de mobiele dienst, maar kijken we ook naar persoonlijke kenmerken van de consument. De drie belangrijkste technologiegerelateerde factoren die op de voorgrond treden zijn risico (hierbij kan men denken aan het niet werken van de server, of de kwaliteit van de dienst), gebruikersgemak, en de mate waarin mobiele diensten in de dagelijkse bezigheden passen. Verder, kunnen we door middel van cluster analyse drie types gebruikers onderscheiden. Het eerste type is de 'game player'. Deze groep let met name op de manier waarop deze services in de dagelijkse bezigheden passen, de navigatiemogelijkheden van het mobiele toestel, maar vooral ook de betalingsmogelijkheden. Deze consumenten zijn vooral geïnteresseerd in abonnementen voor mobiele diensten. Een tweede type is de consument die op zoek is naar de specifieke voordelen die mobiele diensten kunnen bieden. Deze voordelen kunnen misschien nog wel het best samengevat worden door de bekende martini-slogan: 'anytime, anywhere, any 
place'. Tenslotte blijkt dat er ook een groep gebruikers is die sceptisch is. Deze consument is zich bewust van de inflatoire verwachtingen die door Telecom aanbieders zijn gewekt. Verder geldt voor dit type gebruiker dat hij minder ervaring met het reguliere internet heeft in vergelijking met andere consumenten, waardoor de drempel wellicht nog vergroot wordt.

\section{Het creëren van waarde voor het mobiele kanaal en het modererende effect van tijdsbewustzijn}

In hoofdstuk 3 onderzoeken we de gepercipieerde functionele waarde van het mobiele kanaal. We ontwikkelen een conceptueel raamwerk betreffende de voordelen en kosten van het mobiele kanaal die leiden tot de uiteindelijke waardeperceptie in de ogen van de consument. Onze onderzoeksresultaten laten zien dat tijdsgemak en controle belangrijke voordelen zijn die de waarde van het mobiele kanaal beïnvloeden, terwijl het derde voordeel, compatibiliteit met de levenstijl van de consument, niet significant blijkt te zijn. Ook de nadelen, zoals risico en de cognitieve moeite die het kost de dienst te begrijpen, zijn van groot belang voor de waardepercepties. Daarnaast blijkt het van belang hoe tijdsbewust de consument is. We vinden verschillende modererende effecten aangaande tijdsbewustzijn en de relaties tussen de antecedenten en de gepercipieerde waarde van het mobiele kanaal. Opvallend is dat de impact van de voordelen op de waarde van het mobiele kanaal voor tijdsbewuste consumenten versterkt worden, terwijl de nadelen sterk afgezwakt worden. Tot slot heeft de waarde van het mobiele kanaal grote invloed op de intentie om dit kanaal te gebruiken. De perceptie van andere kanalen is daarbij ook van belang. Het blijkt dat wanneer consumenten een positief beeld hebben van alternatieve kanalen, zoals de winkel en het internet, ze minder geneigd zijn om dit nieuwe kanaal te gebruiken.

\section{Imagocongruentie en de adoptie van diensteninnovaties}

In hoofdstuk 4 staat de rol van imagocongruentie centraal. Imagocongruentie refereert naar de mate waarin het imago van de mobiele dienst congruent is aan het imago/zelfbeeld van consumenten. We onderzoeken het effect van deze imagocongruentie op de attitude van consumenten ten opzichte van mobiel bankieren en de intentie om dergelijke diensten te gebruiken. Daarbij wordt ook de rol van de gebruikssituatie (privé versus publiek, en vrienden versus collega's) onderzocht. De resultaten van twee experimenten laten zien dat imagocongruentie niet alleen een direct effect heeft op attitude en intentie, maar dat er ook een interactie-effect is tussen imagocongruentie en de gebruikssituatie. Tegen de verwachtingen in worden consumenten met een lage imagocongruentie meer door hun omgeving beïnvloed 
dan consumenten met een hoge imagocongruentie. Het lijkt erop dat zolang consumenten overeenkomsten zien tussen hun eigen imago en het imago van de mobiele dienst, signalen uit de omgeving genegeerd worden. Wanneer er sprake is van lage imagocongruentie, blijkt diagnostische informatie over mobiele diensten die door vrienden verstrekt wordt een grotere invloed te hebben dan die van collega's.

\section{Het verklaren van de intentie van de consument om diensteninnovaties te gebruiken: kennisacquisitie via mobiele sociale netwerken}

In hoofdstuk 5 belichten we consumentengedrag vanuit een sociaal netwerk perspectief. Het theoretische model laat zien welke factoren bijdrage tot de positie die een consument verwerft in zijn mobiele sociale netwerk en welke marketing-relevante consequenties hieruit voortvloeien. Zowel persoonlijke kenmerken (opinieleiderschap en ervaring met SMS) als de mate waarin er sprake is van dezelfde interesses zijn van invloed op de netwerkpositie die een consument heeft in zijn of haar SMS netwerk. Daarbij constateren we dat deze relaties gemodereerd worden door de mate waarin de consument de behoefte heeft om bij een sociaal netwerk te horen. Ook tonen de resultaten aan dat de netwerkpositie van groot belang is voor kennisacquisitie van consumenten. In het algemeen geldt dat hoe hoger de connectie binnen het netwerk, en hoe lager de mate van integratie, des te meer kennis de consument verwerft met betrekking tot mobiele diensten. De kennis heeft een sterke invloed op de intentie om dergelijke diensten te gebruiken. Daarbij is het opvallend dat niet alleen kennis van de specifieke mobiele dienst de gebruiksintentie bepaald, maar dat ook kennis over andere, gerelateerde mobiele diensten van belang is. Tot slot zien we dat ook de mate waarin het netwerk in staat is om te innoveren bijdraagt tot het vormen van de gebruiksintentie van mobiele diensten.

\section{Conclusie}

Dit onderzoek verschaft inzicht in verschillende factoren die bijdragen tot het verklaren van het consumenten-adoptieproces van mobiele diensten. De resultaten van de verschillende studies laten zien dat er drie verschillende thema's een belangrijke rol spelen in dit proces: de kenmerken van mobiele diensten zelf, persoonlijkheidskenmerken van consumenten, en de sociale omgeving. Begrip van deze factoren en de onderliggende interacties zijn van essentieel belang om beslissingen van consumenten met betrekking tot het gebruik van mobiele diensten te kunnen begrijpen. 


\section{Curriculum Vitae}

Mirella Kleijnen was born on August 18, 1976 in Borgharen, the Netherlands. After completing secondary school at Sint-Maartenscollege in Maastricht (1988-1994), she studied at the Faculty of Economics and Business Administration of Maastricht University, the Netherlands (1994-1998), where she obtained a Master's Degree in Economics specializing in marketing and marketing research. In November 1998, she started her career as a junior lecturer and research fellow at the department of marketing of that same university. During this period she was involved in several research projects, including the "Multi-media project", a pioneer program in educational design.

From August 2000 until August 2004, she worked as a PhD candidate in the marketing department. During this time she worked on her dissertation "Services Unplugged: Four Empirical Studies on Consumer Evaluations of Mobile Service Innovations". Additionally, her work as a teacher during this period was rewarded with the education award for "most promising teacher" in 2001.

As of August 2004 she is working as an Assistant Professor in the marketing department of the Faculty of Economics and Business Administration, Vrije Universiteit Amsterdam. Her main research interests include consumer adoption of innovations, interactive marketing, services marketing and relationship marketing. Her work has been published in Journal of Retailing, Journal of Services Research, Journal of Interactive Marketing, Mobile Commerce: Technology, Theory, and Applications, International Journal of Service Industry Management, Total Quality Management, and Journal of Financial Services Marketing. Her paper on value creation in the mobile service delivery, co-authored with Ko de Ruyter and Martin Wetzels, was given the best paper award for the special issue of Journal of Retailing on 'Competing through Service Excellence' (2007). 